
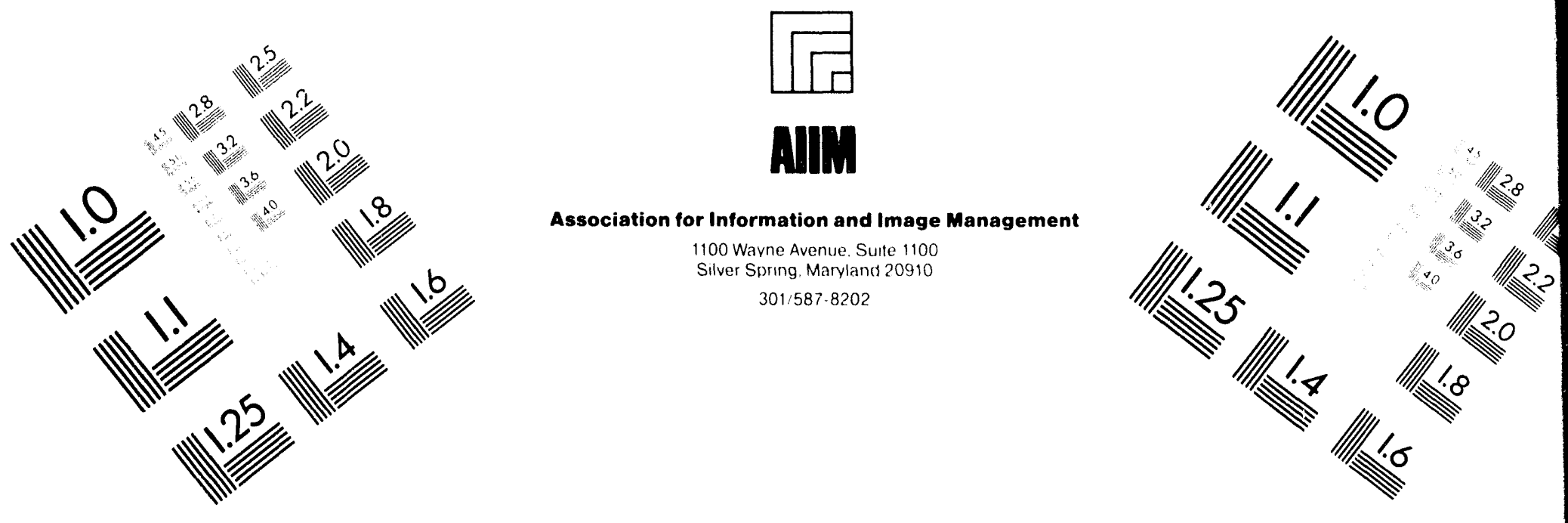

Centimeter

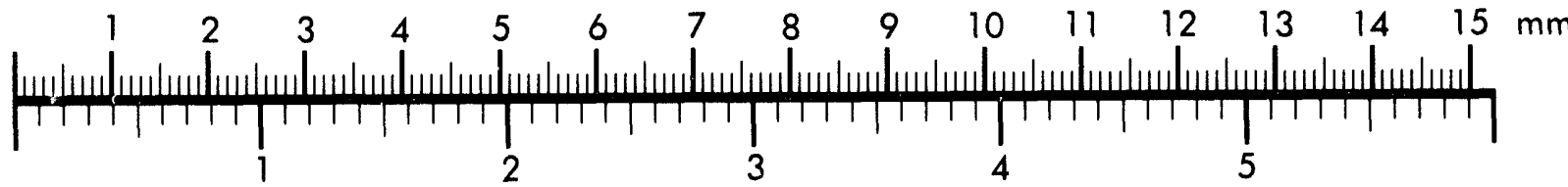
Inches
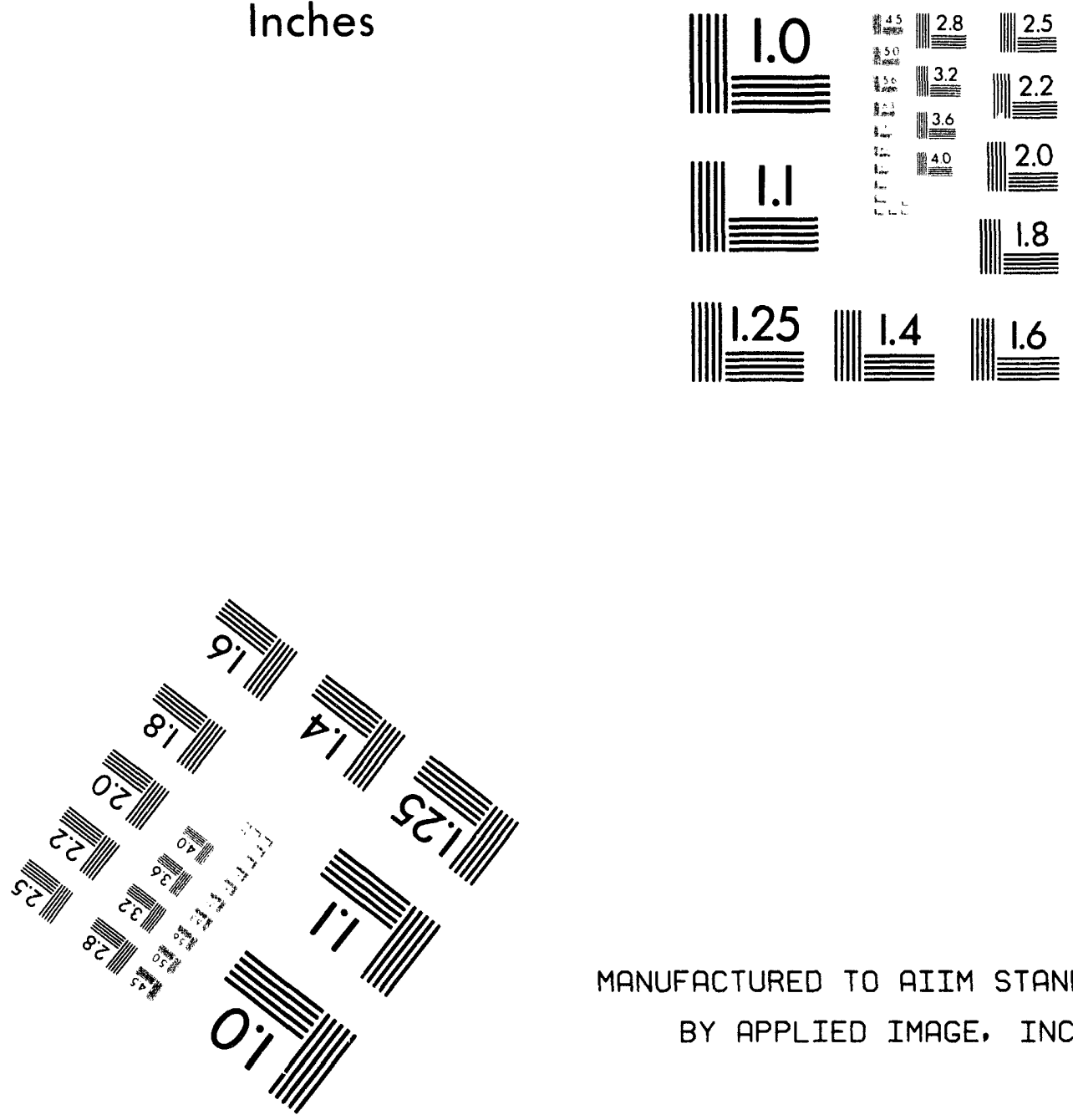

MANUFACTURED TO AIIM STANDARDS

BY APPLIED IMAGE, INC.

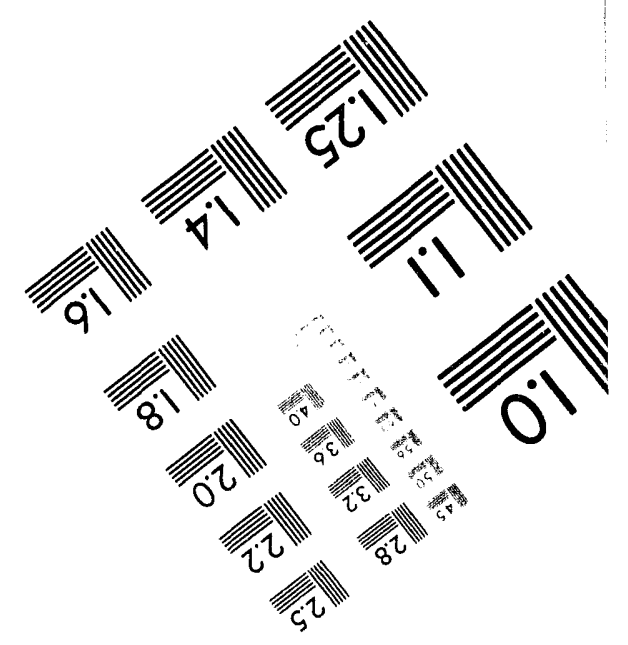



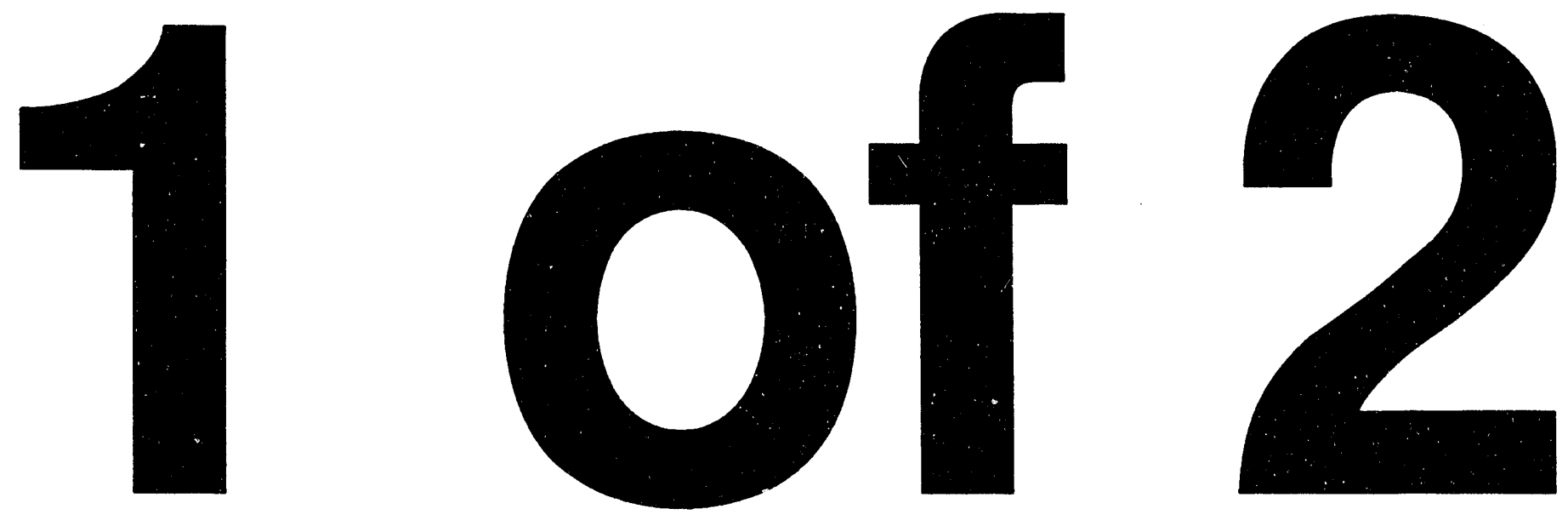


\section{Performance Specifications for Technology} Development: Application for Characterization of Volatile Organic Compounds in the Environment

by S.E. Carpenter, P.V. Doskey, M.D. Erickson, ${ }^{*}$ and P.C. Lindahl

Environmental Research Division,

Argonne National Laboratory, 9700 South Cass Avenue, Argonne, Illinois 60439

July 1994

Work sponsored by United States Department of Energy, Assistant Secretary for Environmental Management, Office of Technology Development

*Principal Investigator. 


\section{Preface}

This report was prepared as a deliverable on the project "Technology Performance Specifications," Technical Task Plan CH2-3-10-01, as part of the Characterization, Monitoring, and Sensor Technology Integrated Program (Caroline B. Purdy and Eric M. Lightner, Program Managers) in the Office of Technology Development (OTD) within the U.S. Department of Energy's (DOE's) Office of Environmental Management (EM).

The inspiration for a mission statement of this project arose out of concerns articulated by Drs. Clyde W. Frank, Caroline B. Purdy, and William C. Schutte of OTD, who believed that measurable goals for DOE's environmental technology development projects were lacking.

Chapters of this document were prepared as follows:

- Chapter 1, "Introduction," Mitchell D. Erickson, Argonne National Laboratory (ANL), (708) 252-7772;

- Chapter 2, "Gas Chromatography," Paul V. Doskey, ANL, (708) 252-7662;

- Chapter 3, "Mass Spectrometry and Gas Chromatography/Mass Spectrometry," William C. McDonald and Mitchell D. Erickson, ANL, (708) 252-7772; and Brian M. Abraham and Albert Robbat, Jr., Chemistry Department, Tufts University, Medford, Massachusetts;

- Chapter 4, "Fiber-Optic Chemical Sensors," Peter C. Lindahl, ANL, (708) 252-3490;

- Chapter 5, "Infrared and Raman Spectroscopy," Scott E. Carpenter, ANL, (708) 252-5338;

- Chapter 6, "Electrochemical Sensors," Paul V. Doskey, ANL, (708) 252-7662; and

- Chapter 7, "Piezoelectric Sensors," Paul V. Doskey, ANL. (708) 252-7662.

In addition to the primary authors, several other individuals contributed technical revisions and comments:

- Joe V. Aldstadt (ANL),

- Shannon Blair (ANL), 
- Thomas L. Isenhour (Triangle Research, Ltd., Manhatten, Kansas),

- Jacqueline Kuo (ANL), and

- Albert Robbat, Jr. (Tufts University).

Editorial and clerical assistance was provided by Eileen Brazelton, Alessandra Klimara, and Jill Thompson. 


\section{Contents}

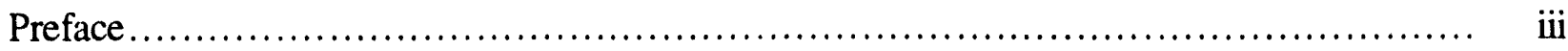

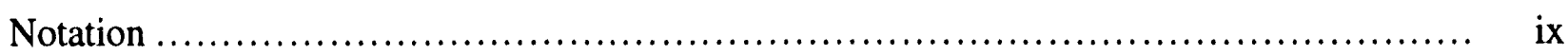

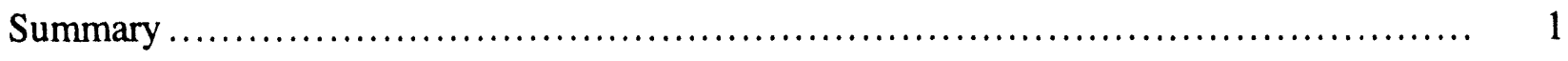

1 Introduction.............................................................. 5

1.1 Performance Specification Process.................................... 5

1.1.1 Baseline Technologies for an Environmental Restoration or Waste Management Need ....................................... 5

1.1.2 Customer's Requirements........................................... 9

1.1 .3 Unmet Requirements................................................. 9

1.1.4 Technology Development Needs ................................ 10

1.2 Overview of Technology Baselines for Volatile Organic Compounds .......... 10

1.2 .1 Introduction........................................................... 10

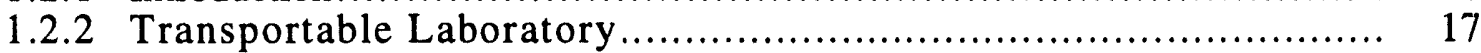

1.2 .3 Portable Analyses ...................................................... 18

1.2.4 On-Line Instrumentation................................................ 19

1.2 .5 In Situ Monitors ................................................ 20

1.2.6 Need for Technology Baselines..................................... 21

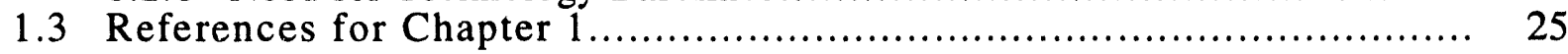

2 Gas Chromatography ................................................... 27

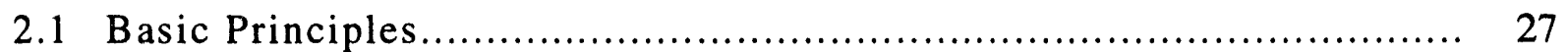

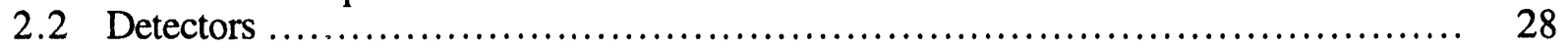

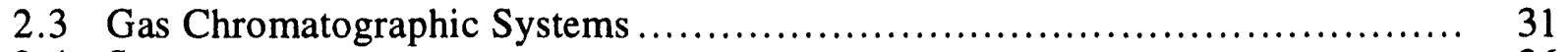

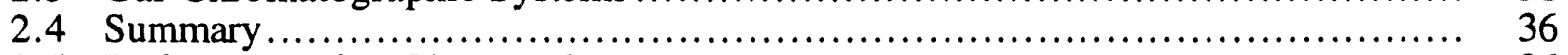

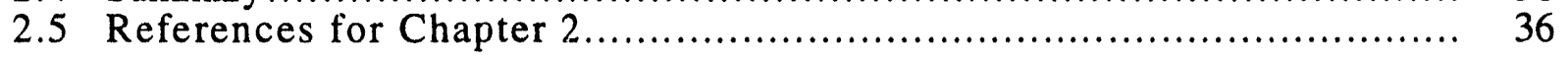

3 Mass Spectrcmetry and Gas Chromatography/Mass Spectrometry................... 39

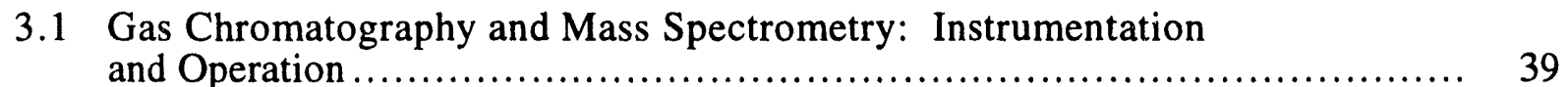

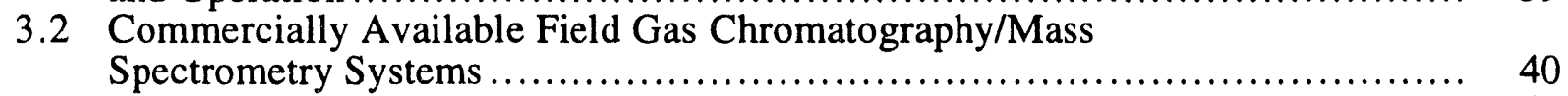

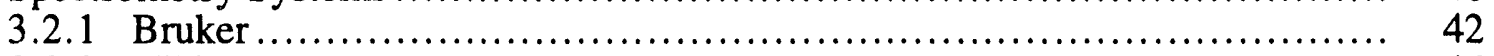

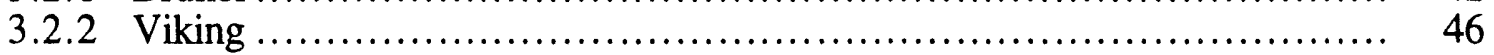

3.2.3 The EPA's Thermal Chromatography/Mass Spectrometry System ....... 47

3.3 Research Efforts .......................................................... 47

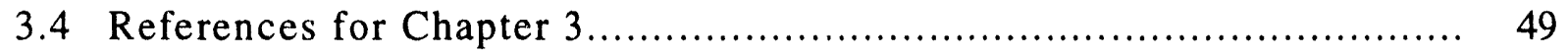

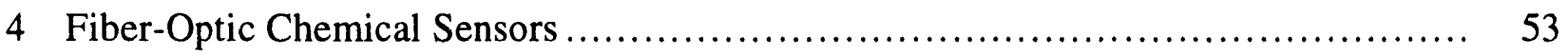

4.1 Analytical Aspects of Sensors ......................................... 53

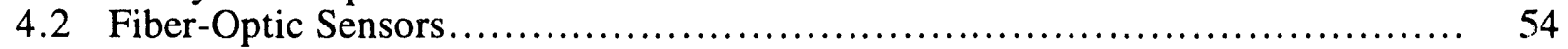

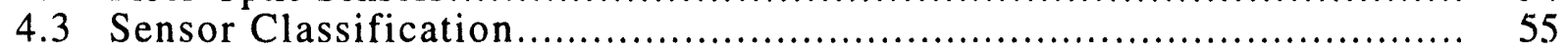

4.4 Advantages and Disadvantages of Optical Sensing ................................ 56

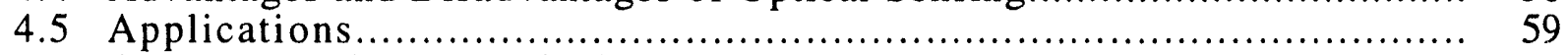

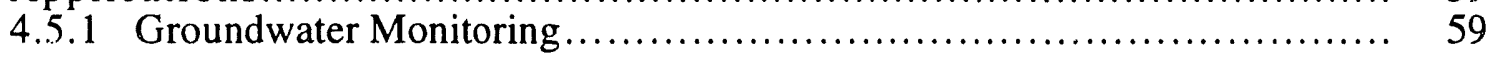




\section{Contents (Cont.)}

4.5 .2 Pollution Monitoring .......................................... 60

4.5.3 Current Status of Fiber-Optic Chemical Sensors for Determining Volatile Organic Compounds for Environmental Application............. 60

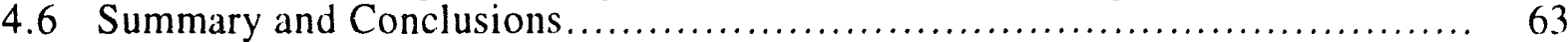

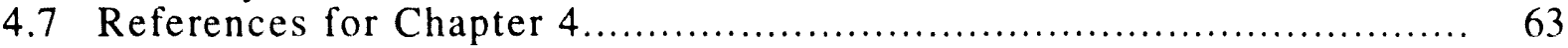

5 Infrared and Raman Spectroscopy...................................... 67

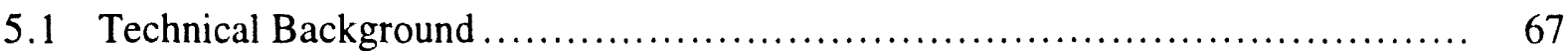

5.1.1 Overview of Vibrational Spectroscopic Measurements .................... 67

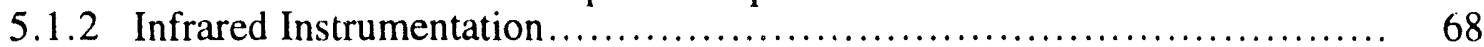

5.1 .3 Raman Instrumentation ........................................... 68

5.2 Survey of Infrared Techniques for Measuring Volatile

Organic Compounds ....................................................... 69

5.2.1 Transmission Measurements of Infrared Absorption ................... 69

5.2.2 Photoacoustic Measurements of Infrared Absorption.................... 70

5.3 Survey of Raman Techniques for Measuring Volatile

Organic Compounds ..................................................... 70

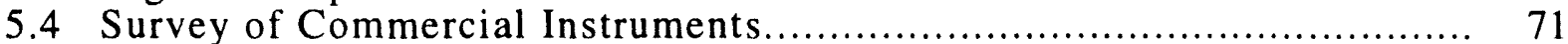

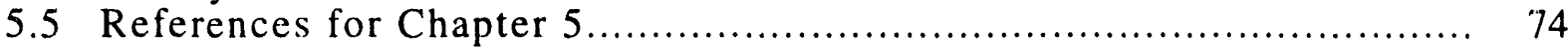

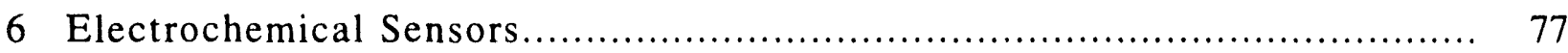

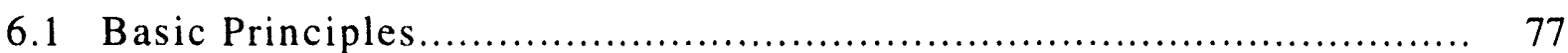

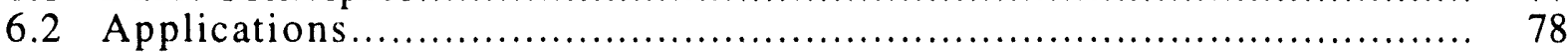

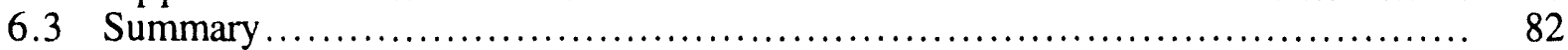

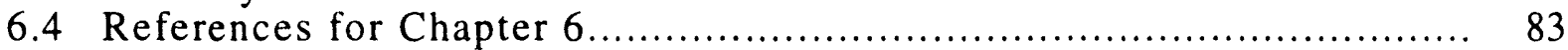

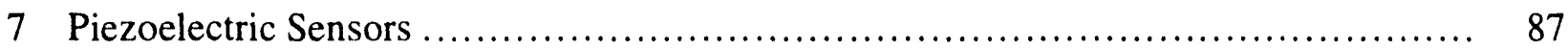

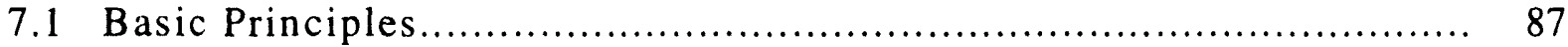

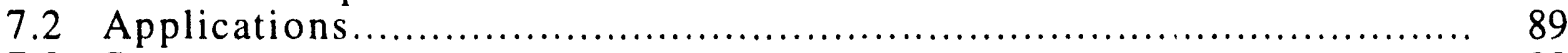

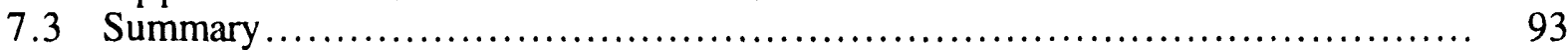

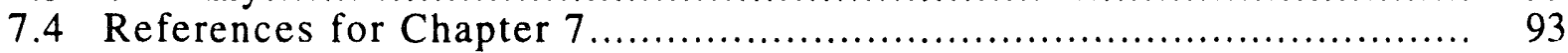

Figures

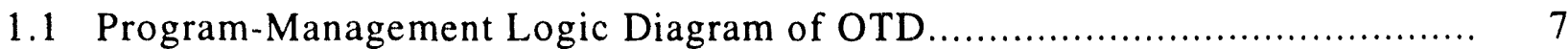

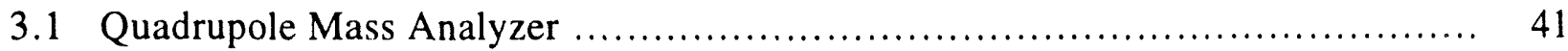

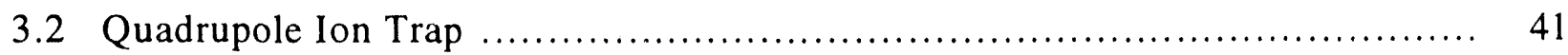

3.3 Total-Ion-Current Chromatogram, Selected-Ion-Current Profile, and Mass Spectra for a Typical GC/MS Analysis ............................. 42

3.4 Weights and Power Requirements of Several GC/MS Systems................. 48 


\section{Tables}

1.1 Analytical Levels Appropriate to Data Uses ................................ 12

1.2 Baseline Technologies for VOC Characterization ............................ 22

2.1 Some Common GC Detectors: Sensitivities, Linear Dynamic Ranges, and Specificities to Various Classes of Organic Compounds ..................... 29

2.2 Manufacturers and Suppliers of GC Systems and Their Salient Features ........ 32

3.1 Key Features of the Bruker MEM and EM-640 and the Viking SpectraTrak 620

4.1 Parameters Measured or Applications That Use Optical Fibers as Extrinsic or Intrinsic Sensors ............................................... 54

4.2 Classification for Optical Sensors and Typical Examples ........................... 56

5.1 Reported Product Specifications for MIRAN 1B2 for Two Example Vapors...................................................... 73

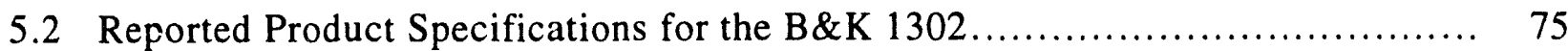

6.1 Commercial Vendors of Electrochemical Sensors ................................... 83

7.1 Developers and Suppliers of Piezoelectric-Based Sensors ...................... 91

7.2 Representative Sensitivities for SAW Devices Coated with Various Substrates 


\section{Notation}

The following is a list of the acronyms, initialisms, and abbreviations (including units of measure) that appear in this document. Some acronyms used only in tables are defined in those tables.

\section{Acronyms, Initialisms, and Abbreviations}

$\begin{array}{ll}\text { ac } & \text { alternating current } \\ \text { AID } & \text { argon ionization detector } \\ \text { ANL } & \text { Argonne National Laboratory } \\ \text { APM } & \text { acoustic-plate mode } \\ \text { BAW } & \text { bulk acoustic wave } \\ \text { B\&K } & \text { Bruel \& Kjaer } \\ \text { BTX } & \text { benzene, toluene, and xylene } \\ \text { CCD } & \text { charge-coupled device } \\ \text { dc } & \text { direct current } \\ \text { DOE } & \text { U.S. Department of Energy } \\ \text { DSITMS } & \text { direct-sampling ion-trap mass spectrometry } \\ \text { ECD } & \text { electron-capture detector } \\ \text { EICD } & \text { electrolytic conductivity detector } \\ \text { EM } & \text { Office of Environmental Restoration and Waste Management } \\ \text { EPA } & \text { U.S. Environmental Protection Agency } \\ & \\ \text { FAM } & \text { field analytical method } \\ \text { FID } & \text { flame ionization detector } \\ \text { FOCS } & \text { fiber-optic chemical sensor } \\ \text { FPW } & \text { flexural plate wave } \\ \text { FTIR } & \text { Fourier transform infrared } \\ \text { FUV } & \text { far ultraviolet detector } \\ \text { GAO } & \text { U.S. General Accounting Office } \\ \text { GC } & \text { gas chromatography } \\ \text { GC/MS } & \text { gas chromatography/mass spectrometry } \\ \text { GC/FTIR } & \text { gas chromatography/Fourier transform infrared spectroscopy } \\ \text { GC/FTIR/MS } & \text { gas chromatography/Fourier transform infrared } \\ & \text { spectroscopy/mass spectrometry } \\ \text { ID } & \text { inner diameter } \\ \text { IDT } & \text { interdigital transducer electrode } \\ \text { InGaAsP } & \text { indium-gallium-arsenic-phosphorus } \\ \text { IR } & \text { infrared } \\ \text { ITD } & \text { ion-trap detector } \\ & \end{array}$




\begin{tabular}{|c|c|}
\hline LANL & Los Alamos National Laboratory \\
\hline LCD & liquid crystal display \\
\hline LED & light-emitting diode \\
\hline LEL & lower explosive limit \\
\hline MAID & micro-argon ionization detector \\
\hline $\mathrm{MCD}$ & microcoulometric detector \\
\hline MEM & Mobile Environmental Mass Spectrometer \\
\hline MOS & metal oxide semiconductor \\
\hline MS & mass spectrometry \\
\hline MSA & Mine Safety Appliance Co. \\
\hline MSD & mass-selective detector \\
\hline MSI & Microsensor Systems, Inc. \\
\hline MTI & Microsensor Technology, Inc. \\
\hline NIR & near-infrared \\
\hline ORNL & Oak Ridge National Laboratory \\
\hline OSHA & Occupational Safety and Health Administration \\
\hline OTD & Office of Technology Development \\
\hline PA & photoacoustic affect \\
\hline PAH & polycyclic aromatic hydrocarbon \\
\hline $\mathrm{PC}$ & personal computer \\
\hline PCB & polychlorinated biphenyl \\
\hline PEG & polyethylene glycol \\
\hline PEO & polyethylene oxide \\
\hline PID & photoionization detector \\
\hline PNL & Pacific Northwest Laboratory \\
\hline QAVQC & quality assurance and quality control \\
\hline $\begin{array}{l}\mathrm{R} \& D \\
\mathrm{rf} \\
\mathrm{RSD}\end{array}$ & $\begin{array}{l}\text { research and development } \\
\text { radio frequency } \\
\text { relative standard deviation }\end{array}$ \\
\hline SAW & surface acoustic wave \\
\hline SERS & surface-enhanced Raman spectroscopy \\
\hline $\begin{array}{l}\text { SH APM } \\
\text { SVOC }\end{array}$ & $\begin{array}{l}\text { shear horizontal acoustic-plate mode } \\
\text { semivolatile organic compound }\end{array}$ \\
\hline TCD & thermal conductivity detector \\
\hline TC/MS & thermal chromatography/mass spectrometry \\
\hline TD & thermal desorption \\
\hline TDGC/MS & thermal-desorption gas chromatography/mass spectrometry \\
\hline TRI & Transducer Research, Inc. \\
\hline TTP & technical task plan \\
\hline UV & ultraviolet \\
\hline UV/VIS & ultraviolet/visible \\
\hline VIS & visible \\
\hline VOC & volatile organic compound \\
\hline
\end{tabular}




\section{Chemicals}

$\mathrm{CCl}_{4} \quad$ carbon tetrachloride

$\mathrm{CH}_{4}$ methane

$\mathrm{CO}$ carbon monoxide

$\mathrm{CO}_{2}$ carbon dioxide

$\mathrm{HCl}$ hydrogen chloride

HF hydrogen fluoride

$\mathrm{NO}_{2} \quad$ nitrogen dioxide

$\mathrm{PbPc} \quad$ lead phthalocyanine

\section{Units of Measure}

$\begin{array}{ll}\begin{array}{l}\mathrm{cm} \\ \mathrm{cm}^{2} \\ { }^{\circ} \mathrm{C}\end{array} & \begin{array}{l}\text { centimeter(s) } \\ \text { square centimeter(s) } \\ \text { degree(s) Celsius }\end{array} \\ \mathrm{eV} & \text { electronvolt(s) } \\ \mathrm{ft} & \text { foot (feet) } \\ \mathrm{ft} & \text { square foot (feet) } \\ \mathrm{g} & \text { gram(s) } \\ \mathrm{GHz} & \text { gigahertz } \\ \mathrm{Hz} & \text { hertz } \\ \mathrm{in} . & \text { inch(es) } \\ \mathrm{kg} & \text { kilogram(s) } \\ \mathrm{km} & \text { kilometer(s) } \\ \mathrm{L} & \text { liter(s) } \\ \mathrm{lb} & \text { pound(s) } \\ \mathrm{m} & \text { meter(s) } \\ \mathrm{m}{ }^{3} & \text { cubic meter(s) } \\ \mathrm{MHz} & \text { megahertz } \\ \mu \mathrm{m} & \text { micrometer(s) } \\ \mathrm{mg} & \text { milligram(s) } \\ \mathrm{min} & \text { minute(s) } \\ \mathrm{mL} & \text { milliliter(s) } \\ \mathrm{mm} & \text { millimeter(s) }\end{array}$




$\begin{array}{ll}\text { ng } & \text { nanogram(s) } \\ \text { pg } & \text { picogram(s) } \\ \text { ppb } & \text { part(s) per billion } \\ \text { ppbv } & \text { part(s) per billion (volume) } \\ \text { ppm } & \text { part(s) per million } \\ \text { ppm-h } & \text { part per million-hour(s) } \\ \text { ppmv } & \text { part(s) per million (volume) } \\ \text { ppt } & \text { part(s) per trillion } \\ \text { s } & \text { second(s) } \\ \text { V } & \text { volt(s) } \\ \text { W } & \text { watt(s) }\end{array}$




\title{
Performance Specifications for Technology Development: Application for Characterization of Volatile Organic Compounds in the Environment
}

\author{
by \\ Scott E. Carpenter, Paul V. Doskey, Mitchell D. Erickson, ${ }^{*}$ and Peter C. Lindahl
}

\section{Summary}

The objective of any project to develop an instrument, technique, or method is to deliver needed and usable technologies to our customers. To help the U.S. Department of Energy's (DOE's) Office of Environmental Management (EM) and its investigators to meet that goal, technology performance specifications are being developed for implementation in research and development and in documentation, testing, and evaluation projects. Technology performance specifications will be used to establish milestones, to evaluate the status of ongoing projects, and to determine the success of completed projects. Preliminary performance specifications will be required in proposals and will be highly weighted in the technical evaluation.

The general approach to performance specifications is to document what currently exists or is nearing completion and to compare that baseline to the customers' needs to identify the unmet requirements. These unmet requirements then form the basis for the technology development needs that the investigators of the DOE Office of Technology Development (OTD) must address. The process needs to be quantitative, where appropriate, to focus project goals away from vague generalities like "better" toward specifics like "reduce detection limit from 50 micrograms per liter to 100 nanograms per liter," or from "cheaper" to "reduce labor costs for step A from 4 hours to 0.5 hour."

This report describes the model for performance specifications in detail. The process of setting performance specifications for a technology development project involves a sequence of actions:

1. Identify and characterize the baseline technologies for an environmental restoration or waste management need.

a. State the need of the customer.

b. Describe the relevant technologies that can be applied to this need.

c. Describe how the technology would be applied.

\footnotetext{
* Principal Investigator.
} 

d. Present tabular quantitative performance specifications for current technologies.

e. Provide documentation.

2. Establish the requirements of the customer. State specifically what technology is needed and when is it needed to meet regulatory or other mandates.

3. Compare baseline technologies to the customer's needs, and list unmet requirements.

4. Identify needs for technology development. Discuss what unmet requirements can realistically be met by the proposed technology; discuss what quantitative improvements can be anticipated.

a. Present tabular quantitative performance specifications tor 'he jroposed technology (i.e., what would improve over the baseline).

b. Present assessments of the quality of estimates (e.g., proven in another application; within theoretical limits of technique; best scientific judgment). Provide or reference documentation, where available.

c. Where appropriate, recommend priorities for which requirements should be addressed. These priorities should be based on the customer's priorities, the probability of success, and the time frame for completion. Discuss all considerations in the prioritization.

The report also reviews the application of the available technologies for characterization and monitoring of volatile organic compounds and assesses the applicability of these technologies to fixed-based laboratories, mobile laboratories, and transportable, portable, and in situ measurements. The technologies for the characterization and monitoring of volatile organic compounds were divided into the following groups according to the principle used for measurement:

- Gas chromatography,

- Mass spectrometry and gas chromatography/mass spectrometry,

- Fiber-optic chemical sensors,

- Infrared and Raman spectroscopy, 
- Electrochemical sensors, and

- Piezoelectric sensors.

Application and implementation of performance specifications within the framework of ongoing planning and management activities will require additional work - the development of a plan for implementaticn, coordination with other planning activities, and implementation. The strategy for implementation involves the following:

- Communicate the status and plans to all stakeholders.

- Integrate implementing activities with other EM management planning activities.

- Reach out to all stakeholders.

- Integrate performance specifications with all ongoing and new technology development activities.

- Use performance specifications in monitoring and reporting projects and programs.

The actions required for implementation include the following:

- A briefing conducted for program managers and other OTD management;

- Standard text modules (for various aspects of performance specifications) written and made available in both hard-copy and disk format for use in preparation of focus area implementation plans and other planning documents;

- Necessary guidance letters and other materials developed in concert with OTD management and prepared for concurrence and issuance;

- Communication of the vision, status, and plans of the performance specification process to all stakeholders;

- Quality assurance reviews conducted by a review panel for all projects: and

- Development of tools for linking all stakeholders and of a process to maintain these linkages. 
This report was prepared as a deliverable on the project "Technology Performance Specifications," Technical Task Plan CH2-3-10-01, as part of the Characterization, Monitoring, and Sensor Technology Integrated Program in the OTD within the DOE's EM program. 


\section{Introduction}

The mission of the Office of Technology Development (OTD) of the U.S. Department of Energy (DOE) is to deliver needed and usable technologies to our customers. To help OTD and its investigators meet that goal, technology performance specifications are being developed for implementation in research and development (R\&D) and in documentation, testing, and evaluation (DT\&E) projects. Technology performance specifications will be used to establish milestones, evaluate the status of ongoing projects, and determine the success of completed projects. Preliminary performance specifications will be required in technical task plans (TTPs) and will be evaluated as part of the TTP evaluation.

Technology performance specifications are a tool for program management. The logic diagram in Figure 1.1 illustrates how these performance specifications fit into the overall framework of program management.

The general approach to performance specifications is to document what currently exists or is nearing completion and to compare that baseline to the customers' needs to identify the unmet requirements. These unmet requirements then form the basis for the technology development needs that OTD investigators must address. The process needs to be quantitative, where appropriate, to redirect project goals from vague generalities (e.g., "faster") toward specifics (e.g., "reduction of labor costs for step A from 4 hours [h] to 0.5 hour"). The following paragraphs explain this approach in greater detail and correlate it with the logic diagram in Figure 1.1.

\subsection{Performance Specification Process}

This section describes the process whereby program planners identify what technologies need development for application to customers' needs.

\subsubsection{Baseline Technologies for an Environmental Restoration or Waste Management Need}

1. State the need of the customer.

a. What problems need to be solved?

b. What are the boundaries of the need? (Limit the scope to a specific need to keep the process in a focus area.)

c. What are the current deficiencies? 
d. What are "needs" versus "desires"? This answer should be supplied in consultation with customers where possible; interactions need to quantify the need and to differentiate needed features and performance specifications from desired, but not required, properties.

Discuss the potential impact of improved technologies. Where possible, provide quantitative estimates of what can be done better, faster, safer, or cheaper. This statement of needs is preliminary and is refined subsequently.

2. Describe the relevant technologies that can be applied to this need. Focus on the customer's needs, not the technique; and address all viable alternatives, not just the direct competition (e.g., for characterization of volatile organic compounds [VOCs] by gas chromatography/mass spectrometry [GC/MS], describe all of the technologies for VOC characterization, not just the competing gas chromatography [GC] or GC/MS related technologies). In addition to the available technologies, address current worldwide development of technology, and assess the probabilities of meeting unmet requirements and the schedule for availability of the technology. For upcoming technologies, present only a brief overview of technologies that are still at the stage of basic research, will not be available within the customer's time frame, or have a low probability of successful implementation. If no technologies currently exist to solve this problem, say so.

The text needs to include descriptions of technical alternatives, their status, their availability (list vendors, including DOE national laboratories), and any barriers to implementation. The text should also cite the sources used in describing the relevant technologies.

\section{Describe how the iechnology would be applied.}

a. What are the conditions of the operating environment (environmental, space, health and safety, and operational constraints)?

b. What are the time requirements (set-up time; measurement time; time to data availability; 24-hour operation)?

c. What are the requirements for the user (education or training; number of operators)?

4. Present tabular quantitative performance specifications for current technologies (include technologies under development that appear to be on a path toward successful and timely implementation and availability to DOE; i.e., do not fund 


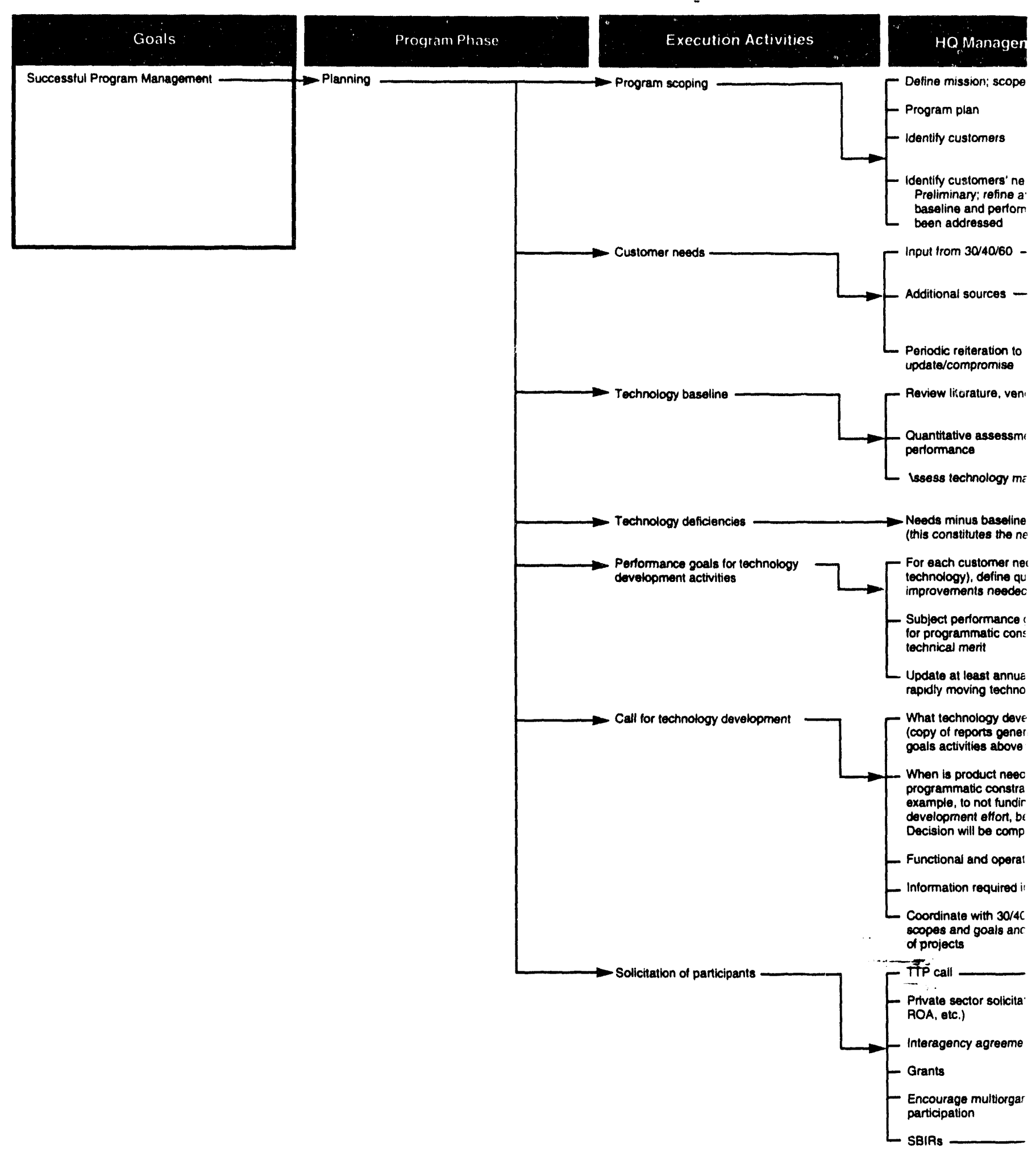

FIGURE 1.1 Program-Management Logic Diagram of OTD (HQ, Headquarters; METC, Morgantown Ene and development announcement; RFP, request for proposals; ROA, research opportunities announcemei 
verables

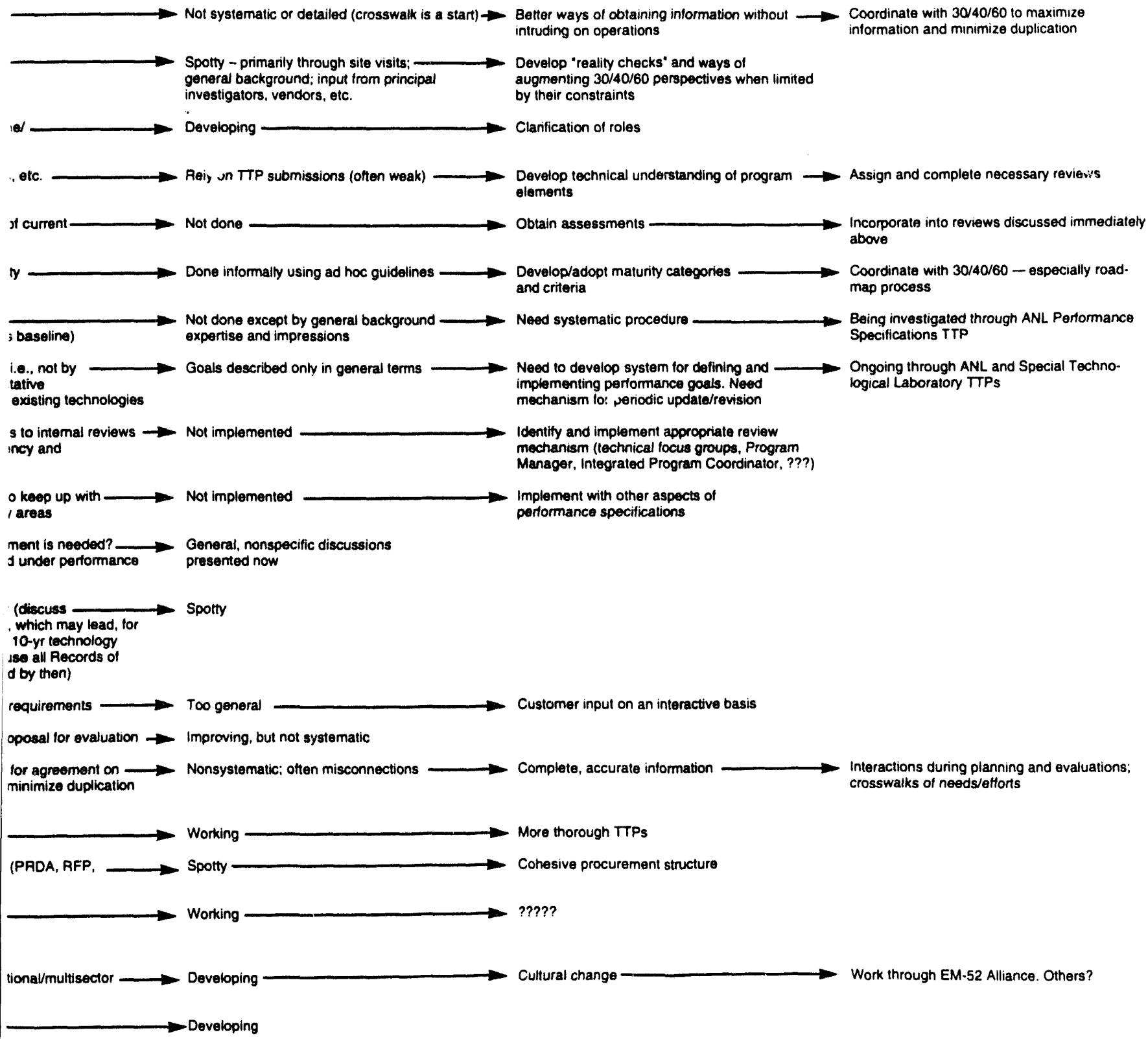

jy Technology Center; $M$ \& O, management and operating contractor; PRDA, program research ; SBIR, small-business innovative research; and SSO, source selection officer) 
Budget

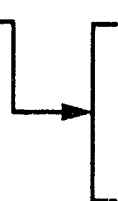

- Out-year planning

Plan

Present

- Defend

- Adjustments _ Additional fund

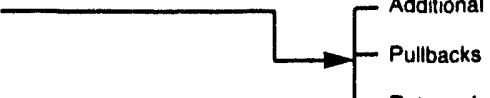

Returns trom c

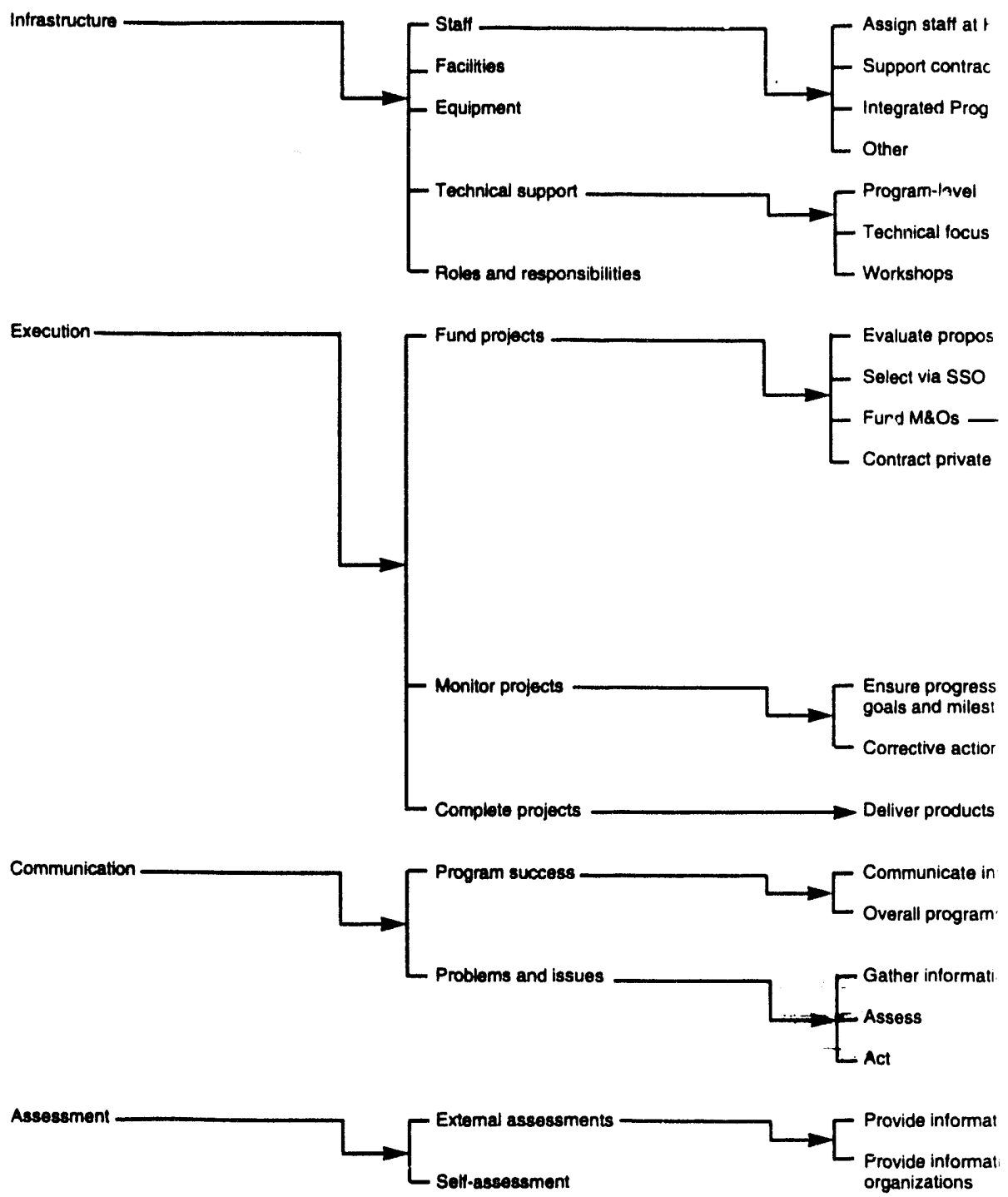

FIGURE 1.1 (Cont.) 
8

ament Activities

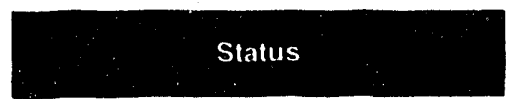

Management Element Needs

Implementation Needs

actors

stat

Manager at M8O

ups

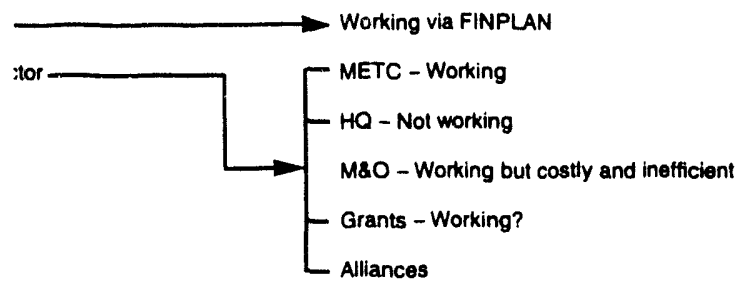

ward agreed-upon $\longrightarrow$ Spotty; midyear reviews lack detail; often

crisis management

customers

dual project success

ic success

10 external bodies

to internal DOE 
new $R \& D$ if something is already in the pipeline). Because considering specifications in dozens of areas (technical performance, cost considerations, applicability, availability, etc.) is possible, to restrict the effort, a limit on the length of the list to the ten most important specifications is requested; cost should be one of the ten.

5. Provide documentation for the previous performance specifications, plus statements of the quality of the information (e.g., [1] average of five vendors' specifications with similar applications to DOE needs; [2] educated guess; no firm information).

\subsubsection{Customer's Requirements}

Revise and refine the customer's statement of needs that was developed in Section 1.1.1. Address the following in more detail:

1. What problems need to be solved? See Section 1.1.1 for more details.

2. Who is the customer or customers? Name sites, suborganizations, individuals, activity data sheets, etc., where available.

3. Where is the technology needed, and what is the latest date for delivery?

4. What are the quantitative requirements (e.g., regulatory drivers)?

5. What are the functional and operating requirements?

6. What is the priority of the need (e.g., critical versus desired for convenience)?

7. What is the urgency of the need (e.g., a starting date for projects, completion date for work plans, etc., by which commitments to technologies must be made)?

8. Document everything listed previously.

\subsubsection{Unmet Requirements}

Compare baseline technologies to the customer's needs, and list unmet requirements. 


\subsubsection{Technology Development Needs}

The "unmet requirements" identified previously must be evaluated and validated to establish a shorter list of needs for technology development, as discussed subsequently:

1. Discuss what unmet requirements can realistically be met by the proposed technology; discuss what quantitative improvements can be anticipated.

2. Present tabular quantitative performance specifications for the proposed technology (i.e., what would improve over the baseline).

3. Present assessments of the quality of estimates (e.g., proven in another application; within theoretical limits of technique; best scientific judgment). Provide or reference documentation, where available.

4. Where appropriate, recommend priorities for which requirements should be addressed. These priorities should be based on the customer's priorities, the probability of success, and the time frame for completion. Discuss all considerations in the prioritization.

5. Identify a source of expertise (organization, name, address, and telephone number) that can be contacted to confirm the validity of the effort.

This document describes the technology baseline for characterization of VOCs in water and soil. Although not directly addressed, various waste matrices can also be characterized by these techniques. Not addressed are technologies for characterization of VOCs in air, combustion effluents ("stack gas"), and other gaseous matrices. This review was limited to technologies of chemical characterization that measure some specific property of the VOCs; excluded are indirect indicators (e.g., changes in vegetative growth) and general measurements of physical properties (e.g., changes in water conductivity that could arise from VOC contamination, as well as from a host of other contaminants).

\subsection{Overview of Technology Baselines for Volatile Organic Compounds}

\subsubsection{Introduction}

Recent years have marked a shift in the U.S. public perception of and policy toward environmental contamination and the production, treatment, and disposal of hazardous wastes. Legislation and changing public attitudes have precipitated a shift in emphasis from expedient waste disposal to waste reduction and treatment and to remediation of contaminated sites. 
indicate that by the year 2020, over 3,000 national Superfund sites will be listed by the U.S. Environmental Protection Agency (EPA), with cleanups costing in excess of $\$ 15()$ billion (University of Tennessee 1991; Hazardous Materials Control Research Institute 1992; U.S. General Accounting Office [GAO] 1992). The facility and landfill cleanups for the DOE and the U.S. Department of Defense are estimated to exceed $\$ 2$ trillion and $\$ 100$ billion, respectively; for example, the DOE faces a monumental task in cleaning up the dozen or so major sites and hundreds of smaller sites that were or are used in the produstion of the U.S. nuclear weapons arsenal and in the development of nuclear technologies for national defense and for peaceful uses (DOE 1991; U.S. Congress 1991). The DOE estimates that it will spend between $\$ 15$ billion and $\$ 45$ billion for analytical services over the next 30 years, the current volume of samples for analysis of hazardous constituents exceeds 400,000 samples per year, and analytical costs at some of the larger DOE sites are in excess of $\$ 10$ million annually (DOE 1992).

Site characterization, one of the most important components of the cleanup process, is conducted before, during, and after remediation, with analytical costs accounting for up to $80 \%$ of the expenses for site delineation and $50 \%$ of those for remediation (Hazardous Materials Control Research Institute 1992). The currently practiced methods of environmental sampling and analysis are time-consuming and costly and can present a potential exposure hazard to workers and the community. Measurement of environmental contaminants in the field can be preferable to laboratory analysis; the time savings realized with the field method translate into cost savings by reducing waiting times and the need for remobilization of field crews, and improved characterization results from "real-time" interactive sampling decisions. In addition to the costs, manipulation during the collection, transportation, and storage of samples can affect the integrity of the samples and thus the analytical results. Therefore, where possible, in situ measurements of environmental contaminants in soil, water, and waste are preferred if such measurements meet the objectives for data quality and are cost competitive.

Field analytical methods (FAMs) are designed to cheaply and rapidly produce data of sufficient quality to support the data quality objectives in near-real time. Table 1.1 compares the EPA's analytical levels with the use, limitations, and quality of data (EPA 1987). Note the following critical point: The FAMs do not inherently have lower quality data than their laboratory counterparts do and may, in some cases (as with VOCs; see subsequent text), routinely produce better data. Cornell $(1992,1993)$ examined the error associated with field and laboratory methods and concluded that maximum overall uncertainties of $200-500 \%$ in field analytical data are acceptable in most site characterization, where the other uncertainties dwarf this error; for example. he noted that the risk assessment values have an uncertainty of at least $100,000 \%$.

The FAMs have a number of potential benefits, with the primary one being cost. Cornell (1992) estimated cost savings for FAMs as high as $70 \%$ over traditional laboratory methods. A detailed life-cycle cost comparison indicated that the total cost of VOC analyses in soil or water that use field-transportable technology is about $18 \%$ of the cost associated with collecting and sending that sample to a commercial laboratory to obtain identical information (Henricks and Grant 1993). The FAMs examined were the Oak Ridge direct-sampling ion-trap mass spectrometry (DSITMS) 


\begin{tabular}{|c|c|c|c|c|}
\hline Data Use & $\begin{array}{l}\text { EPA } \\
\text { Analytical } \\
\text { Level }\end{array}$ & Type of Analysis & Limitations & Data Quality \\
\hline $\begin{array}{l}\text { - Site characterization } \\
\text { - Monitoring during } \\
\text { implementation }\end{array}$ & Level I & $\begin{array}{l}\text { Total vapor detection by using } \\
\text { portable instruments }\end{array}$ & Nonspecific & $\begin{array}{l}\text { If instruments are calibrated and data } \\
\text { are interpreted correctly, can provide } \\
\text { indication of contamination }\end{array}$ \\
\hline $\begin{array}{l}\text { - Site characterization } \\
\text { - Engineering design } \\
\text { Monitoring during } \\
\text { implementation }\end{array}$ & Level II & $\begin{array}{l}\text { - Variety of organics by GC } \\
\text { - Tentative ID; analyte-specific } \\
\text { - Detection limits vary from low } \\
\text { parts per million to low parts } \\
\text { per billion }\end{array}$ & $\begin{array}{l}\text { - Tentative ID } \\
\text { - Mostly volatiles }\end{array}$ & $\begin{array}{l}\text { - Dependent on QAVC steps employed } \\
\text { - Data typically reported in } \\
\text { concentration ranges }\end{array}$ \\
\hline $\begin{array}{l}\text { - Risk assessment } \\
\text { - } \text { PRP determination } \\
\text { - Site characterization } \\
\text { - Monitoring during } \\
\text { implementation }\end{array}$ & Level III & EPA procedures other than CLP & $\begin{array}{l}\text { Tentative ID in some } \\
\text { cases }\end{array}$ & $\begin{array}{l}\text { - Similar detection limits to CLP } \\
\text { - Less rigorous QAVC }\end{array}$ \\
\hline $\begin{array}{l}\text { - Risk assessment } \\
\text { - PRP determination }\end{array}$ & Level IV & $\begin{array}{l}\text { - } \text { CLP-HSL } \\
\text { limits }\end{array}$ & $\begin{array}{l}\text { Tentative ID of } \\
\text { non-HSL parameters }\end{array}$ & $\begin{array}{l}\text { - Goal is data of known quality } \\
\text { - Rigorous QAVC }\end{array}$ \\
\hline $\begin{array}{l}\text { - Risk assessment } \\
\text { - PRP determination }\end{array}$ & Level V & $\begin{array}{l}\text { - Nonconventional parameters } \\
\text { - Method-specific detection limits } \\
\text { - Modification of existing methods } \\
\text { - Appendix } 8 \text { parameters }\end{array}$ & $\begin{array}{l}\text { May require method } \\
\text { development or } \\
\text { modification }\end{array}$ & Method-specific \\
\hline
\end{tabular}

a Selected acronyms: CLP, contract laboratory program; HSL, hazardous substances list; ID, identification; PRP, potentially responsible party; and QAVC, quality assurance/quality control.

Source: Adapted from EPA (1987). 
system (discussed in this document), the Los Alamos GC/ion-trap mass spectrometry (MS) system (discussed in this document), a Hewlett-Packard GC/MS system, a Viking transportable GC/MS system (discussed in this document), a Photovac portable gas chromatograph/photoionization detector, and a Sentex GC system with argon ionization and electron-capture detectors (ECDs). At an annual rate of 3,500 samples analyzed, the cost varied from $\$ 41$ to $\$ 51$ per sample for the transportable technologies, while the cost for analysis at a commercial laboratory was calculated at $\$ 254$ per sample. Cost differences among the transportable instruments depend directly on the complexity and sophistication of the instrument and its capabilities for data analysis. In addition to the direct cost savings, with rapid access to analytical results, the sampling strategy may be modified on-site, reducing the time for analysis and the number of samples needed to determine levels of contamination. By minimizing sampling and providing real-time information about contaminant levels, FAMs improve safety for remediation crews. Minimizing the handling and storage of samples reduces chain-of-custody complications and reduces the likelihood of sample degradation (Ganapathi et al. 1988; Chudyk 1989; Fribush and Fisk 1992). In addition, data acquired in the field may be used to direct the efforts of laboratory analysts, speeding their analysis. Furthermore, laboratory analysis can take weeks or months, causing expensive delays for remediation crews. The potential speed and flexibility offered by FAMs will be essential in cheaply and efficiently characterizing the thousands of hazardous waste sites around the United States. The use of FAMs is appropriate when the following four conditions are met (Cornell 1993):

- A suitable FAM is available.

- The detection limit of the FAM is lower than the regulatory cutoff or other minimum concentration of concern.

- The uncertainty of the FAM-derived measurement accounts for less than $25 \%$ of the overall multiplicative uncertainty of the process for site characterization.

- Rapid access to and use of information in making decisions is desired and is integrated into project planning and management.

The data gathered by field instrumentation generally have been compared with laboratory data under the assumption that laboratory values approximate true values; however, sample degradation during transport may result from factors that include evaporative losses, adsorption to container walls, changes in redox potential of the sample environment, or changes in $\mathrm{pH}$ because of differing partial pressures of carbon dioxide $\left(\mathrm{CO}_{2}\right)$ (Chudyk 1989). Siegrist found that considerable bias may be introduced by the sampling and handling process, from $-100 \%$ to $+25 \%$ in some VOC measurements (Siegrist and Jennsen 1990; Siegrist 1991). Spittler et al. (1988), using the manual Test Methods for Evaluating Solid Waste: Physical/Chemical Methods (EPA 1986) (EPA SW-846, method 5030), also reported a substantial loss of volatiles with increasing sample-holding time. 
The FAMs can range from adaptations of accepted laboratory methods with identical data quality objectives and requirements for documentation to screening methods. The term "screening methods" is variously defined but generally encompasses methods that

- Identify classes of components, not specific compounds;

- Have data quality objectives that are significantly lower than those of an analytical method; or

- Have documentation requirements that are abbreviated.

The field screening methods trade either cost savings or time savings for relaxed data quality objectives. The FAMs encompass transportable (van- or trailer-housed) procedures and instrumentation, portable methods and instrumentation, handheld monitors, test kits, and dosimeters. Rapid screening methods should be capable of providing screening-level results for at least 30 samples per day.

The EPA is changing its stance on the application of field methods in the regulatory arena. If quality assurance and quality control (QA/QC) are sufficient, FAMs may now be considered analytical methods, instead of screening techniques. The EPA remains cautious, however; in most cases, field data must still be verified by conventional laboratory analysis and must be flagged to indicate their source (Fribush and Fisk 1992). Cornell (1992) found the precision of field analysis to closely resemble the precision of laboratory analysis and suggested that the accuracy of field data may be corrected by calibrating th field data by using a site-specific field-versus-laboratory calibration plot. Whether this practic will be accepted at the regulatory level remains to be seen.

Several problems have hindered the application of FAMs. Lack of field-available technology has, until recently, been the most imposing obstacle. Considerable expertise is often required to operate complicated instruments in the field (Fribush and Fisk 1992). Adequate standard methods and QAVQ guidance have not been promulgated to ensure that data of known quality are generated. This lack of information about the quality of data produced by portable instrumentation, especially in terms of legal defensibility, silows the acceptance of FAMs in planning activities for site characterization. Finally, most comparisons between field and laboratory analyses have been case studies; no comprehensive method-validation study has compared field and laboratory analyses.

Volatile organic compounds are routinely measured at trace levels in environmental samples in the laboratory: standard methods have been available for years. Where laboratory analysis is sufficient, the technology is mature, although both evolutionary and revolutionary changes can and do occur. Laboratory-based analyses are still technically deficient in certain areas required by the customer:

- Misidentification of compounds by nonspecific or semispecific detectors occurs; 
- Analyte losses in transport and storage often result in low-biased results;

- Only selected environmental pollutants are on the lists of target compounds;

- Broad lists of target compounds are fine for surveys but are overkill for sites where a narrow list of pollutants is known to be present;

- Cost and turnaround time can be improved through automation, better electronics, and other techniques;

- Data quality (e.g., precision and accuracy) could be improved;

- Work-minimization practices need to be applied to requirements for sample preparation; and

- Different operating environments exist in the field, and faster turnarounds are needed.

Beyond these deficiencies for laboratory-based analyses, an increasing emphasis has been placed on field analyses, ranging from transportable laboratories with the same instrumentation and methods as the fixed-base laboratories, through portable instrumentation, to in situ monitoring sensors. The needs for field analyses are generally based on either direct cost savings or indirect savings realized by receiving information faster. More specifically, field analyses are needed where

- Significant improvements in turnaround time can be realized with field analysis; this improvement can be invaluable where decisions can be made in the field or where waiting for analytical results or remobilization is costly;

- Costs can be reduced significantly (see Chapter 3 for a cost-comparison study of field GC and GC/MS versus fixed laboratory analyses); and

- Analyses can more easily be tailored to the data quality objectives; many on-site laboratory or portable instruments can readily switch between analytical and screening modes.

Some field analytical methods are available for use in addressing needs for environmental characterization and monitoring. Commercial instruments are available, some methods are in place and have been validated, and results have been demonstrated to be equivalent to or better than those for laboratory analyses. Upcoming improvements and maturation of the technology are coming, which will improve quality, improve user-friendliness, provide broader applications, and reduce the currently high capital costs. 
The most common criticism of many FAM systems (notably GC/MS and MS) currently in use is that field analyses require experienced analysts to employ the complex instruments effectively. Investigators have been frustrated by the complexity of instruments and methods and the additional challenges presented by field conditions. Improvements in hardware, software, and component integration have muted these complaints and will undoubtedly continue to make the instruments aind methods more user-friendly.

The Analytical Services Program Five-Year Plan of the DOE Office of Environmental Management (EM) outlines most clearly, for the DOE sites alone, the need for efficient sample analysis:

It is generally agreed that certain types of current analytical capacity for environmental analysis will be overwhelmed when major DOE Environmental Restoration and Waste Management cleanup programs complete their planning phases and enter the analytical chemistry marketplace. The Future Analytical Support Team (FAST), consisting of senior-level DOE Complex personnel from major field laboratories estimated that $1,750,000$ analyses were carried out for DOE EM programs in 1989 , at a cost of more than $\$ 300$ million. About 410,000 of these were analyses of hazardous waste constituents. The annual number of DOE hazardous constituent analyses is expected, at a minimum, to double to 800,000 in five years (DOE 1992, p. 7).

The identification, evaluation, and implementation of FAMs will be of paramount importance in facing this demand for sample analysis, not only for the DOE and other federal agencies, but also for the private sector faced with cleaning up its own sites. "Better, faster, safer, and cheaper" are the watchwords for new technologies for site characterization. The FAMs provide an excellent example of the new tools of chemical analysis, sensors, and geophysical characterization just now becoming available to the environmental assessment community.

The use of FAMs fits into the evolving overall approach to expediting site characterization through rapid, on-site decision making (Burton et al. 1994). The expedited approach to site characterization features the following:

- A flexible work plan that can be adjusted as information becomes available:

- Integration of the regulations into the planning and decision-making process;

- Rapid on-site acquisition, interpretation, and delivery of chemical, radiological, physical, geophysical, and hydrologic measurements;

- Placement of high-level staff in the field who are empowered to interpret data and act on the results; 
- Minimization of intrusive techniques of characterization and superfluous gridpoint sampling; and

- Accurate site characterizations that contain sufficient information to make decisions on remediation within a regulatory framework.

Unlike laboratory analyses, field analyses are not generally considered usable technologies, except in the easiest case of the transportable laboratory that uses the same instrumentation and executes the same methods as its fixed-base counterpart does. For VOCs, improvements are needed in a number of areas.

\subsubsection{Transportable Laboratory}

The assumption is made that samples will be collected under customary protocols and delivered to the transportable laboratory in a container for analysis.

\subsubsection{Instrumentation}

Laboratory-based instrumentation is mature and generally adaptable to needs. Evolutionary improvements (e.g., advanced electronics and data systems) are constantly introduced by commercial vendors. Instrumentation that is available and routinely used is the following:

- GC, and

- GC/MS.

Instrumentation that is available and applicable under certain conditions, but not commonly used, is the following:

- Infrared (IR) spectroscopy, and

- Raman spectroscopy.

Given the availability and success of GC and GC/MS for most applications and the lack of a clear advantage for IR or Raman spectroscopy, the possibility that IR or Raman spectroscopy will break into the field for routine application any time soon is unlikely.

Certain instrumental adaptations to field use that improve ruggedness (e.g., electronics that do not shake loose on transport, broader environmental tolerances) are desirable but are not a high 
priority for R\&D funds. Mass spectrometry continues to evolve to smaller, cheaper, and more rugged instruments. This trend may be expected to continue, blurring the cost and usability distinction between GC/MS and GC with another detector. Fast-GC, advanced MS techniques (e.g., reflectron time of flight) and other instrumental advances may provide additional speed for analysis and also reduce instrumental bulk and cost.

\subsubsection{Apparatus}

Both purge-and-trap and headspace techniques are mature, commercialized technologies. Some automation may be desirable.

Novel techniques, such as thermal desorption (TD) and spray-and-trap, may deserve attention, improvement, validation, and automation. Research needs are limited to automation and on-line analyses.

\subsubsection{Methods}

Methods from the EPA exist. Improvements to keep up with new instrumentation and apparatus may be needed.

Standardization and revisions to address automation and faster analyses are needed. Researchers need to focus on methods that are technically innovative, not, for example, rote adaptations of the EPA manual SW-846 (EPA 1986), which propagate slow, costly, or wasteful procedures such as slow-GC conditions.

\subsubsection{Portable Analyses}

The assumption is made that the sample may be presented to the instrument as a contained sample, much like the transportable laboratory, but that sample preparation and instrument operation must be done under field conditions (e.g., on a table set up on-site).

\subsubsection{Instrumentation}

Six vendors offer portable GC systems, and two offer portable GC/MS systems. Only a few of the GC systems and neither of the GC/MS systems can be operated while being carried; they require an alternating-current (ac) power source, they are too bulky, or they are too sensitive. Although these instruments operate on the same principles as their laboratory cousins, they are designed for field work; for example, the portable GC/MS systems are designed for "sniffing" 
ambient air or thermally desorbed vapors without the extensive sample conditioning for a customary liquid injection, as is done in the laboratory.

The Foxboro Company's MIRAN filter-based analyzers are designed for Occupational Safety and Health Administration (OSHA)-level ambient air monitoring of volatile and gaseous air toxics and have been adapted for use in soil gas. Gas is drawn into a long-path gas cell for measurement. The firm of Bruel \& Kjaer $(B \& K)$ makes two instruments, one a filter and one an interferometer-based instrument (Fourier transform infrared [FTIR] spectroscopy based); both use photoacoustic detection of only a 3-milliliter ( $\mathrm{mL}$ ) volume of gas. The B\&K instrumentation can analyze up to seven analytes simultaneously. Infrared measurement offers near real-time analysis at an affordable capital cost with rugged, mature instrumentation; however, limitations of the technology include a lack of sensitivity, difficulties in detecting a component when others are present at much higher concentrations, and an inability to handle complex mixtures. Advanced signal processing by using chemometric techninues can address these last two limitations.

\subsubsection{Apparatus}

Several techniques for sample introduction (TD, spray-and-trap, and trapping concentrators) are evolving in both the research and vendor areas. Research needs include automation, signal interpretations, engineering systems for field use, and evaluation of novel hardware from vendors and other sources.

\subsubsection{Methods}

The historical tendency has been not to codify field methods in compendia or publications. Nevertheless, the EPA published a Field Screening Methods Catalog User's Guide (EPA 1988), which contained two-page descriptions of FAMs. The methods do not provide sufficient detail for direct implementation and provide no guidance for quality control or reporting requirements. Some field methods have been developed (e.g., field GC/MS). Many of the field GC applications use the EPA manual SW-846 (EPA 1986) or similar methods nearly directly, whether or not the methods are, in fact, appropriate.

\subsubsection{On-Line Instrumentation}

The assumption is made that the instrument will be integrated with the sampling system and that the sample or the purged VOCs from the sample will be directly presented to the instrument. The objective of on-line analyses is rapid analysis with no chance for loss of VOCs. 


\subsubsection{Instrumentation}

Either portable or transportable instrumentation can be used for on-line analyses. The instrumental operating environment depends on the interface and can range from environmentally controlled to hostile. Depending on the operating environment (e.g., level of vibration), the turnaround time needed, and the analytical objectives, any of the previously cited instrumentation can serve as on-line VOC analyzers.

The focus with on-line analyses is rapid analysis with no chance for loss of VOCs. The definition of rapid can vary and can dictate the choice of instrument. Only the sensors can be termed truly real-time (defined here arbitrarily as a less than 1-second [s] response time). Infrared and Raman spectroscopy and MS can provide answers within $5 \mathrm{~s} ; \mathrm{GC}$ and GC/MS require minutes (min), as now practiced.

\subsubsection{Apparatus}

The key to successful on-line analysis is the interface from the source of the sample to the instrument. Regardless of instrument, the sample must be "collected," transported, and conditioned (e.g., water removal). For many applications, some sort of preconcentration or focusing technique is needed to achieve the required sensitivities.

\subsubsection{Methods}

No methods were found.

\subsubsection{In Situ Monitors}

The logical extension of all of the previous categories is to take the sensor directly to the sample and measure the VOCs in situ. The purported advantage of the measurement being made on an undisturbed sample is only partially true: the sensor must be in contact with the groundwater or other matrix; so, by definition, the matrix is disturbed. In situ monitors are particularly attractive for instances where extraction of the sample creates problems of exposure or disposal (e.g., where the matrix is radioactively contaminated), where information is needed in real time (the definition of which varies widely), or where periodic monitoring makes a permanent or semipermanent installation of a sensor attractive. 


\subsubsection{Instrumentation and Apparatus}

In situ monitors must, by definition, fit the physical size and weight constraints of the delivery system and must operate under environmental conditions. Traditionally, we have focused on instrumentation inside wells, where the diameter of the well casing is the major size constraint and is often less than 10 centimeters $(\mathrm{cm})$ in inner diameter (ID). Recently, the emphasis has shifted toward using cone penetrometers to install in situ monitors. Now the size constraints are considerably more stringent; a size of $3 \mathrm{~cm}$ (ID) is typical, although slightly larger rods are in use.

Optical and electrical signals can be transported to the surface. Fluorescence, ultraviolet (UV), and Raman detectors have been integrated with cone penetrometers, wherein optical inputs and outputs are accomplished by using fiber optics. Sapphire, diamond, and other optical materials provide windows for observation of the water or soil. All of the electrochemical and piezoelectric sensors can potentially be used as in situ sensors. Even those requiring chemical reactions with reagent solutions have been packaged for downhole use. Typically, the sensor and necessary electronics are installed downhole, and electronic components that can be separated (e.g., power supplies, data storage) are retained in a surface package.

Instrumentation is still developmental. Active areas of research include the development of fluorescence probes, Raman probes, and TD probes.

\subsubsection{Methods}

No methods were found.

\subsubsection{Need for Technology Baselines}

As the previous discussion indicates, new ways to measure VOCs in the subsurface are needed. This need has been and continues to be an area of intense R\&D interest. In the past year, 146 articles cited in Chemical Abstracts addressed VOC analysis in soil or water. Although scanning the literature, reading critical reviews, and obtaining vendor information appear, on the surface, to be trivial exercises that will yield the needed information, our experience has been that obtaining the information and distilling it into a coherent comparison are daunting tasks. Both vendors and researchers are guilty of providing selected information that illustrates the advantages of their technique but that does not provide quantitative specifications that can be compared.

The following chapters present overviews of technologies of VOC measurement. Table 1.2 presents an overview and comparison of the technologies. 
TABLE 1.2 Baseline Technologies for VOC Characterization

\begin{tabular}{|c|c|c|c|c|c|c|c|c|c|c|}
\hline Technology & $T / P / I P^{a}$ & $\begin{array}{l}\text { Analytes/ } \\
\text { Matrices }\end{array}$ & $\begin{array}{l}\text { Data Quality } \\
\text { Achievable }^{\mathrm{b}}\end{array}$ & $\begin{array}{l}\text { Limit of } \\
\text { Quantitation } \\
\text { Achievablec }\end{array}$ & Key Advantages & Key Disadvantages & Maturity & Vendors $^{d}$ & $\begin{array}{l}\text { Unit Cost } \\
\left(10^{3} \$\right)^{\bullet}\end{array}$ & $\begin{array}{c}\text { Priority } \\
\text { Technology } \\
\text { Development } \\
\text { Needs' }\end{array}$ \\
\hline GC & $T$ & $\begin{array}{l}\text { All/all } \\
\text { (with } \\
\text { proper } \\
\text { methods) }\end{array}$ & II & $\begin{array}{l}\text { Parts per } \\
\text { billion - } \\
\text { varies with } \\
\text { detector }\end{array}$ & $\begin{array}{l}\text { Nearly universal; } \\
\text { adaptable to } \\
\text { simple or complex } \\
\text { mixtures; } \\
\text { accepted }\end{array}$ & Lack of specificity of MS & Mature & $\begin{array}{l}\text { Many; } \\
\text { four } \\
\text { miniaturized }\end{array}$ & 20 & Fast-GC \\
\hline GC & $\mathbf{P}$ & $\begin{array}{l}\text { All/all } \\
\text { (with } \\
\text { proper } \\
\text { methods) }\end{array}$ & ॥ & $\begin{array}{l}\text { Parts per } \\
\text { billion - } \\
\text { varies with } \\
\text { detector }\end{array}$ & $\begin{array}{l}\text { Same as above, } \\
\text { plus portability }\end{array}$ & $\begin{array}{l}\text { Bulky; some are handheld; } \\
\text { not downhole }\end{array}$ & $\begin{array}{l}\text { Mature; } \\
\text { commer- } \\
\text { cialization } \\
\text { evolving }\end{array}$ & $\begin{array}{l}\text { Six } \\
\text { companies }\end{array}$ & 10 & $\begin{array}{l}\text { Hardware } \\
\text { engineering } \\
\text { (?): sample } \\
\text { introduction }\end{array}$ \\
\hline GC/MS & $T$ & $\begin{array}{l}\text { All/all } \\
\text { (with } \\
\text { proper } \\
\text { methods) }\end{array}$ & v & $\begin{array}{l}\text { Parts per } \\
\text { billion and } \\
\text { lower }\end{array}$ & $\begin{array}{l}\text { Same as GC. } \\
\text { plus selective } \\
\text { detection }\end{array}$ & $\begin{array}{l}\text { Cost; operator skill } \\
\text { requirements; can misuse } \\
\text { and misinterpret data }\end{array}$ & Mature & $\begin{array}{l}\text { Extrel: } \\
\text { Finnigan; } \\
\text { Hewlett- } \\
\text { Packard; } \\
\text { Varian; } \\
\text { others }\end{array}$ & 100 & - \\
\hline GC/MS & $\mathbf{P}$ & $\begin{array}{l}\text { All/all } \\
\text { (with } \\
\text { proper } \\
\text { methods) }\end{array}$ & v & $\begin{array}{l}\text { Parts per } \\
\text { billion and } \\
\text { lower }\end{array}$ & $\begin{array}{l}\text { Same as above, } \\
\text { plus portability }\end{array}$ & $\begin{array}{l}\text { Cost much greater than } \\
\text { laboratory GC/MS }\end{array}$ & $\begin{array}{l}\text { Mature: } \\
\text { commer- } \\
\text { cialization } \\
\text { evolving }\end{array}$ & $\begin{array}{l}\text { Bruker: } \\
\text { (Teledyne } \\
\text { MEC): } \\
\text { Viking }\end{array}$ & 200 & $\begin{array}{l}\text { Hardware } \\
\text { engineering: } \\
\text { sample } \\
\text { introduction }\end{array}$ \\
\hline Raman & $T$ & $\begin{array}{l}\text { Most/all } \\
\text { (with } \\
\text { proper } \\
\text { methods) }\end{array}$ & Probably III & $\begin{array}{l}\text { Parts per } \\
\text { million }\end{array}$ & $\begin{array}{l}\text { Able to detect } \\
\text { compounds } \\
\text { in water; } \\
\text { spectral signature } \\
\text { can be unique }\end{array}$ & $\begin{array}{l}\text { Lack of sensitivity; } \\
\text { no separation = cannot } \\
\text { handle complex mixtures; } \\
\text { discrimination of lower } \\
\text { level analytes in presence } \\
\text { of high-concentration } \\
\text { interferents }\end{array}$ & Mature & $\begin{array}{l}\text { BioRad; } \\
\text { Jasco; } \\
\text { Nicolet: } \\
\text { Perkin-Elmer; } \\
\text { SPEX }\end{array}$ & - & $\begin{array}{l}\text { Sample } \\
\text { interfaces }\end{array}$ \\
\hline
\end{tabular}


TABLE 1.2 (Cont.)

\begin{tabular}{|c|c|c|c|c|c|c|c|c|c|c|}
\hline Technology & $T / P / / ?^{\mathbf{a}}$ & $\begin{array}{l}\text { Analytes/ } \\
\text { Matrices }\end{array}$ & $\begin{array}{l}\text { Data Quality } \\
\text { Achievableb }^{\text {b }}\end{array}$ & $\begin{array}{c}\text { Limit of } \\
\text { Quantitation } \\
\text { Achievablec }^{c}\end{array}$ & Key Advantages & Key Disadvantages & Maturity & Vendors $^{d}$ & $\begin{array}{l}\text { Unit Cost } \\
\left(10^{3} \$\right)^{\bullet}\end{array}$ & $\begin{array}{c}\text { Priority } \\
\text { Technology } \\
\text { Development } \\
\text { Needs }\end{array}$ \\
\hline Raman & $\mathbf{P}$ & $\begin{array}{l}\text { Most/all } \\
\text { (with } \\
\text { proper } \\
\text { methods) }\end{array}$ & Probably III & $\begin{array}{l}\text { Parts per } \\
\text { million }\end{array}$ & $\begin{array}{l}\text { Same as } \\
\text { previous, plus } \\
\text { portability }\end{array}$ & $\begin{array}{l}\text { Same as previous, plus } \\
\text { new hardware }\end{array}$ & $\begin{array}{l}\text { Develop- } \\
\text { mental }\end{array}$ & $\begin{array}{l}\text { (EIC); } \\
\text { (GAMMA- } \\
\text { METRICS) }\end{array}$ & - & $\begin{array}{l}\text { Maturation of } \\
\text { first- } \\
\text { generation } \\
\text { portable } \\
\text { instruments; } \\
\text { sample } \\
\text { interfaces }\end{array}$ \\
\hline IR & $T$ & $\begin{array}{l}\text { Most/all } \\
\text { (with } \\
\text { proper } \\
\text { methods) }\end{array}$ & Probably III & $\begin{array}{l}\text { Low to sub- } \\
\text { parts per } \\
\text { million }\end{array}$ & $\begin{array}{l}\text { Unique spectral } \\
\text { signature; can be } \\
\text { near-real time } \\
\text { (<5 s in flow- } \\
\text { through cell) }\end{array}$ & $\begin{array}{l}\text { Lack of sensitivity: } \\
\text { cannot handle complex } \\
\text { mixtures; cannot } \\
\text { ciscriminate lower level } \\
\text { analytes in presence of } \\
\text { high-concentration } \\
\text { interferents }\end{array}$ & Mature & $\begin{array}{l}\text { Analect; } \\
\text { BioRad; } \\
\text { Bomem; } \\
\text { Mattson; } \\
\text { Nicolet; } \\
\text { Perkin-Elmer; } \\
\text { B\&K; } \\
\text { others }\end{array}$ & 30 & - \\
\hline IR & $\mathbf{P}$ & $\begin{array}{l}\text { Most/all } \\
\text { (with } \\
\text { proper } \\
\text { methods) }\end{array}$ & Probably III & $\begin{array}{l}-1 \mathrm{ppm} \\
\text { (MIRAN); } \\
30-200 \mathrm{ppb} \\
\text { (B\&K) }\end{array}$ & $\begin{array}{l}\text { Same as above, } \\
\text { plus portability; } \\
\text { turnkey; minimal } \\
\text { training }\end{array}$ & $\begin{array}{l}\text { Same as above, plus } \\
\text { commercial market aimed } \\
\text { at ambient air monitoring } \\
\text { (OSHA leveis); } \\
\text { marginal sensitivity }\end{array}$ & $\begin{array}{l}\text { Mature: } \\
\text { commer- } \\
\text { cialization } \\
\text { evolving }\end{array}$ & $\begin{array}{l}\text { Foxboro- } \\
\text { MIRAN }\end{array}$ & 20 & $\begin{array}{l}\text { Development } \\
\text { of methods } \\
\text { for long-path } \\
\text { integration }\end{array}$ \\
\hline $\begin{array}{l}\text { Electro- } \\
\text { chemical } \\
\text { sensors }\end{array}$ & $P / I$ & - & $\stackrel{1-}{\text { semispecific }}$ & $\begin{array}{l}\text { Low to sub- } \\
\text { parts per } \\
\text { million in air }\end{array}$ & $\begin{array}{l}\text { Downhole; } \\
\text { cheap; } \\
\text { rugged }\end{array}$ & $\begin{array}{l}\text { Lack of selectivity; } \\
\text { need to separate analyte } \\
\text { from matrix by } \\
\text { membrane, purge, or ? }\end{array}$ & - & $\begin{array}{l}\text { City Tech; } \\
\text { Drager; } \\
\text { Gaztech; } \\
\text { TRI; } \\
\text { TAI }\end{array}$ & - & Smart arrays \\
\hline
\end{tabular}


TABLE 1.2 (Cont.)

\begin{tabular}{|c|c|c|c|c|c|c|c|c|c|c|}
\hline Technology & $T / P / I ?^{a}$ & $\begin{array}{l}\text { Analytes/ } \\
\text { Matrices }\end{array}$ & $\begin{array}{l}\text { Data Quality } \\
\text { Achievableb }^{\mathrm{b}}\end{array}$ & $\begin{array}{c}\text { Limit of } \\
\text { Quantitation } \\
\text { Achievablec }^{c}\end{array}$ & Key Advantages & Key Disadvantages & Maturity & Vendors ${ }^{d}$ & $\begin{array}{l}\text { Unit Cost } \\
\left(10 \$^{3}\right)^{\bullet}\end{array}$ & $\begin{array}{c}\text { Priority } \\
\text { Technology } \\
\text { Development } \\
\text { Neods? }\end{array}$ \\
\hline $\begin{array}{l}\text { Piezo- } \\
\text { electric } \\
\text { sensors }\end{array}$ & $P / I$ & $\begin{array}{l}\text { All/air } \\
\text { or vapor } \\
\text { streams }\end{array}$ & $\frac{1-}{\text { not specific }}$ & $\begin{array}{l}\text { Low parts per } \\
\text { million in air }\end{array}$ & $\begin{array}{l}\text { Downhole; } \\
\text { cheap; } \\
\text { rugged }\end{array}$ & $\begin{array}{l}\text { Lack of sensitivity and } \\
\text { selectivity: need to } \\
\text { separate analyte from } \\
\text { matrix by membrane or } \\
\text { purge }\end{array}$ & - & $\begin{array}{l}9 \text { vendors } \\
\text { listed }\end{array}$ & - & Smart arrays \\
\hline $\begin{array}{l}\text { Fiber } \\
\text { optics }\end{array}$ & 1 & - & II & - & - & - & $\begin{array}{l}\text { Develop- } \\
\text { mental }\end{array}$ & - & - & Smart arrays \\
\hline
\end{tabular}

a $T / P / 1 ?=$ Transportable/portable/in situ?

b Roman numerals are estimates of the EPA Superfund analytical levels as defined in the EPA's Data Quality Objectives for Remedial Response Activities: Development Process (EPA 1987). These data quality objectives are by no means definitive; additional comments are added.

che limits of quantitation listed are generally achievable, representative levels inferred from the information in the review chapters in this report; "best-case The limits of compounds, use of abnormally large sample amounts,

d Vendor lists are provided for information only and may not be inclusive; inclusion of vendors on this list does not imply endorsement; omission of vendors from this list does not imply that vendors are deficient in any way. Vendors listed in parentheses are developmental.

e Cost shown is an approximate low-end. Most manufacturers offer more costly models or accessories that add to costs, depending on needs and applications.

f For brevity, the needs column omits several universal needs (some of higher priority to the DOE than others): (1) advanced software for data interpretation, storage. and

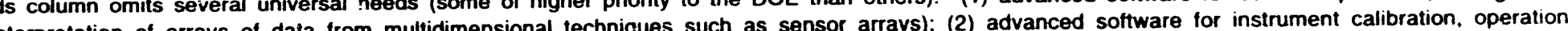
transmission (e.g., interpretation of arrays of data from multidimensional techniques such as sensor arrays): (2) advantion, cost-effectiveness, etc.; and (4) preparation, validation. and data collection; (3) evolutionary engineering improvements in electronics, weight and size reduction, cost-effectiveness. etc.; 


\subsection{References for Chapter 1}

Burton, J.C., et al., 1994, "Expedited Site Characterization: A Rapid, Cost-Effective Process for Preremedial Site Characterization," in Proceedings of SUPERFUND XIV Conference and Exhibition, vol. 2. Hazardous Materials Control Research Institute, Greenbelt, Md., pp. 809-826.

Chudyk, W., 1989, "Field Screening of Hazardous-Waste Sites," Environmental Science and Technology 23:505-507.

Cornell, F.W., 1992, "Site Investigations: The Role of Field Screening and Analysis Devices," in Proceedings of $R \& D$ '92, National Research and Development Conference on the Control of Hazardous Materials, February 4-6, 1992, San Francisco, CA, Hazardous Materials Control Research Institute, Greenbelt, Md.

Cornell, F.W., 1993, "Using Field Screening and Analytical Tools for Site Investigations," in Proceedings of the National Symposium on Measuring and Interpreting VOCs in Soils: State of the Art and Research Needs, Las Vegas, NV, January 12-14, Environmental Liability Management, Inc., Princeton, N.J.

DOE: See U.S. Department of Energy.

EPA: See U.S. Environmental Protection Agency.

Fribush, H.M., and J.F. Fisk, 1992, "Field Analytical Methods for Superfund," Environmental Lab 4:36-41.

Ganapathi, G., et al., 1988, "Cost Analysis for Using Mobile Laboratories versus Fixed-Base Laboratories for Site Characterization at FUSRAP Sites," in First International Symposium: Field Screening Methods for Hazardous Waste Site Investigations, EPA/600/D-89/189, L.R. Williams (editor), U.S. Environmental Protection Agency, Environmental Monitoring Systems Laboratory, Las Vegas, Nev., pp. 463-467.

GAO: See U.S. General Accounting Office.

Hazardous Materials Control Research Institute, 1992, Focus, Greenbelt, Md., Feb., p. 11.

Henricks, A.D., and D.E. Grant, 1993, "The Cost Effectiveness of Field Screening for VOCs," presented at Emerging Technology Symposium, Los Alamos National Laboratory, Los Alamos, N.M. 
Siegrist, R.L., 1991, Volatile Organic Compounds in Contaminated Soils: The Nature and Validity of the Measurement Process, DE91 011368 , Oak Ridge National Laboratory, Oak Ridge, Tenn.

Siegrist, R.L., and P.D. Jennsen, 1990, "Evaluation of Sampling Method Effects on Volatile Organic-Compound Measurements in Contaminated Soils," Environmental Science and Technology 24:1387-1392.

Spittler, T.M., et al., 1988, "A Field Method for Determination of Volatile Organics in Soil Samples," in First International Symposium: Field Screening Methods for Hazardous Waste Site Investigations, EPA/600/D-89/189, L.R. Williams (editor), U.S. Environmental Protection Agency, Environmental Monitoring Systems Laboratory, Las Vegas, Nev., pp. 155-157.

University of Tennessee, 1991, Hazardous Waste Remediation: The Task at Hand, Waste Management Research and Education Institute, Knoxville, Tenn.

U.S. Congress, 1991, Complex Cleanup: The Environmental Legacy of Nuclear Weapons Production, OTA-O-484, Office of Technology Assessment, Washington, D.C., Feb.

U.S. Department of Energy, 1991, Environmental Restoration and Waste Management Five-Year Plan, Fiscal Years 1993-1997, DOE/5-0090P, Washington, D.C.

U.S. Department of Energy, 1992, Analytical Services Program Five-Year Plan, Office of Environmental Restoration and Waste Management, Laboratory Management Division, Washington, D.C., Jan. 29.

U.S. Environmental Protection Agency, 1986, Test Methods for Evaluating Solid Waste: Physical/Chemical Methods, EPA-530-SW-846, 3rd ed., Office of Solid Waste, Washington, D.C., Sept.

U.S. Environmental Protection Agency, 1987, Data Quality Objectives for Remedial Response Activities: Development Process, EPA/540/G-87/003, Office of Emergency Response and Office of Waste Programs Enforcement, Washington, D.C., March.

U.S. Environmental Protection Agency, 1988, Field Screening Methods Catalog User's Guide, Washington, D.C.

U.S. General Accounting Office, 1992, Hazardous Waste: DOD Estimates for Cleaning Up Contaminated Sites Improved but Still Constrained, GAO/NSIAD-92-37, Washington, D.C. 


\section{Gas Chromatography}

Gas chromatographic systems can be categorized as portable (battery-operated), miniaturized, or full-size laboratory. This report will focus on fully portable and miniaturized versions of the gas chromatograph. Full-size laboratory gas chromatographs can also be used in field applications, depending on the available space in the mobile laboratory. The following is a brief discussion of the basic principles of GC and the detectors that are typically used to determine VOCs in the subsurface. Descriptions obtained from product literature of currently available portable and miniaturized GC systems are also presented.

\subsection{Basic Principles}

In gas-liquid chromatography, the separation of analytes is accomplished by partitioning solutes between a mobile gas phase and a stationary liquid phase (Skoog and West 1971; Bauer et al. 1978; Willard et al. 1981). Gas-solid chromatography employs a solid adsorbent as the stationary phase. Gas chromatography is the most important analytical tool for the qualitative and quantitative determination of complex mixtures of organic compounds in air, water, and soil matrices (Schwarzenbach et al. 1984). To perform an analysis by GC, the organic mixture is vaporized in an injection port. The mixture is then transported through a column or tube to a detector in a moving stream of carrier gas. The separation of compounds within the column depends on the affinity of the compounds for materials that are used to pack the column or to coat the inner walls. Compounds being more soluble in or having a stronger affinity for the column's materials take longer to get through the column. Compounds exhibiting different retention behavior are separated. The detector is placed at the exit from the column and records changes in composition in the effluent from the column. The signal is recorded as a series of peaks called a chromatogram. The signal may also be processed further by an electronic integrator that measures peak height or area or by computer software on a personal computer (PC)-based system.

The choice of materials for the injection port and its temperature are critical to a quantitative transfer of organic compounds to the analytical column. The materials must be inert to the sample components, and the temperature must be high enough so that the sample remains in the gaseous state. Analysis of VOCs in many applications requires that the injection port should consist of a preconcentrating device, although some gaseous samples (e.g., ambient air, soil gas) can be directly injected into a conventional injection port via a gas-tight syringe, provided the volume of the sample does not exceed the capacity of the injection port and column and provided the detector possesses the necessary sensitivity for the gascous analyte. For analytes that are present in soil or water, the organic compounds are liberated from their matrix and transported in a stream of inert gas to a solid sorbent (e.g., Tenax, graphitized carbon) or a cryogenically cooled inert substrate (e.g., glass beads). Water samples are sparged with an inert gas. Soils are thermally desorbed or transferred to water and sparged. Once the analytes are preconcentrated, they are thermally desorbed by ballistically heating the sorbent or substrate and are transferred to the column in a small volume of inert carrier gas. 
After injection or TD of the sample, the complex mixtures of organic analytes are separated within the analytical column by partitioning the compounds between a gaseous mobile phase (carrier gas) and the stationary phase. The stationary phase is typically a thin liquid film that is either distributed over an inert granular support (packed column) or is supported as a thin coating on the inner surface of the column. as in the wall-coated open tubular column. Columns may also contain coatings of porous polymers on the inner walls (e.g., the porous-layer open tubular column). The separation of complex mixtures is dependent on the inside diameter and length of the analytical column, as well as on the chemical composition and thickness of the stationary phase. Optimization of all of these factors, in addition to the column temperature, the composition of the carrier gas, and its velocity through the column, determines the speed of the analysis. The temperature of the column can remain constant (isothermal) or be increased at a constant rate during the analysis. The choice of the temperature mode depends on the volatility range and the complexity of the mixture to be separated. The composition of the stationary phase determines the order of elution. Stationary phases can be chosen from a wide range of polarities. The sample can be injected on two columns of differing polarities to change the retention times and to add identification capabilities to the GC method.

Capillary column technology has improved the separation of complex mixtures by decreasing the inside diameter of the column and increasing its length (Jennings 1980). The speed of analysis has been increased by using relatively short capillary columns operated at unusually high flow rates for the carrier gas (Peters et al. 1991). Separation times have been reduced from minutes or hours to seconds and tens of seconds; for example, Ke et al. (1992) have demonstrated that a 34-component mixture of volatile chlorinated organics could be separated in 8-100 s. Further developments of fast GC have incorporated low-dead-time inlet systems, high-precision column switching, and pressure-controlled tunable selectivity to increase the speed of analysis (Sacks and Akard 1993). Synthetic mixtures containing high concentrations of VOCs in zero air or diluted vehicle-exhaust samples have been used to demonstrate the utility of fast-GC analysis (Klemp et al. 1993); however, the volume of sample that is injected into the gas chromatograph is small (a few milliliters) and contains relatively low levels of water and $\mathrm{CO}_{2}$, compared with the levels in the larger volumes $(50 \mathrm{~mL}$ to 1 liter [L]) that must be injected for analysis of environmental samples. These constituents inhibit both separation and detection of complex organic mixtures in high-resolution GC analysis (McClenny et al. 1984; Entech Laboratory Automation 1992). The effect of these constituents on fast-GC analysis needs to be tested.

\subsection{Detectors}

Detectors are selected for an analysis on the basis of their sensitivity, selectivity, linear dynamic range, response time, and dead volume. Sensitivity is a measure of the ability of the detector to produce an electrical signal from the presence of a compound in the effluent of the column (basically, the change in responses per unit weight of material). A quantitative measure of the sensitivity is the (lower) detection limit. The detection limit is the amount per time or the concentration of a compound producing a peak the height of which is twice the noise level. Some detectors are sensitive to the mass of material passing through the detector per unit of time, while others are sensitive to the concentration of a substance within the detector. The linear dynamic 
range is the concentration range or mass per unit of time over which a constant sensitivity is obtained. The response time of the detector is also critical. The peak width is dependent on the dimensions of the column. By using capillary columns (0.10-0.53 millimeters [mm] in ID), the compounds are eluted quickly, and the peak width is very narrow. Therefore the time constant of the detector must be small. The time constant is determined by the volume of the detector, the dissipation constant of the sensing element, and the recording equipment.

A wide variety of detectors are used in GC (Skoog and West 1971; Bauer et al. 1978: Willard et al. 1981; Schwarzenbach et al. 1984). Some of the common detectors and their sensitivities, linear dynamic ranges, and specificity to various classes of organic compounds are summarized in Table 2.1. The most universal and common detector for the analysis of organic compounds is the flame ionization detector (FID); however, many environmental contaminants contain heteroatoms; and because the FID responds to the mass of $\mathrm{CH}_{2}$ groups in the molecule, the sensitivity of the FID for compounds containing heteroatoms is not sufficient. Consequently, developing detectors that are selective and sensitive to compounds containing heteroatoms such as halogens, nitrogen $\left(\mathrm{N}_{2}\right)$, sulfur, or phosphorus $(\mathrm{P})$ has become necessary. By using selective detectors, information about the presence or absence of certain compounds in a complex mixture can be obtained, and interferences of coeluting compounds of a dissimilar chemical nature can be

TABLE 2.1 Some Common GC Detectors: Sensitivities, Linear Dynamic Ranges, and Specificities to Various Classes of Organic Compounds

\begin{tabular}{lccc}
\hline \multicolumn{1}{c}{ Detector } & Sensitivity & $\begin{array}{c}\text { Linear } \\
\text { Dynamic } \\
\text { Range }\end{array}$ & Specificity \\
\hline Argon ionization & $1 \mathrm{ppb}$ & $10^{3}$ & $\begin{array}{l}\text { Aromatic; } \\
\text { halogenated }\end{array}$ \\
Electrolytic conductivity & $10 \mathrm{ppt}$ & $10^{6}$ & Halogenated \\
Electron capture & $1 \mathrm{ppt}$ & $10^{4}$ & Halogenated \\
Flame ionization & $1 \mathrm{ppb}$ & $10^{6}$ & Universal \\
Photoionization & $1 \mathrm{ppb}$ & $10^{7}$ & $\begin{array}{l}\text { Aromatic; } \\
\text { halogenated }\end{array}$ \\
Surface acoustic wave & $1 \mathrm{ppb}$ & Nonlinear & Aromatic \\
Thermal conductivity & $1 \mathrm{ppm}$ & $10^{6}$ & Universal \\
\hline
\end{tabular}

a ppb, parts per billion; ppm, parts per million; and ppt, parts per trillion. 
eliminated. The selective detectors also usually have a lower limit of detection than the universal detectors.

The most common detector is the FID. This detector is a mass-sensitive detector that responds to nearly all organic compounds with roughly the same sensitivity. The linear dynamic range of the FID is $10^{6}$. It has a moderately high sensitivity of $1 \times 10^{-12}$ grams per second $(\mathrm{g} / \mathrm{s})$ and exhibits reasonable stability. The FID operates by mixing the effluent of the column with hydrogen $\left(\mathrm{H}_{2}\right)$ and burning the compounds at the tip of a jet in an excess of air. Organic matter entering the detector is combusted in the flame. The FID is a destructive detector. During combustion, ions are formed and collected at an electrode above the jet. The current is amplified and recorded. The response is proportional to the mass of effective carbon (C) atoms (basically the number of $\mathrm{CH}_{2}$ groups in the molecule). The presence of heteroatoms decreases the sensitivity.

The ECD is a selective detector responding primarily to compounds having functional groups with high electron affinities. The ECD is most sensitive to halogenated hydrocarbons but also responds to nitrogenated, highly oxygenated, and some aromatic compounds. The ECD is extremely sensitive to many halogenated hydrocarbons and has a lower detection limit of $1 \times 10^{-13}$ $\mathrm{g} / \mathrm{mL}$ for lindane, a compound containing six chlorine $(\mathrm{Cl})$ atoms. Picograms (pg) of material can be detected. The ECD is difficult to calibrate because the response is compound-specific and may vary by orders of magnitude, even for compounds having similar structures. Consequently, calibration for each substance is necessary. The dynamic linear range is about $10^{4}$. The detector operates by introducing the effluent of the column into a cell containing a $\beta$-radiation source (tritiated titanium or scandium, or radioactive nickel [ $\left.{ }^{63} \mathrm{Ni}\right]$ ). A detector makeup gas or carrier gas ( $\mathrm{N}_{2}$ or a methane-argon [ $\left.\mathrm{CH}_{4}-\mathrm{Ar}\right]$ mixture) is ionized in the detector, producing a standing current of electrons. When a compound with a high electron affinity enters the detector, the standing current is decreased. The linearity of the detector has been improved by keeping the standing current constant by adjusting the pulser frequency. The relatively large dead volume of the detector has been overcome by adding a thermostated makeup gas to the effluent from the column to decrease baseline drift. The detector is a concentration-sensitive detector; therefore the flow rate of the makeup gas through the detector is critical to its sensitivity. The stability of the detector is sensitive to changes in temperature, ECD-active solvents, dirt, and water. Careful operation and frequent recalibration are prerequisites for quantitative analyses.

The thermal conductivity detector (TCD) is truly a universal detector because it responds to almost any kind of material, including the permanent gases. The TCD is a nondestructive detector that has been of minor importance in trace analysis because of its low sensitivity of about $10^{-9} \mathrm{~g} / \mathrm{mL}$; however, with the recent advent of micromachining, the sensitivity of the TCD has been improved, and increased application in trace analysis is occurring (Overton et al. 1988). The TCD operates on the basis of the difference in thermal conductivity of a hot wire when gases flow across the wire. The carrier gas of choice is helium (He). Detection limits are typically 100 parts per million (ppm); however, in gas chromatographs in which the injector and detector systems have been miniaturized, detection limits of approximately $1 \mathrm{ppm}$ have been reported (Overton et al. 1988). 
Electrochemical detectors such as the microcoulometric detector (MCD) and the electrolytic conductivity detector (EICD) have been developed primarily to provide more specificity for halogenated substances (Driscoll et al. 1984). The effluent from the column is combusted; and the products are dissolved in a liquid, forming ions that are determined by either automatic titration (MCD) or by measuring the electrical conductivity of the solution (EICD). The advantage of the detectors is that the specificity can be adjusted through the choice of combustion parameters (temperature, type of reaction gas [oxidative or reductive], reaction catalyst, and chemical abstractors) and the type of liquid for dissolving the products.

The photoionization detector (PID) works on the principle that compounds can be ionized in the presence of UV radiation (Verner 1984; Driscoll 1985). The PID is more sensitive than the FID for compounds that have photoionizable moieties, such as conjugated double bonds, and some heteroatoms. The PID has found wide application for determining aromatic compounds. The selectivity of the detector can be adjusted by using UV lamps of different energies (e.g., 11.8 electrovolts [eV], $10.6 \mathrm{eV}, 9.5 \mathrm{eV}$, and $8.4 \mathrm{eV}$ ). Sensitivities to compounds having conjugated double bonds are, in general, about 1 part per billion (ppb).

Argon ionization detectors (AIDs) have also been used in environmental applications. In the AID, $\beta$-radiation is used to ionize and excite Ar to a higher electronic energy state $(11.7 \mathrm{eV})$. Organic molecules entering the detector that have ionization potentials less than or equal to the excited Ar will be ionized, producing an electric current that can be monitored. These molecules will include many aromatics, chlorinated alkanes, and chlorinated alkenes (Linenberg 1988; Kaelin and Prichett 1991; Linenberg et al. 1991). The detector is a concentration-sensitive detector having a sensitivity in the low parts-per-billion range. The AID can also be switched to operate as an ECD.

Surface acoustic wave (SAW) devices have also been used as GC detectors, primarily for aromatic compounds. Different coatings are used on the piezoelectric crystals to provide selectivity. These devices are reported to determine mass at the nanogram (ng) to femtogram levels; however, when SAWs are used as GC detectors, the reported sensitivities are in the partsper-billion range. Thie response is nonlinear and must be calibrated with a set of standards.

\subsection{Gas Chromatographic Systems}

The manufacturers and suppliers of portable and miniaturized GC devices and some of the salient features of the systems are summarized in Table 2.2. Much of the information in the following discussion was obtained from product literature. Several manufacturers produce portable (battery-powered) GC systems: Sentex Systems, Inc.; Mine Safety Appliance Co. (MSA); Microsensor Systems, Inc. (MSI); the Foxboro Co.; Microsensor Technology, Inc. (MTI); and Photovac International, Inc. Sentex Systems, Inc., manufactures the Scentoscreen and Scentograph "Plus II." The utility of these instruments has been described (Linenberg 1988; 
TABLE 2.2 Manufacturers and Suppliers of GC Systems and Their Salient Features

\begin{tabular}{|c|c|c|}
\hline $\begin{array}{l}\text { Chromatograph and } \\
\text { Manufacturer or Supplier }\end{array}$ & $\begin{array}{l}\text { Address and } \\
\text { Telephone Number }\end{array}$ & Features \\
\hline Portable Gas Chromatographs & & \\
\hline The Foxboro Co. & $\begin{array}{l}\text { P.O. Box } 500 \\
600 \text { N. Bedford St. } \\
\text { East Bridgewater, MA } \\
02333 \\
\text { Phone: (508) } 378-5556 \\
\text { Fax: (508) } 378-5505\end{array}$ & Packed column; isothermal; FID \\
\hline Microsensor Systems, Inc. & $\begin{array}{l}62 \text { Corporate Ct. } \\
\text { Bowling Green, KY } 42103 \\
\text { Phone: (502) 745-0099 } \\
\text { Fax: (502) } 745-0095\end{array}$ & $\begin{array}{l}\text { Packed column; isothermal; SAW; } \\
\text { TD }\end{array}$ \\
\hline MTI Analytical Instruments, Inc. & $\begin{array}{l}41762 \text { Christy St. } \\
\text { Fremont, CA } 94538 \\
\text { Phone: }(510) \quad 490-0900 \\
\text { Fax: (510) } 651-2498\end{array}$ & Capillary column; isothermal; TCD \\
\hline MSA Instrument Division & $\begin{array}{l}\text { P.O. Box } 427 \\
\text { Pittsburgh, PA } 15230 \\
\text { Phone: (412) } 967-3228 \\
\text { Fax: (412) } 967-3451\end{array}$ & Polycapillary; isothermal; ECD; TD \\
\hline Photovac International, Inc. & 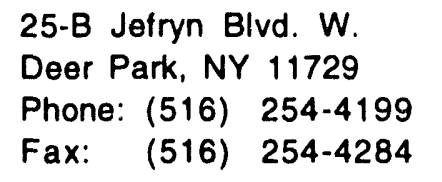 & $\begin{array}{l}\text { Capillary column; isothermal; } \\
\text { PID or FID }\end{array}$ \\
\hline Sentex Systems, Inc. & $\begin{array}{l}553 \text { Broad Ave. } \\
\text { Ridgefield, NJ } 07657 \\
\text { Phone: (201) } 945-3694 \\
\text { Fax: (201) } 941-6064\end{array}$ & $\begin{array}{l}\text { Packed or capillary column; } \\
\text { temperature programmable; } \\
\text { AID, MAID, ECD, PID, or TCD }\end{array}$ \\
\hline Miniaturized Gas Chromatographs & & \\
\hline CDS Analytical, Inc. & 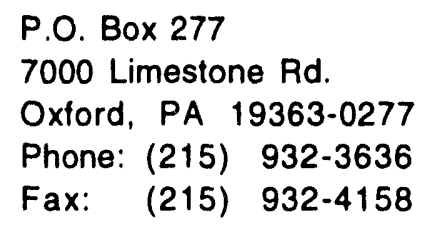 & $\begin{array}{l}\text { Packed or capillary column; } \\
\text { temperature programmable; } \\
\text { FID, TCD, PID, or EICD; } \\
\text { purge-and-trap; TD }\end{array}$ \\
\hline CMS Research Corp. & $\begin{array}{l}200 \text { Chase Park S. } \\
\text { Suite } 100 \\
\text { Birmingham, AL } 35244 \\
\text { Phone: (205) } 733-6900 \\
\text { Fax: (205) } 733-6919\end{array}$ & Capillary column; PID or FID \\
\hline
\end{tabular}


TABLE 2.2 (Cont.)

\begin{tabular}{|c|c|c|}
\hline $\begin{array}{l}\text { Chromatograph and } \\
\text { Manufacturer or Supplier }\end{array}$ & $\begin{array}{l}\text { Address and } \\
\text { Telephone Number }\end{array}$ & Features \\
\hline \multicolumn{3}{|c|}{ Miniaturized Gas Chromatographs (Cont.) } \\
\hline HNU Systems, Inc. & $\begin{array}{l}160 \text { Claremont St. } \\
\text { Newton, MA } 02161 \\
\text { Phone: }(800) \quad 724-5600 \\
\text { Fax: } \quad(617) \quad 965-5812\end{array}$ & $\begin{array}{l}\text { Packed or capillary column; } \\
\text { temperature programmable; } \\
\text { PID, FID, TCD, or ECD }\end{array}$ \\
\hline SRI Instruments, Inc. & $\begin{array}{l}\text { 6700-B Paradise Rd. } \\
\text { Las Vegas, NV } 89119 \\
\text { Phone: }(702) \quad 361-2210 \\
\text { Fax: (702) } 361-9690\end{array}$ & $\begin{array}{l}\text { Packed or capillary column; } \\
\text { temperature programmable; } \\
\text { TCD, FID, PID, ECD, or EICD; } \\
\text { purge-and-trap; TD }\end{array}$ \\
\hline
\end{tabular}

Source: Adapted from Sherve (1993).

Kaelin and Prichett 1991; Linenberg et al. 1991). The Scentoscreen is a single-detector system that weighs 30 pounds (lb). This GC system contains a heated injection port and a column oven that can either be operated isothermally or be programmed for temperature. The oven can accept packed columns having a length of 12 feet ( $\mathrm{ft}$ ) or capillary columns up to 30 meters $(\mathrm{m})$. An eight-hour internal supply of carrier gas is available. Detector options include the AID, micro-AID (MAID), ECD, PID, and TCD. Detection limits of the detectors vary from parts per trillion (ppt) to the percent level. The MAID is a small-volume, higher sensitivity version of the AID. The MAID is sensitive at the level of $1 \mathrm{ppb}$. A detachable laptop PC is used with the system. The Scentograph "Plus II" is similar to the Scentoscreen but weighs $48 \mathrm{lb}$ and has dual-column and dual-detector capability. Detector options are similar to the Scentoscreen, with the exception of an AID/ECD detector.

Photovac International, Inc., manufactures the 10S Plus Portable GC. The use of this instrument in field applications has been described (Jerpe and Davis 1987; Adams and Collins 1988; Berkley 1988; Ho et al. 1988; Berkley et al. 1991). The instrument is driven by PC and weighs $28 \mathrm{lb}$. The PID has a wide dynamic range of $100 \mathrm{ppm}$ to sub-parts per billion and includes a standard 10.6-eV lamp, as well as optional 11.7-eV, 10.0-eV, 9.5-eV, and 8.4-eV lamps. The column oven is isothermal and adjustable from ambient temperature to $50^{\circ} \mathrm{C}$ and uses encapsulated Megabore columns produced by Photovac. An automatic precolumn/backflush is used for contamination-free analysis. Other options include automated "heart-cut chromatography" and multiple-column multiple-detector configurations. Photovac intended to offer an FID detector in their instruments in January 1994. An internal supply of carrier gas for up to 12 hours of fieldwork is available. Photovac also manufactures a handheld toxic vapor analyzer (SnapShot). The portable gas chromatograph weighs only $8.3 \mathrm{lb}$. The system uses a PID with a standard 10.6-eV lamp. The carrier gas is available in cartridges containing an eight-hour supply. Various 
wide-hore capillary columns are available to use in the isothermal oven. Data are recorded by the instrumeni and can be downloaded directly to a PC or printer via an RS232 serial port.

Microsensor Technology, Inc., produces the M200 Micro Gas Chromatograph, the P200 Portable Micro Gas Analyzer, and the Quad 400 Gas Analyzer. The M200S model weighs only $12 \mathrm{lb}$. The injectors and detectors of the MTI chromatographs are miniaturized and are fabricated on silicon wafers in a batch-processing mode, producing a high-quality product consistently. The low-dead-volume injection port allows the use of a single short (about $6 \mathrm{~m}$ ) high-efficiency column that can resolve $C_{1}$ to $C_{8}$ hydrocarbons in less than $80 \mathrm{~s}$; for example, an analysis of VOCs ranging from methylene chloride to $o$-xylene can be performed in $160 \mathrm{~s}$. The oven can be operated isothermally from $30^{\circ} \mathrm{C}$ to $180^{\circ} \mathrm{C}$. The detector is a solid-state TCD with a detection limit of about $1 \mathrm{ppm}$ and a linear dynamic range of $10^{6}$. The system can be run from a PC. The M200D model is a dual-column system that includes two separately controlled micro-GC modules in one housing. The P200 weighs $23 \mathrm{lb}$ and is similar to the M200D, housing two miniature gas chromatographs. The Quad 400 Gas Analyzer is a four-module, high-speed GC device that contains four independently controlled modules, each containing a separate injector, detector, columns, and column heater. The unit weighs $45 \mathrm{lb}$.

The Foxboro Co. produces the Century OVA 128GC device, which weighs about $12 \mathrm{lb}$. The OVA 128 employs an $\mathrm{H}_{2}$ FID that uses charcoal-scrubbed ambient air as the combustion gas and $\mathrm{H}_{2}$ as the carrier gas. The sample is introduced through a sample loop. Packed columns in a variety of lengths from 4 to 48 in. can be used in the system. A portable isothermal kit allows operation of the OVA columns at $0^{\circ} \mathrm{C}, 40^{\circ} \mathrm{C}$, and $100^{\circ} \mathrm{C}$. The results are recorded on a strip chart.

Microsensor Systems, Inc., manufactures the MSI-301 organic vapor monitor for monitoring specific organic vapors at concentrations from $1 \mathrm{ppb}$ to $1,000 \mathrm{ppm}$. The unit weighs 5 kilograms $(\mathrm{kg})$. The system incorporates an isothermal $\left(65^{\circ} \mathrm{C}\right)$ gas chromatograph that uses packed chromatographic columns up to $1.2 \mathrm{~m}$ long. Ambient air that is scrubbed with activated $\mathrm{C}$ is used as the carrier gas. Typical analysis times are $6 \mathrm{~min}$. The solid-state proprietary detector is a SAW device. The piezoelectric crystal is coated with a material into which organic vapors eluting from the gas chromatographic column partition. The frequency change in the SAW device when vapors partition into the coating is related to the instantaneous vapor concentration. The device exhibits some selectivity to aromatic and aliphatic hydrocarbons, alcohols, and ketones. The response is nonlinear, so the detector must be calibrated at several concentrations for high-accuracy applications. The system is run by a microcomputer. The system can nonspecifically monitor a mixture of benzene, toluene, and xylene (BTX) in the range of $1 \mathrm{ppb}$ to $100 \mathrm{ppm}$. Monitors can be configured to selectively detect various organic vapors, such as methanol, ethylene oxide, benzene, and BTX. The instrument also has an RS232 interface, allowing remote control of the unit and transfer of data to a printer or a PC.

The MSA manufactures the EKHO gas chromatograph. The system weighs $11 \mathrm{~kg}$. The column in the instrument is a polycapillary, a composite of about 100-400 extremely short capillary columns $(-30 \mathrm{~cm})$ in parallel, having an estimated 1,000 theoretical plates. The polycapillary provides a quick analysis time of $20-30 \mathrm{~s}$. The oven is operated isothermally at $40^{\circ} \mathrm{C}, 100^{\circ} \mathrm{C}$, 
$150^{\circ} \mathrm{C}$, or $175^{\circ} \mathrm{C}$. The detector is an ECD. Sensitivity for lindane is reported to be 1 ppt in a preconcentration mode.

Several manufacturers also produce miniaturized GC devices that can be run off line power or a generator (Table 2.2). The compact GC devices in the HNU 300 series take up approximately 1.5 square feet $\left(\mathrm{ft}^{2}\right)$ of bench space. The model 311 has a PID and can also incorporate a far UV detector (FUV) and an ECD. Single- and dual-detector configurations are available. The PID has four different lamps $(8.3 \mathrm{eV}, 9.5 \mathrm{eV}, 10.2 \mathrm{eV}$, and $11.7 \mathrm{eV})$. Detection limits are 1-50 ppb. The isothermal oven has a temperature range of ambient temperature to $200^{\circ} \mathrm{C}$ and also has heated injector/detector modules. A carrier gas is included. The oven can accept both packed and capillary columns. The device has a built-in printer/plotter but also has an RS232C output, allowing PC-based operational software for data storage and processing.

HNU Systems, Inc., also produces the model 301, 321, and 301-DP lines of miniaturized chromatographs. All models allow running of two detectors separately or in series. The column oven can accept up to two 12 -ft packed columns or a capillary column on a 6-inch (in.) support cage. The ovens operate from ambient temperature to $300^{\circ} \mathrm{C}$ and are either isothermal or can be programmed for temperature in $1^{\circ} \mathrm{C}$ increments. The PID is standard with lamps of $8.3 \mathrm{eV}$, $9.5 \mathrm{eV}, 10.2 \mathrm{eV}$, or $11.7 \mathrm{eV}$. Other detectors that are available include an ECD, FUV, FID, and TCD. The HNU 301 and 301-DP are isothermal. The HNU 321 can be programmed for temperature. The HNU 301 and 321 can operate any two detectors simultaneously, while the HNU 301-DP can operate any one detector.

CDS Analytical, Inc., produces an integrated purge-and-trap GC analyzer (model EA-600). The system is complete for analyzing VOCs in water, air, and soil. The unit includes a thermal desorber for air cartridge analysis or solid sampling. Tedlar bags or canisters for air sampling can also be processed. Water samples can be sparged. The unit also can include cryogenics. The GC device can accept packed or capillary columns, and the oven is programmable for temperature. The oven can operate from ambient temperature to $400^{\circ} \mathrm{C}$. The available detectors include an FID, TCD, PID, or EICD. The unit takes up less than $4.5 \mathrm{ft}^{2}$ and weighs $100 \mathrm{lb}$.

SRI Instruments, Inc., produces the model 8610 miniaturized gas chromatograph that runs on line power or a generator. This small-footprint GC device has a temperature-programmable oven that operates from ambient temperature to $300^{\circ} \mathrm{C}$. The oven can accept both capillary and packed columns. Several detectors are offered (TCD, FID, PID, ECD, and EICD) and can be mounted at once. Purge-and-trap and TD accessories are also offered. A PC-based data acquisition/integrator system is basic to the unit.

CMS Research Corp. manufactures the series 2000 Minicams. The Minicams can be run off line power or a generator. The units weigh 14-18 lb. Two different detectors are available, a PID and FID. The system can accept capillary columns. It is basically set up to be an air-monitoring system. Therefore, the unit can be equipped with different sizes of gas-sampling loops and a thermal desorber that can accept sorbent cartridges. The data can be sent to a printer, floppy disk drive, or a strip-chart recorder. 


\subsection{Summary}

Gas chromatography is one of the most powerful analytical tools for the qualitative and quantitative measurement of complex mixtures of VOCs. Tentative identification of compounds can be derived via GC by processing the sample on columns having dissimilar polarities and by using hydrocarbon class-specific detectors. The common GC detectors are very sensitive: the PID at the parts-per-billion level for aromatics, the ECD and EICD at the parts-per-trillion level for chlorinated organics, and the FID at the parts-per-billion level for many hydrocarbons. Investigators using fast-GC have demonstrated that high-resolution analyses normally requiring minutes or hours can possibly be shortened to seconds and tens of seconds. The incorporation of many of these features into portable and miniaturized versions of the gas chromatograph have facilitated its use in field applications.

\subsection{References for Chapter 2}

Adams, M., and M. Collins, 1988, "Sensitive Portable Gas Chromatograph with Data Retrieval and Communications Capability for Remote Surveillance of Toxic Gases and Vapours in Plant," Analytical Proceedings (London) 25:190-191.

Bauer, H.H., et al., 1978, Instrumental Analysis, Allyn and Bacon, Inc., Boston, Mass., pp. $678-710$.

Berkley, R.E., 1988, "Ambient Air Sampling with a Portable Gas Chromatograph," in First International Symposium: Field Screening Methods for Hazardous Waste Site Investigations, EPA/600/D-89/189, L.R. Williams (editor), U.S. Environmental Protection Agency, Environmental Monitoring Systems Laboratory, Las Vegas, Nev., pp. 283-290.

Berkley, R.E., et al., 1991, "Comparison of Portable Gas Chromatographs and Passivated Canisters for Field Sampling Airborne Toxic Organic Vapors in the United States and the USSR," Environmental Science Technology 25:1439-1444.

Driscoll, J.N., 1985, "Review of Photoionization in Gas Chromatography: The First Decade," Journal of Chromatographic Science 23:488-492.

Driscoll, J.N., et al., 1984, "Comparison of a New Electrochemical Detector for Gas Chromatographic Analysis with the Electrolytic Conductivity Detector," Journal of Chromatography 302:269-276.

Entech Laboratory Automation, 1992, "Measurement of Volatile Organic Compounds in Air," in Product Application Notes, Simi Valley, Calif. 
Ho, J.S., et al., 1988, "Monitoring Volatile Organics in Water by a Photovac Portable Gas Chromatograph with Multiple Headspace Extraction Method," in First International Symposium: Field Screening Methods for Hazardous Waste Site Investigations, EPA/600/D-89/189, L.R. Williams (editor), U.S. Environmental Protection Agency, Environmental Monitoring Systems Laboratory, Las Vegas, Nev., pp. 261-270.

Jennings, W., 1980, Gas Chromatography with Glass Capillary Columns, Academic Press, Inc., London, England.

Jerpe, J., and A. Davis, 1987, "Ambient Capillary Chromatography of Volatile Organics with a Portable Gas-Chromatograph," Journal of Chromatographic Science 25:154-157.

Kaelin, L.P., and T.H. Prichett, 1991, "A Portable Gas Chromatograph with an Argon Ionization Detector for the Field Analysis of Volatile Organics," in Proceedings of the Second International Symposium: Field Screening Methods for Hazardous Wastes and Toxic Chemicals, Air and Waste Management Association, Pittsburgh, Pa.

Ke, H., et al., 1992, "Analysis of Complex Mixtures of Vapors in Ambient Air by Fast-Gas Chromatography," Journal of the Air and Waste Management Association 42:1446-1452.

Klemp, M., et al., 1993, "Cryofocussing Inlet System for the High-Speed GC Analysis of Volatile Organic Compounds," in Preprints of Papers Presented at the 206th ACS National Meeting, Chicago, Illinois, August 22-27, 1993, vol. 33, No. 2, American Chemical Society, Division of Environmental Chemistry, Washington, D.C., pp. 120-123.

Linenberg, A., 1988, "Hazardous Waste Site Measurements of ppb Levels of Chlorinated Hydrocarbons Using a Portable Gas Chromatograph," in First International Symposium: Field Screening Methods for Hazardous Waste Site Investigations, EPA/600/D-89/189, L.R. Williams (editor), U.S. Environmental Protection Agency, Environmental Monitoring Systems Laboratory, Las Vegas, Nev., pp. 271-274.

Linenberg, A., et al., 1991, "Hazardous Waste Site Measurements of Low Levels of Chlorinated Hydrocarbons Using a Portable Gas Chromatograph," Hazardous Material Control 4:42-46.

McClenny, W.A., et al., 1984, "Automated Cryogenic Preconcentration and GasChromatographic Determination of Volatile Organic-Compounds in Air," Analytical Chemistry 56:2947-2951.

Overton, E.B., et al., 1988, "Correlation Chromatography with a Portable Microchip Gas Chromatograph," in First International Symposium: Field Screening Methods for Hazardous Waste Site Investigations, EPA/600/D-89/189, L.R. Williams (editor), U.S. Environmental Protection Agency, Environmental Monitoring Systems Laboratory, Las Vegas, Nev., pp. 275-277. 
Peters, A., et al., 1991, "Instrumentation and Strategies for High-Speed Gas Chromatography," Analyst 116:1313-1320.

Sacks, R., and M. Akard, 1993, "Selectivity Tuning for High-Speed GC Analysis of Volatile Organic Compounds," in Preprints of Papers Presented at the 206th ACS National Meeting. Chicago, Illinois, August 22-27, 1993, vol. 33, No. 2, American Chemical Society, Division of Environmental Chemistry, Washington, D.C., pp. 124-127.

Schwarzenbach, R.P., et al., 1984, "Gas Chromatography," in Water Analysis: Organic Species, vol. 3, R.A. Minear and L.H. Keith (editors), Academic Press, Inc., London, England, pp. 167-251.

Sherve, D., 1993, "Technology, Portability Enhance Use of Field GCs," Environmental Lab, April/May, pp. 40-43.

Skoog, D.A., and D.M. West, 1971, Principles of Instrumental Analysis, Holt, Rinehart, and Winston, Inc., New York, N.Y., pp. 640-662.

Verner, P., 1984, "Photoionization Detection and Its Application in Gas Chromatography," Journal of Chromatography 300:249-264.

Willard, H.H., et al., 1981, Instrumental Methods of Analysis, Wadsworth Publishing Co., Belmont, Calif., pp. 454-494. 


\section{Mass Spectrometry and Gas Chromatography/Mass Spectrometry}

Rapid advances in field technology have established the need for a comprehensive study of transportable MS for the on-site characterization of VOCs. This section reviews the basic technologies of quadrupole MS, relates recent advances in field analysis that are based on GC/MS, and discusses the state of the art in existing methods, instrumentation, and research efforts in mass-spectrometric field analysis. Field analysis by using GC/MS can now be routinely achieved and can help expedite environmental characterization.

This chapter reviews the state of the art and the application of one FAM, GC/MS. This important organic analytical technique is a prime example of the trend, in several areas of chemical and physical measurements, of taking the measurement to the sample and providing information rapidly to facilitate decision making.

\subsection{Gas Chromatography and Mass Spectrometry: Instrumentation and Operation}

Gas chromatography separates compounds primarily on the basis of their volatility. Compounds sequentially exiting the GC column are detected, in this case, by a mass spectrometer that ionizes and fragments the molecules and then detects these ions according to their mass. The GC retention time and the mass spectrum provide a qualitative identification of the compounds, and the intensity of the response is proportional to concentration. Fribush and Fisk (1992) attributed the beginnings of the EPA Superfund field methods program to Thomas Spittler's use of portable GC for an investigation of a waste site in 1978. Since that time, GC with nonspecific or semispecific detectors (such as the FID, PID, and ECD) has been used increasingly to monitor VOCs, often the chief contaminants of a waste site. Mass spectrometry provides the specificity needed for many complex environmental samples. Related technologies such as portable GC/ionmobility spectrometry (Snyder et al. 1993) are outside the scope of this report. Efforts are currently underway to improve the speed of the chromatograph without sacrificing resolution (Hyver and Phillips 1987; Mouradian et al. 1990; Levine et al. 1991), and new high-temperature columns extend the lifetime of the column and expand the range and variety of compounds currently studied by GC/MS (Bowen and Pullen 1989). In addition, the previously ubiquitous packed column has largely been replaced by capillary columns. These and other developments in GC are expected to be rapidly incorporated into the instrumentation and practice of field GC/MS. Despite the power of GC/MS, GC retains the advantages of simplicity, lower weight, and much lower cost. Only recently, as mass spectrometers have become more amenable to field analysis, has GC/MS commonly been employed in the field.

The focus of this report is on the mass analyzers most commonly used in the field: the linear quadrupole and the quadrupole ion trap. A review of the elementary theory of quadrupole mass analyzers is available (Campana 1980). A quadrupole mass analyzer, also known as a 
quadrupole mass filter or a linear quadrupole, consists of four parallel conducting hyperbolic or cylindrical rods (Figure 3.1). Because of its simplicity, durability, and ability to operate at relatively high pressures, the quadrupole has been the most commonly employed mass analyzer in field analysis. The quadrupole mass analyzer suffers somewhat from a moderate to low resolution capability. Researchers and instrument developers continue to work on improving the sensitivity, selectivity, ruggedness, and other features of merit of this analyzer.

The quadrupole ion trap is a three-dimensional quadrupole, consisting of a ring electrode and two end-cap electrodes (Figure 3.2). The quadrupole ion trap can be thought of as a solid of revolution formed by rotating a linear quadrupole around an axis passing perpendicularly through the center of a pair of opposing (equipotential) hyperbolic rods. Recent advances in ion-trap technology have produced an instrument that is compact, durable, highly sensitive (10-100 times more sensitive than currently available linear quadrupoles [Cooks and Kaiser 1990]), moderately selective, and capable of ion storage and tandem MS; all of these advantages are attractive for field applications. Scanning routines to improve the sensitivity of the ion-trap mass spectrometer continue to be developed (Creaser et al. 1991). On the downside, the quadrupole ion trap has difficulties with reactions involving ions or molecules from air and water, with resulting complications in spectra. For a discussion of the relative merits and limitations of the different types of mass analyzers, the reader is referred to Brunnee's excellent discussion (1987).

The GC/MS technique combines the separating power of chromatography with the identifying capabilities of MS. The technique gathers and records sequentially acquired mass spectra, with the mass analyzer typically scanning the mass range of the instrument once every second for the length of the chromatographic run. This information can be presented in three ways (Figure 3.3): (1) as the individual mass spectrum of each band eluted from the column; (2) as a total-ion-current chromatogram that resembles the response of a conventional GC detector; and (3) as a selected-ion-current profile, also known as selected-ion extraction, a record of the abundance of a single $\mathrm{m} / \mathrm{z}$ as a function of chromatographic retention time. A technique known as selected-ion monitoring decreases the limit of detection of GC/MS; a band eluting from the column is subjected to mass analysis for a single $\mathrm{m} / \mathrm{z}$ value, eliminating much of the background noise associated with a full scan.

\subsection{Commercially Available Field Gas Chromatography/Mass Spectrometry Systems}

Unlike laboratory-based GC/MS systems, relatively few portable (as opposed to transportable) GC/MS systems are commercially available. The portable GC/MS system must be hardened to withstand a wide range of environmental conditions and be powered by batteries or a small generator. In contrast, only minor modifications of a commercial laboratory GC/MS system are needed to make it transportable for use in a field laboratory with a controlled environment and available power. These modifications may include mountings to ensure safe transport and minor configurational changes to accommodate space constraints. 


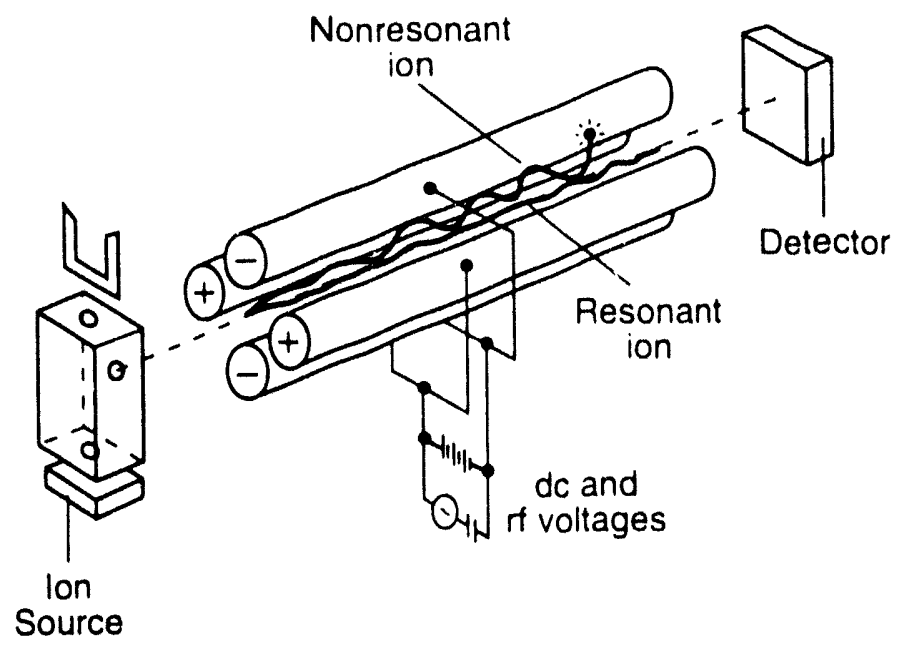

FIGURE 3.1 Quadrupole Mass Analyzer

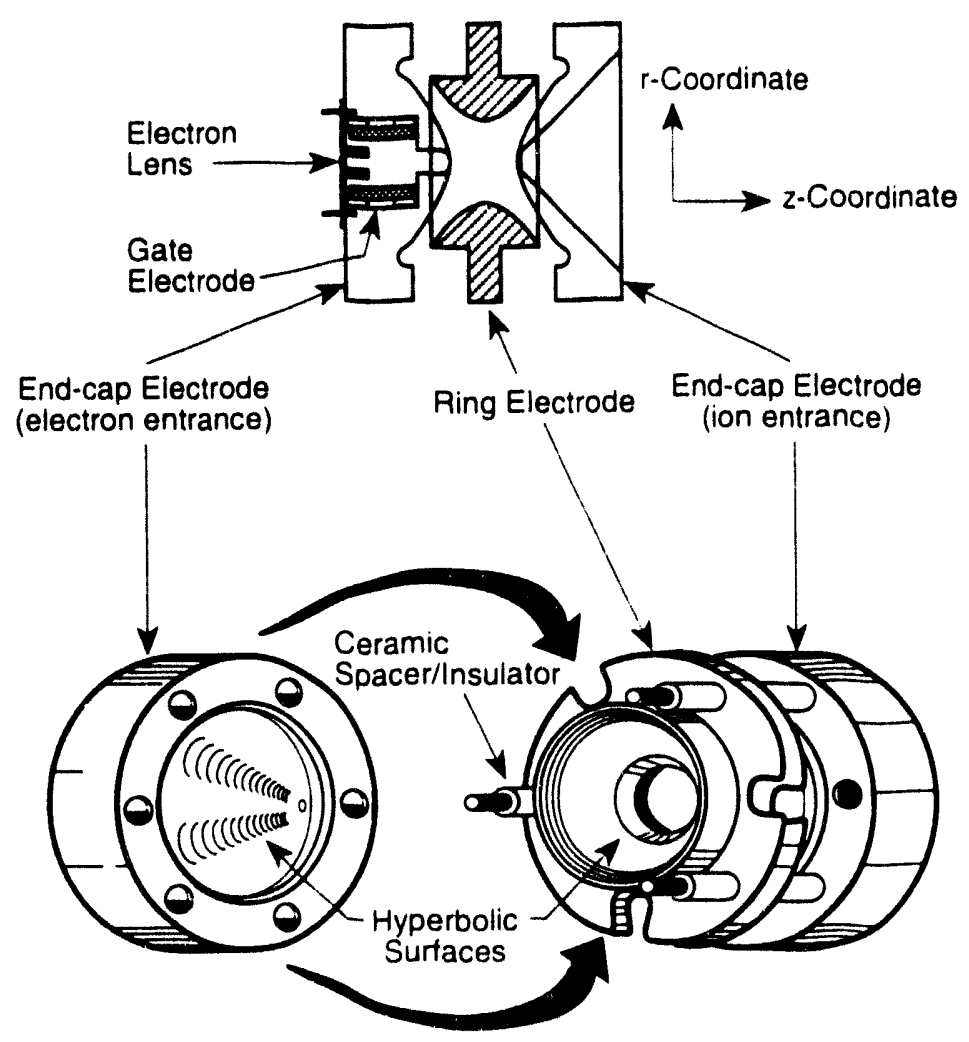

FIGURE 3.2 Quadrupole Ion Trap 


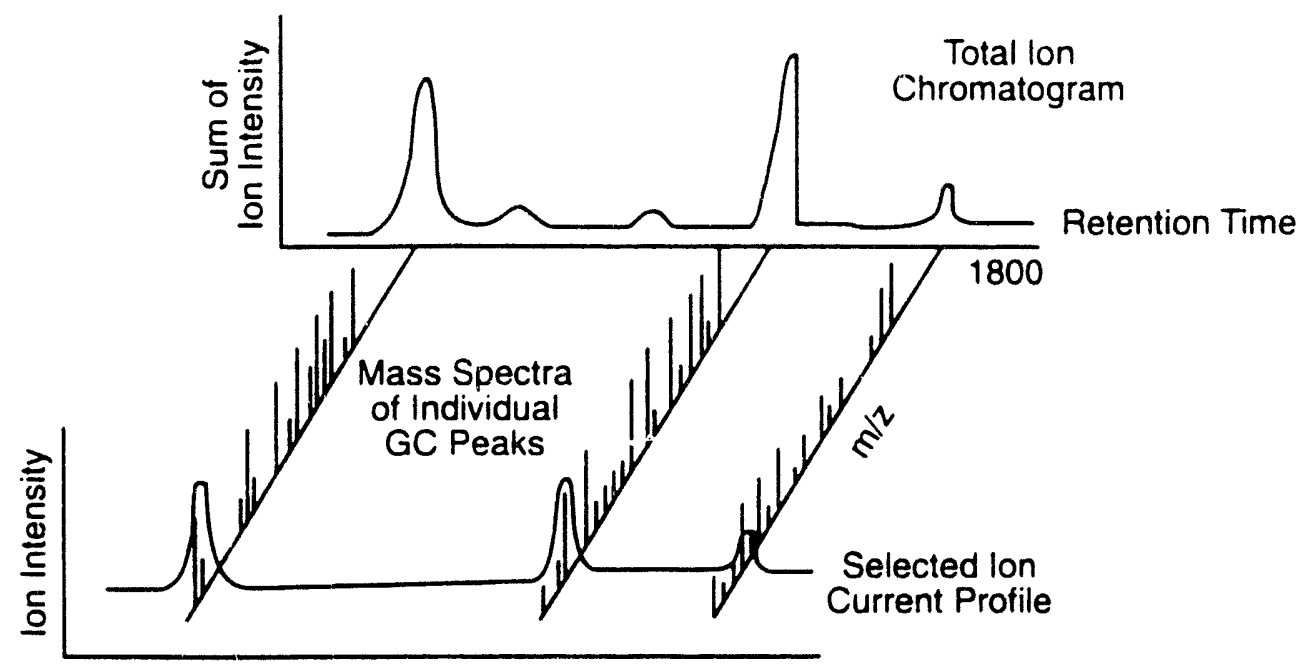

FIGURE 3.3 Total-Ion-Current Chromatogram, Selected-lon-Current Profile, and Mass Spectra for a Typical GC/MS Analysis

\subsubsection{Bruker}

Bruker Instruments, Inc. (Fortune Drive, Manning Park, Billerica, MA 01821), has marketed the Mobile Environmental Mass Spectrometer (MEM) for several years and recently, in 1993, introduced an update, the EM-640. Table 3.1 presents selected specifications for the Bruker MEM and the Bruker EM-640, along with the Viking SpectraTrak ${ }^{T M} 620$ (discussed subsequently). The MEM design was derived from Bruker's Mobile Mass Spectrometer (MM-1), which was deveioped as a detector for battlefield chemical warfare agents (Trainor and Laukien 1988: Meuzelaar et al. 1991). The MM-1 was initially a direct air-sampling mass spectrometer without a gas chromatographic attachment. Although Hague et al. (1988) praised the durability of the $\mathrm{MM}-1$, false positives and false negatives were common when complex mixtures were analyzed or when compounds were present that were not in the computer's MS target library.

The Bruker MEM features several sampling accessories that allow a wide range of monitoring. The head of the sampling probe contains a heated silicone membrane that is selectively permeable to organic vapors. The heated head thermally desorbs analytes directly from the substrate or from solvent-substrate solutions. Upon passing through the sampling head. analytes enter a flexible $3.5-\mathrm{m}$ fused-silic. . pillary column housed in a temperature-programmable umbilical. A second silicone membrane protects the vacuum of the mass analyzer and concentrates the sample. A GC accessory was designed for use with complex samples when the additional separating power of a longer GC column proves useful. The MEM is normally mounted in a vehicle and is taken directly to the test site. The basic cost of the instrument. including GC accessory and data system, was approximately $\$ 225.000$ in 1993. 
TABLE 3.1 Key Features of the Bruker MEM and EM-640 and the Viking SpectraTrak ${ }^{\mathrm{TM}} 620^{\mathrm{a}}$

\begin{tabular}{|c|c|c|c|}
\hline Feature & Bruker MEM & Bruker EM-640 & Viking SpectraTrakm 620 \\
\hline Sample introduction & $\begin{array}{l}\text { TD; purge-and-trap accessory } \\
\text { available }\end{array}$ & $\begin{array}{l}\text { Liquid injection, TD; automatic air } \\
\text { sampler and automatic soil } \\
\text { sampler planned }\end{array}$ & $\begin{array}{l}\text { Liquid injection, TD, direct air } \\
\text { sampling (bypass GC); air } \\
\text { sampling by trapping on } \\
\text { sorbent/TD; purge-and-trap } \\
\text { accessory available }\end{array}$ \\
\hline GC & $\begin{array}{l}\text { Temperature-programmable } 3.5-\mathrm{m} \\
\text { capillary in sampling umbilical }\end{array}$ & $\begin{array}{l}3.5-\mathrm{m} \text { short capillary or } 20-\mathrm{m} \\
\text { high resolution; quick-connect } \\
\text { modules }\end{array}$ & $\begin{array}{l}\text { Temperature-programmable } \\
\text { capillary }\end{array}$ \\
\hline Carrier gas & Filtered ambient air & $\mathrm{N}_{2}$ or filtered ambient air & $\mathrm{He}, \mathrm{N}_{2}, \mathrm{H}_{2}$ \\
\hline GC-MS interface & Membrane (methyl silicone) & $\begin{array}{l}\text { Hollow fiber or flat silicone } \\
\text { membrane }\end{array}$ & Membrane \\
\hline Mass analyzer & $\begin{array}{l}\text { Metal-coated quartz hyperbolic } \\
\text { quadrupole }\end{array}$ & Same quadrupole as MEM & $\begin{array}{l}\text { Hewlett-Packard 5971A mass- } \\
\text { selective quadrupole detector }\end{array}$ \\
\hline lonization & Electron impact & Electron impact & Electron impact/chemical impact \\
\hline Scan time (amu/s) & 800 & 2,000 & 2,000 \\
\hline Mass range (amu) & $1-400$ & $1-640$ & $1-650$ \\
\hline Mass resolution (amu) & 1 (10\% peak definition) & 1 & 1 \\
\hline Power needs & $\begin{array}{l}600-W, 24-V \text { dc (six } 24-V \\
\text { batteries, generator, or laboratory } \\
\text { power) }\end{array}$ & $\begin{array}{l}250-W \text { (peripherals, } 350 \mathrm{~W} \text { ), } \\
24-V \text { dc }\end{array}$ & $\begin{array}{l}1.2 \mathrm{~kW}, 50 / 60 \mathrm{~Hz}, 110 \mathrm{~V} \\
\text { (dc battery power possible on } \\
\text { request) }\end{array}$ \\
\hline Warm-up time (min) & 15 & 15 & 30 \\
\hline
\end{tabular}


TABLE 3.1 (Cont.)

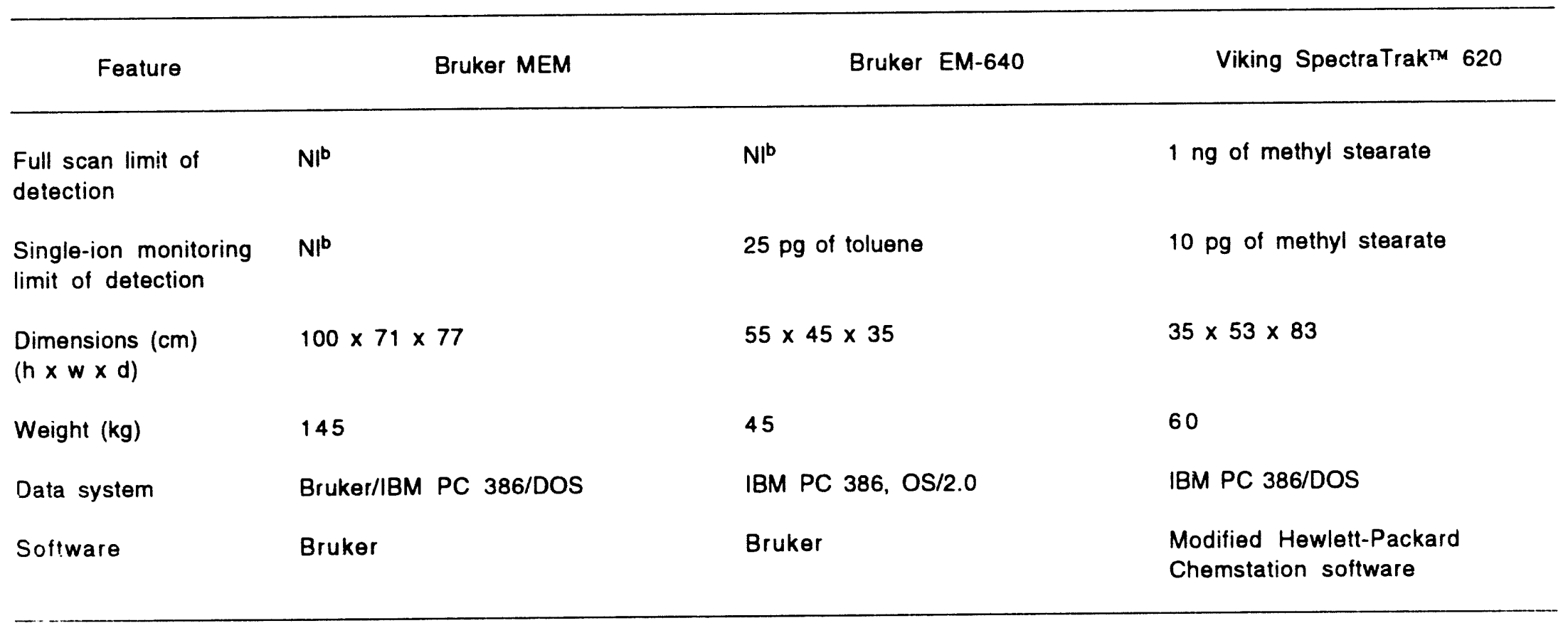

a Abbreviations: amu, atomic mass unit(s); dc, direct current; Hz, hertz; kW, kilowatt(s); V, volt(s); and W, watt(s).

b NI, No information available. 
Research at Tufts University by Abraham and Robbat has established methods for using the Bruker GC/MS system for the field characterization of polychlorinated biphenyls (PCBs) (Robbat et al. 1992a), polycyclic aromatic hydrocarbons (PAHs) (Robbat and Xyrafas 1988), and VOCs; these methods have been submitted to the EPA for possible inclusion in the manual of Test Methods for Evaluating Solid Waste (SW-846) (EPA 1986). We have successfully used the shortcolumn sampling probe as fast-GC, obtaining quantitative results (percent relative standard deviation $[\% \mathrm{RSD}] \leq 30)$ in the low parts-per-million range for VOCs, PCBs, and PAHs. Data quality and turnaround time are dependent on the method of sample preparation; PCB screening is completed in less than $1 \mathrm{~min}$ per sample; semiquantitative results are generally obtained in 2-7 min per sample; quantitative purge-and-trap VOC analyses take about 10 min per sample; quantitative results are available in 10-15 min per soil sample for PCBs and in 20-30 min per soil sample for PAHs, chlorinated pesticides, and phenols, with statistically equivalent data compared with standardized EPA methods (Robbat et al. 1992b).

Rapid screening and quantitative field methods have been developed and implemented for EPA-listed VOCs. Field demonstration and validation were accomplished through the EPA's Superfund Innovative Technology Evaluation Program by one of the authors (EPA 1991). In this study, the sample was introduced by employing a specially designed TD oven. The EPA collected samples of pond water from various locations at the creosote-contaminated Hocomonco Pond Superfund site in Westborough, Massachusetts. On the basis of spike recoveries, the precision of measurements was better for the laboratory (EPA method 8260) than for the 5-min screening analysis with thermal-desorption GC/MS (TDGC/MS) (<20\% RSD, compared with 20)-35\% RSD). On the other hand, the accuracy of measurement, even in the "screening" mode, was better for the field TDGC/MS than for the laboratory-based analysis. As part of an expedited site characterization, contamination with carbon tetrachloride $\left(\mathrm{CCl}_{4}\right)$ and chloroform in the subsurface resulting from fumigation of grain stored in Nebraska was measured on-site by TDGC/MS (Burton et al. 1994). The effects of holding times on recovery were consistent with the earlier findings of other investigators discussed previously. Losses from water samples on shipment to a laboratory were observable but not significant; however, losses from soil were significant. The TDGC/MS detected chloroform or $\mathrm{CCl}_{4}$ (or both) in 10 of 12 soil samples; the laboratory reported "not detected" for all 12 samples. In a controlled study of a field soil sample, losses were observed within even a few minutes, with continuing loss of analyte over several hours. The inescapable conclusions from these studies and a general knowledge of VOCs are that laboratory-based analyses for VOCs in soil by using standard EPA methods are most probably erroneously low and that a significant number of false negatives are being reported. Modification of current protocols $t()$ use field GC or field GC/MS analysis is one, but not the only, way to accurately assess VOCs.

In addition to the improved quality of data and the more rapid availability of data, field analyses cost less than laboratory analyses in the expedited site characterization (Franzen et al. 1993). To secure a rapid data turnaround time of three days, a fee of $\$ 700$ per sample was paid. Thus, the cost of laboratory analyses was $47 \times \$ 70()$, or $\$ 32,900$, compared with $\$ 5(),(0)()$ for 126 samples, or $\$ 397$ per sample, for the field-analyzed samples. These direct cost savings exclude indirect savings realized by cost reduction of other field operations, minimization of return visits to a site, and improvements in the on-site decision-making process; all of these savings can be considerable and often overshadow the direct costs for analytical chemistry within the site characterization process. 
The Bruker model EM-640, introduced in 1993, operates on 24-volt (V) power, uses 250 watts (W), and weighs $45 \mathrm{~kg}$. Fast-GC techniques that use a $3.5-\mathrm{m}$ capillary column in a quick-connect modular GC system have been incorporated to permit complete analyses in 3-5 min. yielding 5()-100) analyses per shift (Franzen et al. 1993). Preliminary results indicate the utility of the fast-GC technique. An 18 -component mixture ranging from acetone through 1,1,2,2-tetrachloroethane was chromatographed within $3 \mathrm{~min}$; the use of selected ion traces or more sophisticated deconvolution algorithms could easily compensate for the lack of complete chromatographic resolution in the reconstructed total-ion chromatogram. The modular GC system permits flexible operation by standard syringe injection, TD, or gas sampling/TD (Weiss et al. 1993). Water analyses are performed by the rapid (4-min) spray-and-trap technique, which extracts some gases, VOCs, and the lighter semivolatile organic compounds (SVOCs), such as anthracene, frorn water by generating an aerosol of the aqueous solution (Matz and Kesners 1993). The high-surface-area liquid facilitates partitioning of the organics between the aqueous and gaseous phases, although further validation may be needed. The organics are then concentrated from the gas stream onto a Tenax sorbent trap for subsequent TD. Detection limits for VOCs in the range of 10-90 $\mathrm{ng} / \mathrm{L}$ have been reported (Baykut et al. 1993; Matz and Kesners 1993). The VOCs in air can be monitored with an automatic air sampler that adsorbs the VOCs onto a trap, which is, in turn, thermally desorbed into the GC/MS system.

\subsubsection{Viking}

The Viking SpectraTrak ${ }^{\text {TM }} 620$ (Viking Instruments Corp., 12007 Sunrise Valley Drive, Reston, VA 22091-3406) was developed specifically for environmental applications by modifying Hewlett-Packard's mass-selective detector (MSD). The SpectraTrak 620 weighs $60 \mathrm{~kg}$ and is designed to be transported by a handcart. The mass analyzer is the monolithic quadrupole used in the Hewlett-Packard 5971A MSD. Like the Bruker MEM, the SpectraTrak is also capable of membrane sample introduction to the mass analyzer and can operate in three different modes: (1) direct air sampling to the mass spectrometer across the semipermeable membrane;

(2) concentration of air, headspace gas, or purged samples with a sorbent trap and subsequent TD to a GC column or the direct-sampling membrane; and (3) split/splitless injection and cryofocusing GC/MS. The Viking SpectraTrak uses an oven-based, temperature-programmable GC that can accommodate fused-silica capillary columns of various dimensions. Cryofocusing for VOCs is achieved by cooling an uncoated portion of the GC column with a Peltier (thermoelectric) cooling device to subambient conditions (e.g., $-50^{\circ} \mathrm{C}$ ). The data system is based on Hewlett-Packard's Chemstation, with a graphic user interface and standard peripherals and the library-searching capabilities of the National Institute of Standards and Technology. The features are summarized in Table 3.1. The base price of the instrument was $\$ 145,000$ in 1993.

In a system demonstration (Eckenrode and Owens 1992) analyzing groundwater wells for VOCs, the SpectraTrak was transported in the back of a pickup and was powered by a generator. The instrument was ready for analysis within $20 \mathrm{~min}$. Headspace samples from vials were injected with a gas-tight syringe and concentrated on a Tenax GC trap for $1 \mathrm{~min}$. Several wells could be sampled from a central location by using tubing to transport the samples from the wells to the GC/MS system; the type and temperature of the transfer line were not specified. In another test 
(Eckenrode and Drew 1993), the system was configured to provide continuous monitoring of headspace gas from a groundwater well. Gas was drawn past the membrane separator by the system's vacuum pump, bypassing the GC system. Trichloroethylene, chloroform, and dichloroethylene were detected but not quantitated. Rapid screening of VOCs in indoor air has also been reported (Kuehn and Bell 1993). No information is available to compare the data obtained by the Viking instrument with data obtained by other techniques or from EPA-approved methods.

A case history in which 1,000 soil samples were analyzed within three weeks, with a peak operation of 60 samples per day, illustrated the potential for cost and time savings with field GC/MS (Greenlaw et al. 1990). In this example, the average cost was $\$ 30$ per sample, including the personnel and operating costs. Costs for off-site contract analysis were estimated at $\$ 350-\$ 500$ per sample. The schedule for the remedial investigation/feasibility study was accelerated by six months with the use of field GC/MS. Greenlaw et al. (1990) also presented a cost analysis comparing field GC/MS with fixed-laboratory GC/MS. Field GC/MS becomes more attractive as the sample volume increases, with the advantage shifting at about 25 samples per week, depending on the assumptions regarding cost elements on both sides of the comparison.

\subsubsection{The EPA's Thermal Chromatography/Mass Spectrometry System}

The field analytical screening project of the EPA's Region 2 assembled a thermal chromatography/mass spectrometry (TC/MS) system for use in a van (Kuehn and Bell 1993). The system consisted of a ThermEx ${ }^{\mathrm{TM}}$ (Ruska Instrument Corp., Houston, Texas) thermal extractor (desorption device) and a GC coupled to a Finnigan INCOS 500 quadrupole MS. The system was placed on two shock-mounted carts to permit operation either inside of a van with generator power or in a fixed-base laboratory. The Ruska thermal extractor uses liquid $\mathrm{CO}_{2}$ cooling to trap and uses temperature-programmed heating to desorb compounds onto the GC column. The TC/MS system was used around the clock in an emergency response action to analyze dust samples from homes for diphenylamine, benzothiazole, and mercaptobenzothiazole. The instrument was running within one hour of arrival at the site and ran continuously for four days without incident. Limitations noted were residue contamination in the thermal extractor trap, operator fatigue, and the need for cleaning of the MS quadrupole.

\subsection{Research Efforts}

Meuzelaar and associates of the University of Utah have been developing a man-portable, "wearable" GC/MS device designed for emergency response (Trainor and Laukien 1988; Meuzelaar 1993). The instrument consists of a fully automated, repetitive air-sampling inlet; a short isothermal GC column; a modified Hewlett-Packard MSD; a hybrid bulk-getter/ion-getter vacuum system; and a portable computer. The instrument weighs less than $30 \mathrm{~kg}$, consumes about $80 \mathrm{~W}$ of power, and has an operable life of two to three hours per set of batteries. An instrument of this size has potential applications in remote operation, space exploration, medicine, and 
numerous other fields. Figure 3.4 compares the weights and power requirements of this manportable instrument with those of other commercially available MS instruments.

A transportable GC/MS system that is based on quadrupole ion-trap technology is being developed at Los Alamos National Laboratory (LANL), Los Alamos, New Mexico. Hemberger et al. (1991) have developed a microprocessor to control the sampling system, software designed to integrate the sampling and ion-trap functions, and a custom purge-and-trap GC sample-introduction system for a modified Finnigan MAT ion-trap detector (ITD). The system could be built from commercially available parts and interfaced with computer control technologies developed at LANL for about \$75,000 (1992 cost estimate). Analyses of VOCs can be completed within $20 \mathrm{~min}$. The detection of trichloroethylene in water at $10 \mathrm{ppt}$ was demonstrated in the laboratory. Purging of VOCs from soil has also been accomplished.

In a separate effort at LANL, Leibman's group has modified commercially available components more extensively, creating a custom purge-and-trap/temperature-programmable GC system for the instrument (Leibman et al. 1991, 1993). Detection limits of low parts per trillion have been achieved in the laboratory, but the team seeks detection limits of $100 \mathrm{ppt}$ to $100 \mathrm{ppb}$ in the field. Analysis of the 80 compounds outlined in method 8260 in EPA manual SW-846 (EPA 1986) is achieved in approximately 10 min (Leibman et al. 1993). In a direct comparison of the field analysis with standard laboratory-based GC/MS analyses, colocated samples exhibited values 25-75\% lower in the laboratory. Leibman et al. (1991) speculate that these results may reflect the loss of volatile components during sample transport.

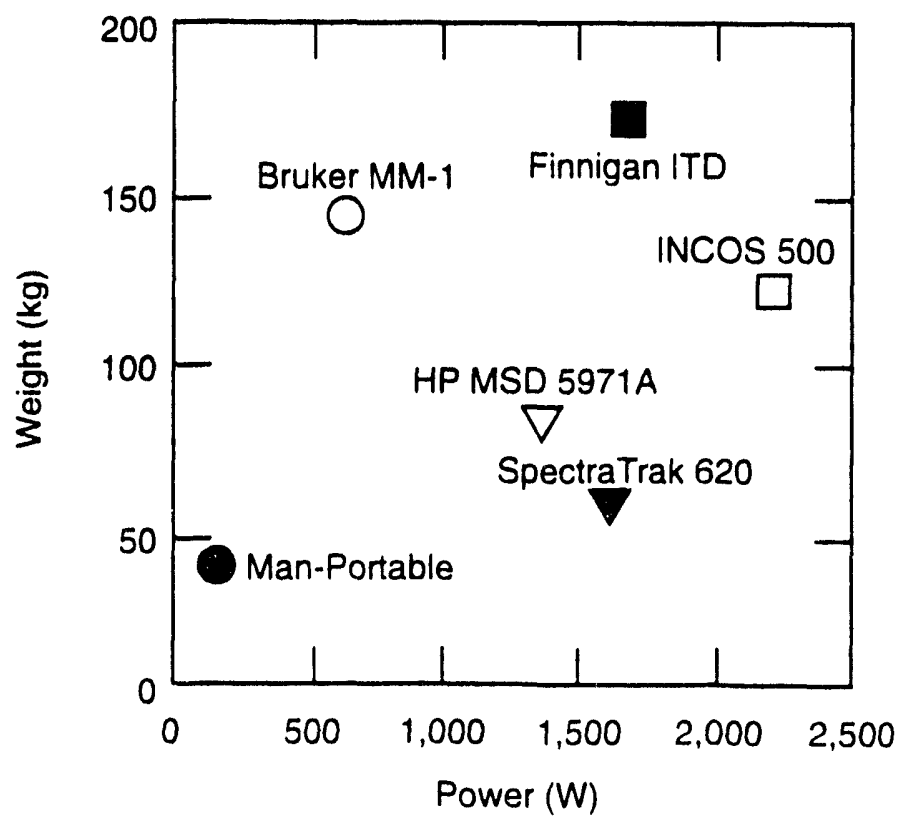

FIGURE 3.4 Weights and Power Requirements of Several GC/MS Systems 
Investigators at Oak Ridge National Laboratory, Oak Ridge, Tennessee, are developing DSITMS technology. Wise et al. (1993) and Leibman et al. (1993) have extensively modified a Finnigan ion trap to produce an instrument with lower power demands that employs both chemical and electron impact ionization and is capable of screening and quantitative analyses of VOCs. No gas chromatograph is provided for separation of compounds; the mass spectral discrimination is judged sufficient for many applications. The response is linear over at least four orders of magnitude, with instrumental detection limits of about $0.5 \mathrm{ppb}$ for most analytes. In the sampleintroduction systems that have been developed and integrated, VOCs in water and soil slurries are purged directly into the DSITMS system, with total analysis times of 3 min and quantitation limits of 1-5 ppb for water and 10-30 ppb for soil, depending on the analyte. Air may be continuously monitored for VOCs, with detection limits of about 1 ppb (volume) (ppbv) for most VOCs; alternatively, VOCs may be desorbed from sorbent cartridges into the DSITMS system. The SVOCs may be thermally desorbed from soil with mass detection limits of 50-100 pg; concentration detection limits are dependent on the size of the sample desorbed.

\subsection{References for Chapter 3}

Abraham, B.M., et al., 1993, "Data Comparison Study between Field and Laboratory Detection of Polychlorinated Biphenyls and Polycyclic Aromatic Hydrocarbons at Superfund Sites," Hazardous Waste and Hazardous Materials 10:461-473.

Baykut, G., et al., 1993, in Proceedings of the Third International Symposium: Field Screening Methods for Hazardous Wastes and Toxic Chemicals, Air and Waste Management Association, Pittsburgh, $\mathrm{Pa}$.

Bowen, D.V., and F.S. Pullen, 1989, "Can Aluminum-Clad Capillary Columns Be Used for Gas Chromatography/Mass Spectrometry on a Sector Mass Spectrometer?" Rapid Communication Mass Spectrometry 3:67-68.

Brunnee, C., 1987, "The Ideal Mass Analyzer: Fact or Fiction?" International Journal of Mass Spectrometry and Ion Processes 76:125-237.

Burton, J.C., et al., 1994, "Expedited Site Characterization: A Rapid, Cost-Effective Process for Preremedial Site Characterization," in Proceedings of SUPERFUND XIV Conference and Exhibition, vol. 2, Hazardous Materials Control Research Institute, Greenbelt, Md., pp. 809-826.

Campana, J.E., 1980, "Elementary Theory of the Quadrupole Mass Filter," International Journal of Mass Spectrometry and Ion Physics 33:101-117.

Cooks, R.G., and R.E. Kaiser, Jr., 1990, "Quadrupole Ion Trap Mass-Spectrometry," Accounts of Chemical Research 23:213-219. 
Creaser, C.S., et al., 1991, "Novel Scan Routines for Selected lon Monitoring Using an Ion Trap Mass Spectrometer," International Journal of Mass Spectrometry and Ion Processes 106:21 -31.

Eckenrode, B., and K.C. Drew, 1993, in Proceedings of the Third International Symposium: Field Screening Methods for Hazardous Wastes and Toxic Chemicals, Air and Waste Management Association, Pittsburgh, $\mathrm{Pa}$.

Eckenrode, B.A., and B. Owens, 1992, "Onsite Well Screening with a Transportable GC/MS System," Environmental Lab 4:42.

EPA: See U.S. Environmental Protection Agency.

Franzen, J., et al., 1993, in Proceedings of the Third International Symposium: Field Screening Methods for Hazardous Wastes and Toxic Chemicals, Air and Waste Management Association, Pittsburgh, Pa.

Fribush, H.M., and J.F. Fisk, 1992, "Field Analytical Methods for Superfund," Environmental Lab 4:36-41.

Greenlaw, P.D., et al., 1990, "Using TC/MS to Analyze Soils in Preremedial Site Investigations," Hazardous Material Control 3:34-41.

Hague, R.E., et al., 1988, "Results from the Environmental Response Team's Preliminary Evaluation of a Direct Air Sampling Mass Spectrometer," in First International Symposium: Field Screening Methods for Hazardous Waste Site Investigations, EPA/600/D-89/189, L.R. Williams (editor), U.S. Environmental Protection Agency, Environmental Monitoring Systems Laboratory, Las Vegas, Nev., pp. 227-232.

Hemberger, P.H., et al., 1991, "A Transportable Turnkey Gas-Chromatograph Ion Trap Detector for Field Analysis of Environmental-Samples," International Journal of Mass Spectrometry and Ion Processes 106:299-313.

Hyver, K.J., and R.J. Phillips, 1987, "Considerations in Enhancing Resolution, Speed, and Sensitivity in Capillary Gas-Chromatography and Gas-Chromatography Mass-Spectrometry," Journal of Chromatography 399:33-46.

Kuehn, T.J., and D.A. Bell, 1993, in Proceedings of the Third International Symposium: Field Screening Methods for Hazardous Wastes and Toxic Chemicals, Air and Waste Management Association, Pittsburgh, $\mathrm{Pa}$. 
Leibman, C.P., et al., 1991, Transportable GC/Ion Trap Mass Spectrometry for Trace Field Analysis of Organic Compounds, LA-UR-91-1764, Los Alamos National Laboratory, Los Alamos, N.M.

Leibman, C.P., et al., 1993, in Proceedings of the Third International Symposium: Field Screening Methods for Hazardous Wastes and Toxic Chemicals, Air and Waste Management Association, Pittsburgh, Pa.

Levine, S.P., et al., 1991, in Proceedings of the Second International Symposium: Field Screening Methods for Hazardous Wastes and Toxic Chemicals, Air and Waste Management Association, Pittsburgh, Pa., p. 265.

Matz, G., and P. Kesners, 1993, "Spray and Trap Method for Water Analysis by ThermalDesorption Gas-Chromatography Mass-Spectrometry In-Field Applications," Analytical Chemistry 65:2366-2371.

Meuzelaar, H.L.C., 1993, in Proceedings of the Third International Symposium: Field Screening Methods for Hazardous Wastes and Toxic Chemicals, Air and Waste Management Association, Pittsburgh, Pa.

Meuzelaar, H.L.C., et al., 1991, in Proceedings of the Second International Symposium: Field Screening Methods for Hazardous Wastes and Toxic Chemicals, Air and Waste Management Association, Pittsburgh, Pa., p. 289.

Mouradian, R.F., et al., 1990, "Evaluation of a Nitrogen-Cooled, Electrically Heated Cold Trap Inlet for High-Speed Gas-Chromatography," Journal of Chromatographic Science 28:643-648.

Robbat, A., Jr., and G. Xyrafas, 1988, "Evaluation of a Field-Based Mobile, Gas Chromatograph-Mass Spectrometer for the Identification and Quantification of Volatile Organic Compounds on EPA's Hazardous Substances List," in First International Symposium: Field Screening Methods for Hazardous Waste Site Investigations, EPA/600/D-89/189, L.R. Williams (editor), U.S. Environmental Protection Agency, Environmental Monitoring Systems Laboratory, Las Vegas, Nev., pp. 343-348.

Robbat, A., Jr., et al., 1992a, "Evaluation of a Thermal-Desorption Gas-Chromatograph MassSpectrometer: On-Site Detection of Polychlorinated-Biphenyls at a Hazardous-Waste Site," Analytical Chemistry 64:358-364.

Robbat, A., Jr., et al., 1992b, "Field Detection of Organochlorine Pesticides by ThermalDesorption Gas-Chromatography Mass-Spectrometry," Journal of Chromatography 625:277-288. 
Snyder, A.P., et al., 1993, "Portable Hand-Held Gas-Chromatography Ion Mobility Spectrometry Device," Analytical Chemistry 65:299-306.

Trainor, T.M., and F.H. Laukien, 1988, "Design and Performance of a Mobile Mass Spectrometer Developed for Environmental Field Investigations," in First International Symposium: Field Screening Methods for Hazardous Waste Site Investigations, EPA/600/D-89/189, L.R. Williams (editor), U.S. Environmental Protection Agency, Environmental Monitoring Systems Laboratory, Las Vegas, Nev., pp. 299-310.

U.S. Environmental Protection Agency, 1986, Test Methods for Evaluating Solid Waste: Physical/Chemical Methods, EPA-530-SW-846, Office of Solid Waste, Washington, D.C., Sept.

U.S. Environmental Protection Agency, 1991, Demonstration of the Bruker Mobile Environmental Monitor, EPA/600/x-91-079, Environmental Monitoring Systems Laboratory, Las Vegas, Nev.

Weiss, G., et al., 1993, in Proceedings of the Third International Symposium: Field Screening Methods for Hazardous Wastes and Toxic Chemicals, Air and Waste Management Association, Pittsburgh, Pa.

Wise, M.B., et al., 1993, "Direct Sampling Ion Trap Mass Spectrometry," Spectroscopy 8:14-22. 


\section{Fiber-Optic Chemical Sensors}

A chemical sensor is a device capable of continuously and reversibly recording a physical parameter or the concentration of a chemical species. Ideally, such a sensor can be placed directly into the sample, and the result of the measurement will be displayed within a few seconds. No sampling, addition of reagent, or dilution is required. This feature is a distinct advantage of sensors because these operations are known to introduce errors into all kinds of analytical assays.

The use of optical fibers in chemical sensing dates from the early 1970s, when the fibers were specifically identified as sensors for oxygen and iodine. Since that time, the use of optical fibers as either the sensor itself or as part of a sensor system has expanded considerably (Wolfbeis 1991; DOE 1993). These sensors are commonly referred to as fiber-optic chemical sensors (FOCSs).

In the field of chemical sensors, optical fibers are classified as extrinsic or intrinsic. In extrinsic applications, the fiber acts only as a light pipe, transmitting light from a source to some external medium, either a medium that contains the analyte or a material that responds in a specified way to an analyte. A corresponding signal generated by the analyte is transmitted back through the fiber to a detector system that interprets the signal as to the character of the analyte. Intrinsic fibers are a part of the sensing mechanism, with interaction with an analyte causing some optical change in the fiber itself or in a selective coating on the fiber. Extrinsic fibers are not sensors in the strict sense but are such an integral part of a sensing mechanism that they are included in the broad definition of sensors. Wolfbeis defines a sensor as "a device capable of continuously and reversibly recording a physical parameter or the concentration of a chemical or biochemical species" (Wolfbeis 1991, p. 1). Some of the parameters measured or the applications that use fibers as extrinsic or intrinsic sensors are listed in Table 4.1. In this review, only those applications of optical fibers to chemical sensors that pertain to the determination of VOCs in environmental restoration and waste management activities will be addressed.

\subsection{Analytical Aspects of Sensors}

Continuous sensing of chemical analytes is a matter of growing interest by virtue of the real-time nature of most sensors. Increasing concern about environmental quality and-in a more and more cost-conscious world-considerable personnel savings, in comparison with manual off-line methods, contribute to the desirability of sensors. Hence, tremendous effort has been devoted to the development of various sensing devices that partially, in combination with laboratory robotic systems, will enable analyses to be performed fully automatically or on-line.

In view of the different requirements imposed on sensors for various purposes, their complexity can vary considerably; for example, an optical sensor can be a simple fiber that guides a laser beam to a fluorescent analyte and guides fluorescence back to a detector. The incoming light beam may be considered the question and the returning beam as the encoded answer; however, 
TABLE 4.1 Parameters Measured or Applications that Use Optical Fibers as Extrinsic or Intrinsic Sensors

\begin{tabular}{ll}
\hline \multicolumn{1}{c}{ Extrinsic } & \multicolumn{1}{c}{ Intrinsic } \\
\hline Fluorescence & Fluorescence \\
Scattering, including Raman & Absorption \\
Absorption & Refractive index \\
Atomic emission & Transmission \\
Chemiluminescence & Chemiluminescence \\
Colorimetric & Colorimetric \\
& Evanescent wave \\
\hline
\end{tabular}

most molecules of analytical interest require more sophisticated instrumentation, particularly when they are not colored or fluorescent by themselves. In most of these cases, the sensor consists of a light source, a monochromator (except in the case of laser light sources), a light coupler, the waveguide (a planar waveguide, a fiber, or a fiber bundle), an analyte-sensitive coating, a transducer (if necessary), a secondary filter (if necessary), an optical detection unit, an amplifier, a unit for data acquisition and processing, and a data output or display.

\subsection{Fiber-Optic Sensors}

Optical fibers are based on the phenomenon of total internal reflection. Step-index fibers consist of a core surrounded by a cladding. The core has a higher refractive index than the cladding. Most fibers are covered with a mechanically protective jacket that has no effect on the waveguiding properties. Incident light is transmitted through the fiber if the light strikes the cladding at an angle greater than the critical right angle, so that the light is totally internally reflected at the core-cladding interface. Light entering the end of the fiber within an acceptance cone is transmitted.

Basically, three kinds of fibers are in use, namely, the multimode step-index and multimode graded-index fibers and the single-mode step-index fibers. All of the optical sensor types consist of a light source, a coupler and decoupler, fiber light guide(s), sensor chemistries (as far as necessary), and a light detector and signal processor. 
For many applications, a fiber per se is not required. Total internal reflection will occur at any interface between a transparent solid or liquid and air, as long as their refractive indices are different. Glass capillary tubes have successfully been used for chemical sensors. Furthermore, nothing requires that the "fiber" be round. Rather, several advantages are found in using flat glass slides as the medium for light propagation. A flat surface is easier to coat with a reagent layer. Also, the angle of incidence of the source radiation is more easily controlled.

\subsection{Sensor Classification}

The first sensor designed to collect information via fiber optics relied on the fact that alterations in a specific physical property of the medium being sensed would cause a predictable change in the light transmission characteristics of the fiber. The field of application of fiber sensors in analytical chemistry greatly increased when other kinds of optical spectroscopy were coupled with the fiber-optic technique. As a result, sensing is no longer restricted to measuring parameters that change the transmission of a fiber but can be extended to numerous organic analytes (1) that have an intrinsic color or fluorescence, (2) for which indicators are known, or (3) that give rise to any kind of meas able change in the optical system. These sensors are referred to as extrinsic fiber sensors and may be subdivided into first-, second-, and third-generation sensors, respectively ("Table 4.2). In the first group, the fiber simply acts as a light guide. It allows remote specirometric analysis of any analyte having an intrinsic optical property (such as light absorption or emission) that can be discerned from the background. Thus, the analyte provides the analytical information directly. These sensors are also called bare-ended fiber sensors or plain fiber sensors or passive optrodes.

However, a variety of chemical species do not have an analytically useful intrinsic absorbance or fluorescence and therefore cannot be probed directly via optical techniques. Moreover, the matrix may contain various colored interference with optical properties similar to those of the species of interest. Fiber sensors were then expanded into those in which the analytical information is mediated by some sort of indicator chemistry. These sensors are sometimes referred to as second-generation sensors or active optrodes. A subgroup of second-generation sensors is called "reservoir sensors." Because a variety of chemical species can be detected optically only by continuous addition of reagent, fiber sensors were constructed with a reaction volume at the end that is fully accessible to the analyte and is continuously supplied with a chemical reagent contained in a reservoir near the sensing site. The reaction between reagent and analyte produces a measurable chromophore or fluorophore.

Unfortunately, for a variety of analytes, no indicators are known that (1) give fully reversible color changes at room temperature, (2) react without the addition of aggressive reagents at near neutral $\mathrm{pH}$, and (3) fulfill the condition of being highly specific. In order to detect these species, a biocatalytic process is usually coupled to either plain fiber sensors or to an indicatormediated sensor such as an oxygen optrode. This coupling resulted in a third-generation sensor. 
TABLE 4.2 Classification for Optical Sensors and Typical Examples

\begin{tabular}{|c|c|c|}
\hline Sensor Type & Chemical Sensors & Examples \\
\hline First generation & $\begin{array}{l}\text { Remote spectrometers for on-line } \\
\text { monitoring of chemical species }\end{array}$ & $\begin{array}{l}\text { Remote detection of } \mathrm{CH}_{4} \text { via its NIR } \\
\text { absorption }\end{array}$ \\
\hline Second generation & $\begin{array}{l}\text { Fiber sensors based on immobilized } \\
\text { indicators }\end{array}$ & $\begin{array}{l}\text { Monitoring } \mathrm{pH} \text { via color changes of a } \mathrm{pH} \\
\text { indicator }\end{array}$ \\
\hline Third generation & $\begin{array}{l}\text { Second-generation sensor coupled to } \\
\text { enzymatic reaction }\end{array}$ & $\begin{array}{l}\text { Organic chloride sensor based on the } \\
\text { enzymatic degradation of alkylhalides by } \\
\text { certain enzymes; consumption of oxygen } \\
\text { monitored with an oxygen optrode }\end{array}$ \\
\hline
\end{tabular}

a NIR, Near infrared.

Another kind of classification is based on the signal response of optical information that is used. Thus, one may differentiate between absorbance, reflectance, intensity of luminescence, lifetime of luminescence, refractive index, surface plasmon resonance, or ellipsometric sensors. The signal responses can be mathematically manipulated to improve signal-to-noise ratios and to extract compound-specific spectral information.

A final method of classification is according to the field of application. One may differentiate chemical sensors, enzyme-based biosensors, and immunosensors.

Two fundamental technologies are available for the construction of optical sensors. In the first, the sensor chemistry is manufactured first and then attached to the fiber or fiber bundle. The sensor layers are usually produced on planar supports such as glass, cellulose, or plastic and then are glued or mechanically fixed at the tip of the fiber. In the second type, the chemistry is manufactured directly on the fiber, after coating and cladding have been removed from the end.

\subsection{Advantages and Disadvantages of Optical Sensing}

In the DOE arena, optical fiber sensing can offer a number of advantages in the monitoring and detecting of VOCs:

1. The ease of miniaturization allows the development of very small, light, and flexible fiber sensors. This miniaturization is of great utility in the case of subsurface or downhole detectors. 
2. Low-loss optical fibers allow transmittance of optical signals over wide distances, typically 10-1,000 m; and even larger distances seem feasible when use is made of the amplifiers currently found in optical telecommunication. Remote sensing makes possible the performance of analyses when samples are hard to reach, dangerous, too hot or too cold, in harsh environments, or radioactive. In fiber-optic sensors, the instrument comes to the sample, rather than the sample to the instrument. Even when no remote sensing is required, the use of fibers provides much more spatial flexibility for the arrangement of other optical components.

3. Analyses can be performed in real time because no sampling, with its inherent drawbacks, is necessary.

4. Because several fiber sensors placed in different sites can be coupled to one instrument via a chopper, the method allows multiple analyses with a single control instrument. Placement of the spectrometer at a central location remote from the sensor head (which experiences varying experimental conditions) makes routine maintenance checkout possible, assures that calibration will be preserved, and consequently renders the instrument more reliable.

5. Coupling of small sensors for different analytes to produce a sensor bundle of small size allows simultaneous monitoring of various analytes by hybrid sensors without cross talk of the single strands.

6. Fibers are manufactured from nonrusting materials so that they have excellent stability when in permanent contact with electrolyte solutions. Plastic and glass easily withstand aggressive reductants in the analyte solutions and also appear to be resistant to radiation doses on the order of $10 \mathrm{rad}$ or more.

7. A fiber optic can transmit much more information than an electrical lead can. High density of information can be achieved because the optical signals can differ with respect to wavelength, phase, decay profile, polarization, or intensity modulation. Thus, one single fiber may guide green and red light in one direction and guide blue and yellow light in the other. As a result, a single fiber can, in principle, guide a huge number of signals simultaneously. In practice, a single fiber may be used to assay several analytes at the same time because different analytes or indicators can respond to different analytical wavelengths. Time resolution, along with spectral selection, offers a particularly fascinating new technique in fiber-optic sensing and can make superfluous the need for hybrid sensors.

8. Many sensors are simple in design and can easily be replaced by substitute parts, even if manufacturing the sensor head requires relatively complex chemistry. These sensors therefore can offer cost advantages over other sensor 
types. Consequently, single-use and disposable optical sensors will likely experience a bright future.

9. Most fiber sensors can be employed over a wider range of temperatures than electrodes can, and some have a smaller temperature dependence.

Notwithstanding a number of advantages over other sensor types, fiber sensors exhibit the following disadvantages:

1. Ambient light can interfere. Therefore, optical sensors must either be used in dim or dark surroundings, or the optical signal must be encoded so that it can be resolved from ambient background light, or the signal must be covered with an optically tight layer ("optical isolation").

2. Sensors with indicator phases are likely to have limited long-term stability because of photobleaching or washout. Signal drifts can be compensated for by relating the signals obtained under two different excitation wavelengths, by relating the signal to an intrinsic standard by a ratio, or by measuring parameters such as lifetime, which are independent of indicator concentration. The efficiency of photobleaching increases with increasing intensity of irradiation. Consequently, a powerful laser should be used only when necessary (e.g., when long optical cables with their considerable attenuation make lasers indispensable).

3. The fiber optics used at present have impurities of a spectral nature that can give background absorption, fluorescence, and Raman scatter. Low-priced (plastic) fibers are confined to wavelengths between about 420 and 800 nanometers $(\mathrm{nm})$, whereas UV light is efficiently transmitted only by rather expensive quartz fibers. The losses in intensity in very long fibers are further complicated by spectral attenuation and change in the numerical aperture as a function of fiber length.

4. Commercial accessories of the optical system are not ootimal yet. Stable and long-lived light sources; better connectors, terminations, and optical fibers; inexpensive lasers; and, in particular, blue light-emitting diodes (LEDs) and semiconductor lasers for the whole visible range are needed.

In summary, optical sensors, despite several limitations, have the potential to become an attractive alternative to other sensing methods and to perform diagnostic, environmental, or processing monitoring functions better, faster, more accurately, or less expensively than existing approaches do. 


\subsection{Applications}

Applications where a plain fiber is used as a light pipe may be differentiated from true optrode applications. Plain fibers will have application in all situations where classical optical analysis is to be performed "remotely." Instrumentation for the remote acquisition of UV/visible (UV/VIS) data is commercially available. The instruments are intended for use in radioactive areas, high-voltage areas, and explosive and dangerous areas.

Optrodes (in the sense of indicator-phase sensors) offer a much wider field of application and are of potential use in all kinds of analytical sciences, including those covered by electrodes at present. Typical areas are pollution control, process control, and defense. The ruggedness of optrodes and their capability of transmitting signals over wide distances make possible their use in locations too harsh and inaccessible for the instrument, because the meter can be located in the benign environment of the laboratory, while the fiber comes to the sample.

\subsubsection{Groundwater Monitoring}

In the face of increasing public concern about the quality of drinking water, continuous monitoring of groundwater has become a major aspect of modern analytical chemistry. Rather than digging a well field with numerous boreholes large enough to admit sample collectors that are brought to a laboratory for analysis, the proposal has been made (Hirschfeld et al. 1981; EPA 1983) to introduce long-distance communication-grade fibers down to the groundwater level and to monitor $\mathrm{pH}, \mathrm{Cl}$, uranium, organic pollutants, and tracer substances by using the corresponding optrodes. Several fibers may then be coupled to one spectrometer at a central remote location up to 1 kilometer $(\mathrm{km})$ distant. The ability to make up to 50 unattended in situ measurements by using a reasonably priced centralized fluorimeter system has been discussed (Hirschfeld et al. 1983).

The much smaller diameter of the fiber hold (typically 1 to $2 \mathrm{~cm}$ ) allows the use of small boreholes. Luibbers et al. (1977) have stated that, at typical sites, such as chemical or nuclear plants, the savings in drilling costs can be as much as $\$ 500,000$. Moreover, the sample can be studied in situ and in real time, with almost no opportunity for contamination of a container or the well itself from outside.

For nuclear waste repositories, environmental monitoring of nuclear installations, or study of underground nuclear tests, the hazards associated with the samples can be avoided by leaving them safely underground. Even if the fiber is damaged by radiation, the fiber is easier and cheaper to replace than the whole monitor. 


\subsubsection{Pollution Monitoring}

A new approach (O'Neil et al. 1980; Zirino 1985) for the continuous control of water and air pollution includes the possibility of remote sensing of environmental parameters without the use of fibers. Increasing efforts have been directed to the detection of PAHs in the environment, which are by-products of many new coal-processing factories, including coal-liquidification plants. Similarly, mineral oil spills released by ships can be distinguished from seawater background by this technique and can even be classified into subgroups.

A variety of optical sensors for primary pollutants are known to work in principle. Thus, sensing air pollution for industrial applications and environmental research may be performed with a network of specific optrodes hooked to a central measurement station by optical fibers. The sensors may be instantaneously concentration-sensitive or may be designed for cumulative measurements of the total integrated exposure (fiber dosimeters). Sensors have been developed for formaldehyde, ammonia, nitrogen oxides, chloroform, hydrogen sulfide, sulfur dioxide, and reactive hydrocarbons. Pollution control appears to be a major future field of application that is particularly compatible with fiber-optic sensing methods.

\subsubsection{Current Status of Fiber-Optic Chemical Sensors for Determining Volatile Organic Compounds for Environmental Application}

\subsubsection{Atmospheric Monitoring}

Methane and Related Gases. Infrared-absorption-based schemes for detecting alkane vapors have been developed. Stueflotten et al. (1984) have developed a detector for the remote monitoring of explosive gases (e.g., $\mathrm{CH}_{4}$ ) that is based on near-IR (NIR) absorption measurements. The detector comprises three main units: (1) a microcomputer-based signal control and processing unit, (2) a fiber-optic sensor, and (3) an optical fiber cable module.

Inaba et al. (1984; Chan et al. 1987) have presented a similar scheme for the detection of $\mathrm{CH}_{4}$ and related gases such as propane. In this system, the gases were detected via plain fiber absorptiometry by using fiber links as long as $20 \mathrm{~km}$. Low-loss fibers, a 50-cm-long compact absorption cell, and bright LEDs operated at 1.34 and 1.61 micrometers $(\mu \mathrm{m})$ resulted in detection sensitivities for $\mathrm{CH}_{4}$ of $25 \%$ of the lower explosive limit (LEL) in air. Propane was detected in air at $1.684 \mu \mathrm{m}$, with a detection limit of $14 \%$ of the LEL.

Methane also has been detected via its optical absorption, which coincides with the 3.39- $\mu \mathrm{m}$ line of a He-neon laser. In one case (Saito et al. 1988), a conventional gas cell was used. In another case (Tai et al. 1987), a single fiber is used as both the sensor and the transmission line; however, the attenuation of present-day IR fibers will prevent the use of this wavelength in 
practice. When a fiber $1.8 \mu \mathrm{m}$ in diameter and $10 \mathrm{~mm}$ in length is used, the minimum detectable concentration of $\mathrm{CH}_{4}$ is less than 5\% in air. Possible interferents are ethane, propane, and water. The strong $3.3-\mu \mathrm{m}$ band, in being a $\mathrm{C}-\mathrm{H}$ vibration band, not only is given by $\mathrm{CH}_{4}$, but by all aliphatic hydrocarbons, which hence may interfere in the detection of $\mathrm{CH}_{4}$. A minimum measurable concentration of $\mathrm{CH}_{4}$ of $60 \mathrm{ppm}$ can be estimated. Water vapor also absorbs at $3.3 \mu \mathrm{m}$ and can interfere.

Via its relatively strong absorption band at around $1.33 \mu \mathrm{m}, \mathrm{CH}_{4}$ has been reproducibly determined by using a 2-km low-loss optical fiber network and compact absorption cells in conjunction with high-radiant indium-gallium-arsenic-phosphorus (InGaAsP) LEDs. Methane at 1 torr was detectable (Alarcon et al. 1987). The system also was operated (Chan et al. 1985) with fiber cables as long as $10 \mathrm{~km}$. Laser diodes of the InGaAsP type were run below the threshold current level as LEDs, and their emission wavelengths of 1.34 and $1.61 \mu \mathrm{m}$ neatly matched the NIR absorption bands of $\mathrm{CH}_{4}$. A similar technique was applied (Dakin et al. 1987) to sense $0.25 \% \mathrm{CH}_{4}$ in air over several kilometers, with a response time of $1.5 \mathrm{~s}$.

Samson et al. (1989) studied the feasibility of remote Raman spectrometry by optical fiber for the measurement of gas concentrations. Many advantages of Raman spectroscopy are found to be offset by its inherently weak nature. Experimental results were presented for mixtures of $\mathrm{CH}_{4}$, $\mathrm{N}_{2}$, oxygen, and $\mathrm{CO}_{2}$ at atmospheric pressure. Theoretical analysis showed that an incident wavelength exists that maximizes the detection of Raman light when optical fibers are used. Presently, the method is limited to short fibers.

An optical-fiber sensing system to monitor $\mathrm{CH}_{4}$ at a single point in underground coal mines has been constructed and tested (Samson and Stuart 1988). The system uses a white-light source, NIR-transmissive fibers, and 50-cm-path sensor cells at the fiber ends. The device was regularly calibrated and showed a close correlation with a conventional methanometer in the $0.2-1.5 \%$ range. To protect the device from dust, with its detrimental effects on the absorption, the device was covered with a gas-permeable membrane. The minimum detectable $\mathrm{CH}_{4}$ pressure depends, of course, on the fiber length and the operational wavelength.

Solvent Vapors. Vapors of polar solvents can be detected on-line by virtue of their decolorizing effect upon certain blue papers, as used in thermal printers (Posch et al. 1988). Typical vapors that can be detected include ethers, alcohols, esters, and ketones; while hydrocarbons and chlorinated hydrocarbons remain inert. Detection limits (with a device consisting of a yellow LED light source and a phototransistor as the detector) vary from 10 to $1,000 \mathrm{ppm}$, and both conventional flow-through cell sensing (via absorptiometry) and fiber-optic sensing (via reflectometry) were found to be applicable. Response times vary from 0.5 to $4 \mathrm{~min}$.

Certain triphenylmethane dyes, in combination with an acidic component such as bisphenol A, have an intense blue color that is decolorized in the presence of vapors of polar solvents (Dickert et al. 1988). The sensing layer was prepared by dissolving the lactone form of the dye and bisphenol $\mathrm{A}$ in polyvinyl chloride and casting it as a $1-\mu \mathrm{m}$ layer on a solid support. This 
membrane has been used to optically sense these species by placing it on either the distal end or the core of a waveguide. Detection limits as low as a few parts per million were reported. The method was also applied to sense polar solvents dissolved in water (Dickert et al. 1989). This sensing was achieved by covering the sensing membrane with a gas-permeable but water-impermeable membrane.

\subsubsection{Groundwater Monitoring}

Chloroform Probe. Studies have shown that groundwater from $33 \%$ of the hazardous waste sites in the United States is contaminated with chloroform (Plumb and Pitchford 1985; Plumb 1987). The combination of a FOCS for chloroform (based on fluorescence detection of a chloroform reaction product) and an associated field-portable fiber-optic fluorometer has been described in the literature (Milanovich et al. 1986b). The results of a preliminary field demonstration of a first-generation chloroform FOCS that uses a high-powered laser and photoncounting techniques have been published (Milanovich et al. 1986a). The portable fiber fluorometer system and the gas-phase chloroform FOCS have been used to characterize a chloroform-contaminated water-well field (Herron et al. 1989). This study was able to provide a good linear correlation between gas-phase chloroform concentrations near the water surface in the wells and the observed FOCS signal, and concentrations in the parts-per-billion range were detected for aqueous chloroform.

Additional studies have led to the development of a working device that has been tested in contaminated wells. The results were verified by independent analysis by GC-MS.

General Hydrocarbons. Some work has been reported on the use of FOCSs for the detection of hydrocarbons. In most cases where fiber optics are used, their purpose is to get the exciting light to the sample and the return signal to a spectral sorter so that wavelength information can be used for identification (Chan et al. 1987; Farahi et al. 1987). In addition, total internal optical scattering is reported (Guiliani and Jarvis 1984) for simple alkanes. Successful detection of hydrocarbons by using organophilic compounds on single and multimode fibers has been reported (Kawahara et al. 1983; EPA 1987). This process could improve the ability to perform analyses of the vadose zone and groundwater (Posch et al. 1988).

Fiber Chem, Inc. (Klainer 1993), is currently marketing a reversible hydrocarbon probe. The probe contains the FOCS and all of the signal-processing electronics. The probe operates in water, in air, or at the water-air interface and can measure concentration levels from percent to parts per billion.

Gasoline. The gasoline sensor (EPA 1988) can be used to monitor leaking underground storage tanks, spills, and the spaces between the walls of double-liner storage tanks. This 
capability is urgently needed because the contamination of drinking water and groundwater by gasoline leaking from underground storage tanks presents a considerable health hazard in the United States. Because this leakage directly relates to the availability of potable water, the need to monitor is acute. Early detection of leaking gasoline is imperative because such detection would not only protect the nation's water supplies but would also prevent costly cleanup operations and avoid heavy government penalties and fines. The EPA's program for underground storage tanks mandates that these tanks be monitored; however, the monitor must be reliable, inexpensive, easy to operate, and able to reversibly detect and quantify gasoline as a vapor, a liquid, or a water emulsion. While the use of FOCSs to detect gasoline and jet fuel has been demonstrated (EPA 1987), attempts to develop a gasoline sensor that meets the previously mentioned requirements have been unsuccessful (Leak-X Corp. 1988; Mallory Electronics Group 1988; Owens Corning Fiberglass Corp. 1988; Westinghouse Bio-Analytic System Co. 1988).

\subsection{Summary and Conclusions}

Technologies for measuring VOCs in soil and water are available and provide acceptable data. All technologies can, of course, be improved, with the general objectives of cheaper, faster, better, and safer. Improvements in VOC measurement are ongoing and will find their way into applications for the DOE's problems. Efforts at improvement need to be conducted with a solid understanding of the baseline of technologies currently available.

\subsection{References for Chapter 4}

Alarcon, M.C., et al., 1987, "All-Optical Remote-Sensing of City Gas through $\mathrm{CH}_{4}$ GasAbsorption Employing a Low-Loss Optical Fiber Link and an InGaAsP Light-Emitting Diode in the Near-Infrared Region," Applied Physics B: Photophysics and Laser Chemistry B43:79-83.

Chan, K., et al., 1985, "Ten-Kilometer Long Fiber-Optic Remote Sensing of Methane Gas by Near Infrared Absorption," Applied Physics B: Photophysics and Laser Chemistry B38:11-15.

Chan, K., et al., 1987, "All-Optical-Fiber-Based Remote-Sensing System for Near-Infrared Absorption of Low-Level $\mathrm{CH}_{4}$ Gas," Journal of Lightwave Technology 5:1706-1711.

Dakin, J.P., et al., 1987, "A Novel Optical Fibre Methane Sensor," International Journal of Optical Sensors 2:261-267.

Dickert, F.L., et al., 1988, "Substituted 3,3-Diphenylphthalides as Optochemical Sensors for Polar-Solvent Vapors," Analytical Chemistry 60:1377-1380.

Dickert, F.L., et al., 1989, "Fiber-Optic Dipping Sensor for Organic-Solvents in Waste-Water," Analytical Chemistry 61:2306-2309. 
DOE: See U.S. Department of Energy.

EPA: See U.S. Environmental Protection Agency.

Farahi, F., et al., 1987, "Optical-Fiber Flammable-Gas Sensor," Journal of Physics E: Scientific: Instruments E20:435-436.

Guiliani, J.F., and N.L. Jarvis, 1984, "Detection of Simple Alkanes at a Liquid Glass Interface by Total Internal Optical-Scattering," Sensors and Actuators 6:107-112.

Herron, N.R., et al., 1989, "Remote Detection of Organochlorides with a Fiber Optic Based Sensor: III. Calibration and Field Evaluation of an Improved Chloroform Fiber Optic Chemical Sensor," Analytical Instrumentation 18:107-126.

Hirschfeld, T., et al., 1981, presented at Pittsburgh Conference and Exposition on Analytical Chemistry and Applied Spectroscopy, sponsored by the Society for Analytical Chemists of Pittsburgh and the Spectroscopy Society of Pittsburgh, held in Atlantic City, N.J.

Hirschfeld, T., et al., 1983, "Feasibility of Using Fiber Optics for Monitoring Groundwater Contaminants," Optical Engineering 22:527-531.

Inaba, H., et al., 1984, "All-Optical Remote Gas Sensor System over a $20 \mathrm{~km}$ Range Based on Low-Loss Optical Fibers in the Near-Infrared Region," Proceedings of the Society of PhotoOptical Instrumentation Engineers 514:211-214.

Kawahara, F.K., et al., 1983, "Development of a Novel Method for Monitoring Oils in Water," Analytica Chimica Acta 151:315-327.

Klainer, S.M., 1993, "The Role of Fiber Optic Chemical Sensors," Environmental Lab 5:34.

Leak-X Corp., 1988, "Leak-X," Englewood Cliffs, N.J.

Lübbers, D.W., et al. (assigned to Max-Planck-Gesellschaft zur Foderung der Wissenschaften eV, Munich, Germany), 1977, Method and Arrangement for Measuring the Concentration of Gases, U.S. Patent 4,003,707, Jan. 18.

Mallory Electronics Group, 1988, "Pollulert," Indianapolis, Ind.

Milanovich, F.P., et al., 1986a, "Remote Detection of Organochlorides with a Fiber Optic Based Sensor," Analytical Instrumentation 15:137-147. 
Milanovich, F.P., et al., 1986b, "Remote Detection of Organochlorides with a Fiber Optic Based Sensor: 2. A Dedicated Portable Fluorimeter," Analytical Instrumentation 15:347-358.

O'Neil, R.A., et al., 1980, "Field Performance of a Laser Fluorosensor for the Detection of Oil Spills," Applied Optics 19:863-870.

Owens Corning Fiberglass Corp., 1988, "Hydrostatic Tank Monitor," Toledo, Ohio.

Plumb, R.H., Jr., 1987, "A Comparison of Ground Water Monitoring Data from CERCLA and RCRA Sites," Ground Water Monitoring Review 7:94-100.

Plumb, R.H., Jr., and A.M. Pitchford, 1986, "Volatile Organic Scans: Implications for Ground Water Monitoring," in Proceedings of the National Water Well Association/American Petroleum Institute Conference on Petroleum Hydrocarbons and Organic Chemicals in Ground Water, National Water Well Association, Dublin, Ohio, pp. 207-222.

Posch, H.E., et al., 1988, "Optical and Fibre-Optic Sensors for Vapors of Polar-Solvents," Talanta 35:89-94.

Saito, M., et al., 1988, "Optical Remote Sensing for Hydrocarbon Gases Using Infrared Fibers," Journal of Applied Physics 63:269.

Samson, P.J., and A.D. Stuart, 1988, "Coal Mine Methane Sensing by Optical Fibers," in Proceedings of the Australian Conference on Optical Fiber Technology, Hobart, Australia, Dec., p. 117.

Samson, P.J., et al., 1989, "Fiber Optic Gas Sensing Using Raman Spectrometry," presented at 14th Australian Conference on Fourier Transform Spectroscopy, Brisbane, Australia, Dec.

Stueflotten, S., et al., 1984, "An Infrared Fiber Optic Gas-Detection System," Proceedings of the Society of Photo-Optical Instrumentation Engineers 514:87-90.

Tai, H., et al., 1987, "Fiber-Optic Evanescent-Wave Methane-Gas Sensor Using OpticalAbsorption for the 3.392-Mu-M Line of a He-Ne-Laser," Optics Letters 12:437-439.

U.S. Department of Energy, 1993, Literature Search, Review, and Compilation of Data for Chemical and Radiochemical Sensors Task 1 Report, DOE/HWP-130, Hazardous Waste Remedial Actions Program, Oak Ridge, Tenn., Jan.

U.S. Environmental Protection Agency, 1983, The Feasibility of Using Fiber Optics for Monitoring Groundwater Contaminants, EPA DA-89-F-2A074, Washington, D.C. 
U.S. Environmental Protection Agency, 1987, Status Report on Design and Evaluation of Fiber Optics Toxic Chemical Analyzer, final draft report, contract 68-03-3224, Washington, D.C., Aug.

U.S. Environmental Protection Agency, 1988, A Fiber Optic Chemical Sensor (FOCS) for Monitoring Gasoline, EPA 600/X-88/259NV, Washington, D.C.

Westinghouse Bio-Analytic System Co., 1988, "Hydrocarbon Sensor System," Madison, Pa.

Wolfbeis, O.S. (editor), 1991, Fiber Optic Chemical Sensors and Biosensors, vols. 1 and 2, CRC Press, Boca Raton, Fla.

Zirino, A. (editor), 1985, Mapping Strategies in Chemical Oceanography, Advanced Chemistry Series 209, American Chemical Society, Washington, D.C. 


\section{Infrared and Raman Spectroscopy}

Current efforts at characterization and remediation of waste sites have created a demand for rapid, field-portable sensors that can identify and measure VOCs in soil and groundwater. Among the myriad types of sensors being evaluated, sensors based upon vibrational spectroscopic measurements stand out as gosd candidates for measuring VOCs, on the basis of the wellestablished use of vibrational spectroscopy for qualitative and quantitative analysis of organic compounds. This section provides an overview of vibrational spectroscopy, describes off-theshelf commercially available spectrometer systems that can be used for field measurements of VOCs, and surveys current research efforts that use vibrational spectroscopy to detect VOCs in soil, the vadose zone, or groundwater.

\subsection{Technical Background}

\subsubsection{Overview of Vibrational Spectroscopic Measurements}

Vibrational characterization of molecules is typically performed by IR spectroscopy or Raman spectroscopy. Although both spectroscopic methods provide qualitative and quantitative information, the information from each method is not identical because each monitors a different process at the molecular level. Infrared spectroscopy is a measure of the amount of IR radiation $(2.5-25 \mu \mathrm{m})$ absorbed by a given molectle at a particular IR excitation frequency or range of excitation frequencies. Absorption can only take place if the molecule can undergo a change in

dipole moment. The amount of IR light transmiticd after interaction with the molecule(s) is typically measured and then converted to absorbance information. In licu of a transmission measurement, the photoacoustic signal caused by molecular absorption can also be measured.

In contrast, Raman spectroscopy measures the light that is scattered by the molecule after irradiation with intense monochromatic excitation, typically provided by a UV, visible (VIS), or NIR laser. Much of the light is scattered elastically at the same frequency as the laser excitation. This type of scattering, referred to as Rayleigh scattering, does not provide useful spectroscopic information about the molecule; however, some of the exciting light is scattered inelastically at frequencies slightly higher and slightly lower than the Rayleigh scattering. Inelastic scattering is caused by induced polarization of bonding electrons because of the vibrational motion of the molecule; this phenomenon is referred to as the Raman effect. Raman spectroscopy measures these characteristic frequencies of inelastically scattered light and their associated magnitudes. The frequency positions of Raman spectral bands are commonly expressed relative to their frequency offset from the Rayleigh line.

Infrared and Raman spectroscopies are complimentary techniques for obtaining qualitative information about chemical structure, conformation, and morphology. Because the two methods have different selection rules, a distinct difference appears in the resulting spectra. Infrared spectra exhibit strong spectral features that correspond to more polar moieties of a molecule, whereas 
intense Raman spectral bands usually correspond to more nonpolar functional groups. Therefore, spectral bands that appear strong in a Raman spectrum are usually weak in an IR spectrum and vice versa; for example, groups such as S-S, C-S, and N-N are good Raman scalterers; however, these groups are weak IR absorbers. On the other hand, an O-H group is a strong IR absorber but a weak Raman scatterer. Therefore, Raman spectroscopy would be the preferred method for analyzing aqueous samples because water strongly absorbs IR light.

\subsubsection{Infrared Instrumentation}

A conventional IR spectrometer consists of an IR source, a spectral isolation device (such as a grating monochromator or light filter), a sample compartment, transfer optics, a detector, and an output device. The spectral isolation device is used to select the IR frequency to be passed through the sample. The selected frequency is passed through the sample, and the detector measures the amount of light that is transmitted after interaction with the sample. The grating or filter is then adjusted to observe a different IR frequency, and the measurement is repeated until the sample has been examined over the desired range of frequencies. Alternatively, the same measurements could be performed simultaneously by using an FTIR spectrometer. With an FTIR spectrometer, many frequencies from a broadband IR source are multiplexed sy an interferometer before passing through the sample. The detector then measures the amount of multiplexed light transmitted by the sample. A Fourier transform is then used to convert the digitized signal (intensity versus time) to a conventional IR spectrum (amplitude versus frequency).

Alternatively, the amount of IR absorption by a sample can be determined by IR photoacoustic spectrometry. The photoacoustic affect (PA), also known as the optoacoustic or acousto-optic effect, is the production of heat caused by absorption of IR energy. Photoacoustic IR instruments employ a modulated IR source that causes periodic heating and cooling of the sample. This process causes pressure waves in the sealed sample cell, which are then detected by a microphone or piezoelectric device. Because different samples absorb different IR frequencies, the resulting PA signal is characteristic of a given sample. Photoacoustic cells for both gases and solids are commercially available.

\subsubsection{Raman Instrumentation}

Most commercial Raman spectrometers consist of a UV, VIS, or NIR laser source, a sample compartment, a spectral isolation device (such as a grating), transfer optics, Rayleigh filters, a detector, and an output device. The grating, transfer optics, Rayleigh filters, and detector that are employed are directly dependent on the wavelength of the laser. After interaction with the laser, the scattered light is collected at some angle, typically $90^{\circ}$ or $180^{\circ}$, relative to the laser beam. The grating is then used to spatially disperse the scattered light according to frequency. By moving the grating and by using a slit, each frequency can be examined by the detector; however, using a two-dimensional array detector or a charge-coupled device (CCD) camera to look at the various frequencies in the focal plane of the grating simultaneously is also possible. In the NIR region, all 
frequencies can also be exaniined simultaneously by using a Fourier transform NIR Raman spectrometer. This spectrometer replaces the grating with an interferometer, which is used to multiplex the scattered light. The digitized detector signal is later demultiplexed by using the Fourier transform to yield an intensity spectrum. The placement of the Rayleigh filter differs from instrument to instrument; however, placement is one of the most critical elements. Because the intensity of the Rayleigh scattering is typically several orders of magnitude greater than the Raman scattering, the Rayleigh scattering must be removed by filtering to prevent swamping of the

detector. The detector always responds in the same spectral region as the laser excitation. Thus, a NIR source requires a NIR detector, a UV source requires a UV detector, and so on; however, the frequency positions of Raman spectral bands are expressed in terms of their frequency shift from the excitation frequency. Therefore, all sample matrix effects aside, a Raman spectrum collected with NIR excitation and a Raman spectrum collected with UV excitation will be very similar in terms of band positions and will differ only in band intensities.

\subsection{Survey of Infrared Techniques for Measuring Volatile Organic Compounds}

\subsubsection{Transmission Measurements of Infrared Absorption}

In general, IR spectroscopic measurements of VOCs have been gas-phase measurements performed with a long-path gas cell. A typical IR gas cell contains mirrors at each end that cause the IR light beam to pass multiple times through the gas within the cell. Although the physical length of most commercial cells is less than a meter, the effective path length through the cell can be up to tens of meters. The Beer-Lambert law, which states that absorbance is proportional to concentration multiplied by path length and molar absorptivity, makes apparent the fact that increasing the path length increases absorbance. Therefore, longer path lengths are typically used when working with very small concentrations of analyte.

Infrared spectroscopic measurements with long-path gas cells form the basis of a VOC detection technique being developed at Argonne National Laboratory, Argonne, Illinois (Clapper-Gowdy et al. 1992; Junk and Haas 1992; Demirgian et al. 1993). This technique was originally developed to identify and quantify explosives in soil on the basis of gas-phase FTIR spectroscopic measurements; however, this method can also be applied to VOCs in soil and soil gas, as well as to SVOCs and pesticides. For organics in soil, the measurement consists of placing a soil sample in a TD unit, which is evacuated and heated to $180^{\circ} \mathrm{C}$. The vaporized sample is collected into a variable-path-length, long-path gas cell for FTIR analysis. Spectral data consisting of 128 co-added scans at $0.1-\mathrm{cm}$ resolution are collected and stored for subsequent quantitative analysis by using the classic least-squares algorithm. Data collection takes approximately $1 \mathrm{~min}$, and the entire analysis takes approximately $10 \mathrm{~min}$. The method has been successfully applied to five VOCs and has achieved detection levels of 20-40 ppm. 
Other IR-based techniques have been reported; however, the details of these projects are few. Arrendale et al. (Junk and Haas 1992) have developed techniques for measuring VOCs in gas and water. These measurements apparently involve the use of UV-VIS-IR spectrophotometers and single-strand optical fibers for sampling liquid-phase samples. The technique has been used to detect BTX and iodine species in aqueous solutions. Chlorinated hydrocarbons in aqueous solution have been detected at levels of 1 milligram per liter $(\mathrm{mg} / \mathrm{L})$, and lower limits appear to be achievable. A different project conducted at Pacific Northwest Laboratory (PNL) also used IR detection of liquid-phase analytes (Junk and Haas 1992). In the PNL technique, samples are first extracted from soil by using supercritical fluid extraction and then are analyzed by a field-portable IR spectrometer. Analytes that have been examined include alkyl phosphates, a mixture of triglycerides, and $\mathrm{CCl}_{4}$. An additional project has shown the utility of FTIR detection combined with gas chromatography (GC/FTIR) and with gas chromatography and mass spectrometry (GC/FTIR/MS) for analysis of hazardous waste (Shafer et al. 1984). In both methods, the IR spectrum can be used for rapid qualitative identification of eluting peaks; however, the cost of these two techniques is a limiting factor.

\subsubsection{Photoacoustic Measurements of Infrared Absorption}

An interesting project conducted by McClelland (1993) at Ames Laboratory, Ames, Iowa, employs a commercially available photoacoustic FTIR gas analyzer to measure gas-phase VOCs (Jones et al. 1992; Junk and Haas 1992; McClelland 1993). The commercial instrument has been adapted for field measurements of trichloroethylene, 1,1,1-trichloroethane, $\mathrm{CCl}_{4}$, and other chlorinated hydrocarbons. These analytes can be quantitatively determined down to sub-parts-permillion levels, even after the analytes have been transported through $300 \mathrm{ft}$ of Teflon-lined polyethylene tubing. The analysis time for each sample, including purging of the sample cell, is approxinat ly $2 \mathrm{~min}$. Details of the commercial analyzer are presented in Section 5.4.

\subsection{Survey of Raman Techniques for Measuring Volatile Organic Compounds}

Raman spectroscopy, combined with fiber-optic sampling, has been found to be particularly useful for detecting and monitoring VOCs in groundwater. Investigators at EIC Laboratories, Inc. (Norwood, Massachusetts), are developing a small, suitcase-sized fiber-optic surface-enhanced Raman spectrometer that can be easily transported to the field and used to screen for both organic and metallic pollutants in groundwater (Carrabba et al. 1988, 1991, 1992; Junk and Haas 1992). The spectrometer uses a diode laser, a coarse Echelle diffraction grating, and a CCD detector array. This instrumental configuration combines the advantages of no moving parts and high optical throughput to produce a rugged spectrometer that provides good sensitivity. Fiber-optic probes are used to perform surface-enhanced Raman spectroscopy (SERS) of analyte molecules adsorbed to the surface of an electrode contained in the end of the probe assembly. The SERS measurement produces a dramatic increase in Raman scattering intensity, which ultimately provides better analyte detection limits. The increase in scattering intensity is dependent on the roughness and other scattering properties of the metallic substrate to which the analyte is adsorbed. 
Therefore, two different analytes may require two different electrode materials to achieve optimal sensitivity; this factor increases cost and complexity for environmental survey applications. The need for multiple types of probes to optimally measure different analytes can be justified only from the standpoint of selectivity. If a target analyte is known a priori, selecting an electrode that provides optimal sensitivity while discriminating against certain interferences from other adsorbed species should be possible. EIC Laboratories, Inc., has tested fiber-optic SERS probes with gold, silver, and copper electrodes. A proprietary biphase SERS substrate has also been employed. The SERS instrument has been used successfully to detect and identify chlorinated hydrocarbon solvents.

The use of SERS for real-time subsurface monitoring is also being investigated at Oak Ridge National Laboratory (ORNL), Oak Ridge, Tennessee. The ORNL research has demonstrated the use of SERS under harsh conditions and has developed a method for tailoring SERS substrates for optimal performance at particular excitation wavelengths. The ORNL project has used SERS to detect $\mathrm{CCl}_{4}$ and trichloroethylene in groundwater (Junk and Haas 1992). A collaborative effort between GAMMA-METRICS (Selph et al. 1992) and T. Vo-Dinh at ORNL has produced a portable SERS analyzer for toxic chemicals. The prototype instrument has undergone field trials, and a design for a commercial version of the instrument has been developed. The spectrometer uses a diode laser, a double monochromator, and a single-element detector or an optional detector array. Data acquisition times are expected to be on the order of a few seconds to $10 \mathrm{~min}$, depending on the analyte and required operating parameters. Fiber-optic SERS measurements of trace-level organic and inorganic contaminants are also being conducted at Lawrence Livermore National Laboratory, Livermore, California; further details on this work are not available (Junk and Haas 1992).

Other Raman instruments that are not based on SERS and have not been directly applied to VOC measurement have been reported. Vess and Angel (1992) have developed a spectrometer for multipoint process monitoring. This spectrometer can measure the light input from up to 10 fiberoptic probes simultaneously. A near-visible laser is used for excitation, and optical multiplexing is rovided via CCD detection. McCreery (1992) has described the development of a remote fiber-optic Raman spectrometer that employs a diode laser and CCD detector.

\subsection{Survey of Commercial Instruments}

Presently, no commercial, field-portable Raman instruments are available for measuring VOCs; however, EIC Laboratories, Inc., and GAMMA-METRICS (San Diego, California) are both working on instruments that may soon be available. Off-the-shelf IR instruments exist that might be adapted for downhole measurements of VOCs in soil gas. The newest members in the line of MIRAN ${ }^{\mathrm{TM}}$ ambient air analyzers produced by the Foxboro Co. (East Bridgewater, Massachusetts) are possible candidates. The newest analyzers, the MIRAN 1B2 and the MIRAN $1 \mathrm{BX}$, are functionally equivalent; however, the $1 \mathrm{BX}$ has an explosion-proof IR source and is approved by OSHA for use in Class I, Division I hazardous locations where flammable gases may be present. The units weigh approximately $14 \mathrm{~kg}(31 \mathrm{lb})$ and are designed to be held by a handle or transported with a shoulder strap. The approximate dimensions of the analyzers are 
$71 \mathrm{~cm} \times 23 \mathrm{~cm} \times 28 \mathrm{~cm}(28$ in. $\times 9$ in. $\times 11$ in. $)$. Each analyzer is a single-beam IR spectrometer equipped with a variable-path-length $(0.75-20 \mathrm{~m})$ gas sample cell. Samples are drawn into the 3.4-L gas sample cell by an internal pump at a rate of $25-30 \mathrm{~L} / \mathrm{min}$. The same pump is also used to flush the sample cell. In the current configuration, a 3-ft section of corrugated polyethylene tubing is externally attached to the analyzer pump, thereby allowing the operator to "probe" an area of interest. I ower is provided by a rechargeable nickel-cadmium battery pack that provides four hours of continuous operation. Extra battery packs or an ac/dc converter is required for extended operation. Each analyzer is controlled by a microprocessor that provides interactive operation via an external keyboard and liquid crystal display (LCD).

The spectrometer uses a Nichrome wire IR radiation source and a pyroelectric lithium tantalate substrate detector. Analytical wavelengths are selected by a three-segment $(2.5-4.3 \mu \mathrm{m}$, 4.3-7.7 $\mu \mathrm{m}$, and 7.7-14.1 $\mu \mathrm{m}$ ) circular variable filter. Path length through the sample cell is adjusted automatically by the analyzer for each particular analysis. The variable path length allows measurement of both low concentrations in parts per million and higher concentrations in percent. With longer path lengths, many gases can be measured at sub-parts-per-million levels. Measurement parameters for over 100 different target analytes are programmed into the microprocessor's memory. The operator simply inputs the code for a selected target gas or vapor; and the microprocessor adjusts the instrumental parameters, performs a scan, and presents concentration data on the LCD display. Product specifications listing typical instrumental parameters and the corresponding nominal detection limits for analytes such as trichloroethylene and perchloroethylene are presented in Table 5.1 (MIRAN 1B2 Portable Ambient Air Analyzer) (Foxboro Co. 1992). Additional target gases to those in the memory can also be programmed by the user. Unknown gases can be identified by sending a spectrum collected by the analyzer to a laptop computer equipped with Spectra/Match software for spectral library search. The advantages of this turnkey analyzer also include minimal training time of field personnel. Currently, the cost of the MIRAN 1B2 analyzer is approximately $\$ 19,000$, and the cost of the MIRAN 1BX analyzer is approximately $\$ 20,000$. The Spectra/Match software for either unit can be purchased for $\$ 2,500$.

The MIRAN 1B2 and 1BX analyzers are reasonably compact and portable, and they are commonly used in a variety of industrial and commercial scenarios for ambient air monitoring and leak detection. A report by Devitt et al. (1987) suggests that a MIRAN analyzer could also be used for the detection of VOCs in soil gas. This report listed the MIRAN 1A, an earlier model of analyzer with manual adjustments, as a candidate instrument. As sold commercially, the sample-collection systems employed by the MIRAN 1A and the newer, microprocessor-controlled $1 \mathrm{~B} 2$ and $1 \mathrm{BX}$ analyzers are not directly suitable for downhole continuous monitoring of soil gases at waste and remediation sites. Downhole measurements require longer sampling lines and a pumping system that can transport samples over longer distances. These modifications to the sample-collection system would allow these newer MIRAN analyzers to be evaluated as tools for field screening and analysis of VOCs.

Another off-the-shelf analyzer that has been successfully demonstrated is the IR PA instrument manufactured by B\&K (Denmark). The use of a B\&K analyzer for the detection of 
TABLE 5.1 Reported Product Specifications for MIRAN $1 B 2$ for Two Example Vapors

\begin{tabular}{lccc}
\hline $\begin{array}{c}\text { Target } \\
\text { Compound }\end{array}$ & $\begin{array}{c}\text { Analytical } \\
\text { Wavelength }(\mu \mathrm{m})\end{array}$ & $\begin{array}{c}\text { Path Length } \\
(\mathrm{m})\end{array}$ & $\begin{array}{c}\text { Minimum Detection } \\
\text { Limit }(\mathrm{ppm})\end{array}$ \\
\hline Trichloroethylene & 10.84 & 0.75 & 3.00 \\
Perchloroethylene & 11.10 & 2.25 & 0.60 \\
\hline
\end{tabular}

Source: Adapted from Foxboro Co. (1992).

VOCs in soil gas has been demonstrated by McClelland (1993) (see Section 5.2.2). Currently, two models of B\&K analyzers are available; the B\&K 1301 analyzer weighs approximately $18 \mathrm{~kg}$ (approximately $40 \mathrm{lb}$ ) and has dimensions of $20.5 \mathrm{~cm} \times 43 \mathrm{~cm} \times 50 \mathrm{~cm}$ (approximately 8 in. $\times 17$ in. $\times 20$ in.); the B\&K 1302 version weighs about $9 \mathrm{~kg}$ (approximately $20 \mathrm{lb}$ ) and has dimensions of $17.5 \mathrm{~cm} \times 39.5 \mathrm{~cm} \times 30 \mathrm{~cm}$ (approximately 7 in. $\times 16$ in. $\times 12$ in.). Both analyzers are IR spectrometers that employ PA detection; however, the B\&K model 1301 is a single-beam FTIR spectrometer, whereas the B\&K model 1302 is a filter-based single-beam IR spectrometer. The B\&K 1302 employs multiple IR optical filters mounted on a filter carousel to select the analytical wavelength and a mechanical chopper to modulate the IR source. Modulation is provided by the interferometer in the $B \& K 1301$. At present, the approximate cost of the $B \& K$ 1301 is $\$ 37,900$; and the approximate cost of the B\&K 1302 with five optical filters is $\$ 26,100$.

Both models have a fixed-path-length gas cell with a volume of approximately $3 \mathrm{~mL}$. The PA signal is measured by two microphones mounted in the gas cell. Dual microphones are used to compensate for any instrumental vibrations or temperature fluctuations. Both models also contain an internal pump that is used to both purge and fill the sample cell at a maximum rate of $30 \mathrm{~mL} / \mathrm{s}$. The power requirement for both analyzers is $100-127 \mathrm{~V}$ ac. The display and front panel on the two units are quite different. In addition to a keypad for user interaction, the B\&K 1301 has a small cathode-ray tube (CRT) screen and a floppy disk drive in lieu of the simpler digital display on the B\&K 1302.

The $\mathrm{B} \& \mathrm{~K} 1301$ can provide quantitative monitoring for up to seven gases simultaneously; however, this limit seems to be caused by software restrictions. Because the B\&K 1301 records an entire spectrum, a quantitative analysis for a larger number of compounds should be possible with different software. The $B \& \mathrm{~K} 1302$ provides quantitative analysis for up to five components and water vapor simultaneously; however, this restriction is caused by hardware. The filter wheel in the B\&K 1302 holds six filters, one of which is used for determining water vapor in a gas sample. The other five filters are selected by the user for optimal measurement of particular target gases. Different filters would be required for optimal monitoring of a different set of five target analytes. 
For purposes of comparison, the detection limits obtainable with the B\&K 130)? trichloroethylene and perchloroethylene are presented in Table 5.2 (B\&K 1993). Although the detection limits at only one analytical wavelength are shown in Table 5.2, choosing other analytical wavelengths is often possible for a given target compound; however, in some cases, this freedom from interferences may be obtained at the cost of sensitivity. The detection limits in Table 5.2 represent the best reported values obtained at the optimal analytical wavelength for both compounds with the B\&K 1302 analyzer.

\subsection{References for Chapter 5}

B\&K: See Bruel \& Kjaer.

Bruel \& Kjaer, 1993, "Gas Detection Limits," product specifications BG 0552-12, Denmark.

Carrabba, M.M., et al., 1988, "The Suitability of Surface Enhanced Raman Spectroscopy (SERS) to Fiber Optic Chemical Sensing of Aromatic Hydrocarbon Contamination in Groundwater," in First International Symposium: Field Screening Methods for Hazardous Waste Site Investigations, EPA/600/D-89/189, L.R. Williams (editor), U.S. Environmental Protection Agency, Environmental Monitoring Systems Laboratory, Las Vegas, Nev., pp. 31-40.

Carrabba, M.M., et al., 1991, "Spectroelectrochemical Sensing of Chlorinated Hydrocarbons for Field Screening and In Situ Monitoring Applications," in Proceedings of the Second International Symposium: Field Screening Methods for Hazardous Wastes and Toxic Chemicals, Air and Waste Management Association, Pittsburgh, Pa.

Carrabba, M.M., et al., 1992, "Spectroelectrochemical Technologies and Instrumentation for Environmental and Process Monitoring," in Environmental and Process Monitoring Technologies: 20-22 January 1992, Los Angeles, California, T. Vo-Dinh (editor), SPIE proceedings series 1637, Society of Photo-Optical Instrumentation Engineers, Bellingham, Wash., p. 82.

Clapper-Gowdy, M., et al., 1992, A Quantitative Method to Detect Explosives and Selected Semivolatiles in Soil Samples by Fourier Transform Infrared Spectroscopy, ANL/CP-76749, Argonne National Laboratory, Argonne, Ill.

Demirgian, J.C., et al., 1993, "Identification and Quantitation of Volatile Organics in Soils by Use of Fourier Transform Infrared (FTIR) Spectroscopy," presented at the National Symposium on Measuring and Interpreting VOCs in Soils: State of the Art and Research Needs, sponsored by the U.S. Environmental Protection Agency, Washington, D.C., held in Las Vegas, Nev., Jan.

Devitt, D.A., et al., 1987, Soil Gas Sensing for Detection and Mapping of Volatile Organics, National Water Well Association, Dublin, Ohio. 
TABLE 5.2 Reported Product Specifications for the B\&K 1302

\begin{tabular}{ccc}
\hline $\begin{array}{c}\text { Target } \\
\text { Compound }\end{array}$ & $\begin{array}{c}\text { Center of Optical } \\
\text { Filter Band-Pass } \\
(\mu \mathrm{m})\end{array}$ & $\begin{array}{c}\text { Detection } \\
\text { Limit } \\
(\mathrm{ppm})\end{array}$ \\
\hline Trichloroethylene & 10.6 & 0.2 \\
Perchloroethylene & 10.6 & 0.03 \\
\hline
\end{tabular}

Source: Adapted from B\&K (1993).

Foxboro Co., 1992, "MIRAN 1B2 Portable Ambient Air Analyzer Product Specifications," PSS 6-5A1 D, East Bridgewater, Mass.

Jones, R.W., et al., 1992, "On Site Infrared Analysis for Complex Systems," in Proceedings of the Information Exchange Meeting on Characterization, Sensors, and Monitoring Technologies, Conf.-920791, U.S. Government Printing Office, Washington, D.C., July.

Junk, G.A., and W.J. Haas, Jr., 1992, Technology Projects for Characterization-Monitoring of Volatile Organic Compounds (VOCs), Ames Laboratory, Ames, Iowa.

McClelland, J.F., 1993, "Field Analysis of VOCs by Photoacoustic Detection" (poster), presented at the National Symposium on Measuring and Interpreting VOCs in Soils: State of the Art and Research Needs, sponsored by the U.S. Environmental Protection Agency, Washington, D.C., held in Las Vegas, Nev., Jan.

McCreery, R.L., 1992, "Remote, High Sensitivity Raman Spectroscopy with Fiber Optics, Diode Lasers and CCD Spectrometers," in Environmental and Process Monitoring Technologies: 20-22 January 1992, Los Angeles, California, T. Vo-Dinh (editor), SPIE proceedings series 1637 , Society of Photo-Optical Instrumentation Engineers, Bellingham, Wash., p. 208.

Selph, W., et al., 1992, "Portable Surface Enhanced Raman Toxic Chemical Analyzer Development," in Environmental and Process Monitoring Technologies: 20-22 January 1992, Los Angeles, California, T. Vo-Dinh (editor), SPIE proceedings series 1637, Society of Photo-Optical Instrumentation Engineers, Bellingham, Wash., p. 180.

Shafer, K.H., et al., 1984, "Analysis of Hazardous Waste by Fused-Silica Capillary Gas-Chromatography Fourier-Transform Infrared Spectrometry and Gas-Chromatography Mass-Spectrometry," Analytical Chemistry 56:237-240. 
Vess, T.M., and S.M. Angel, 1992, "Near-Visible Raman Instrumentation for Remote Multi-Point Process Monitoring Using Optical Fibers and Optical Multiplexing," in Environmental and Process Monitoring Technologies: 20-22 January 1992, Los Angeles, California, T. Vo-Dinh (editor), SPIE proceedings series 1637, Society of Photo-Optical Instrumentation Engineers, Bellingham, Wash., p. 118. 


\section{Electrochemical Sensors}

Electrochemical sensors have been developed to measure ions and gases and have found wide application as biosensors in the areas of biochemical and clinical chemistry (Janata 1989). This review of the technology examines the electrochemical detection of gases as it relates to the determination of VOCs in the subsurface. Electrochemical sensors can be classified as potentiometric, amperometric, or conductimetric according to the influence of the analyte on the voltage, current, or conductance, respectively, of an electrochemical cell. Measurements of gases can be made with electronic conducting polymers, semiconductors, and amperometric devices. Most electrochemical sensors are passive in that they do not alter the analyte; however, during amperometric measurements, the analyte is oxidized or reduced. To be detected, the gases must elicit an electrochemical response; however, most VOCs are electrochemically inactive and must be converted to electroactive reaction products (e.g., carbon monoxide [CO], $\mathrm{Cl}_{2}$, hydrogen chloride $[\mathrm{HCl}]$, or hydrogen fluoride $[\mathrm{HF}]$ ) by using pyrolytic techniques before detection.

\subsection{Basic Principles}

Amperometric gas sensors have been used to identify and quantify electroactive species in aqueous and gas phases (Cao et al. 1992). In amperometry, the current generated in an electrochemical cell between a working (sensing) and counter (auxiliary) electrode is measured at a fixed or pulsed potential. The counter electrode is a reference and cannot be penetrated by the analyte, while the sensing electrode is easily accessible to the analyte gas. An electrolyte, which can be in aqueous solution or in solid form (like porous ceramic zirconium oxide), separates the two electrodes (Wong 1992). A low-impedance external electrical circuit connects the two electrodes, and a diffusion barrier controls diffusion to the sensing electrode. For gas-phase analytes, the unique interfacial transport processes frequently control the response of the sensor; for example, if a reducing, reactant gas diffuses through a liquid electrolyte to the sensing electrode, a shift in potential in the cathodic direction is produced, creating a potential difference between the two electrodes and causing a current to flow in the external circuitry. Platirum (Pt) or enzyme electrodes accelerate the process by acting as electrocatalysts, while electrodes such as the silver-silver chloride or lead-lead oxide electrodes are consumed. For amperometric sensors with solid electrolytes, the reference and sample cells are separated by a porous solid material that has a high conductivity for an ionized gas. The partial pressure of the gas in the sample side of the cell is reduced from the ambient levels that are present in the reference cell. Migration of the ionized gas in the reference side will pick up ions at the solid, with the voltage giving an indication of the concentration of the gas. The selectivity of amperometric sensors for various gases can be adjusted by choosing the geometry for gas exposure and electrolyte confinement, the appropriate materials for electrodes, and the electrochemical method (fixed potential or pulsed potential). The systems contain low-cost components, are small, and consume very little power.

Other types of electrochemical gas sensors include the solid-state sensors such as the sintered-metal-oxide semiconductor sensor (Wong 1992). When a gas comes in contact with the surface of a semiconductor, the difference in energy levels between the adsorbed gas and the semiconductor surface results in a transfer of electrons. If a gas with a high electron affinity is 
adsorbed, electrons will travel from the semiconductor to the adsorbed gas, leading to a decrease in conductivity. The sensor is fabricated from sintered, powdered tin oxide to produce many grain boundaries between individual crystals. The adsorption of oxygen creates potential barriers at the grain boundaries and reduces the conductivity of the semiconductor. Because the partial pressure of oxygen in ambient air is nearly invariant, the conductivity of the semiconductor can be kept constant by controlling the temperature of the crystal. The adsorption of reducing or combustible VOCs to the surface of the semiconductor increases the electron density in the space charge layer and decreases the potential barriers at the grain boundaries. The increase in conductivity of the sensor can be related to the concentration of the gas.

The metal-oxide semiconductor (MOS) sensor is a transistor in which the conduction between the source and drain is modified by a charge or potential on the gate electrode (Lundstrom 1981; Lundstrom and Soderberg 1981/1982; Wong 1992). This sensor can also be considered a capacitor in which one electrode is the gate and the other electrode is the channel. A charge on the gate induces a charge in the channel, which modifies its conductivity. If the charge or potential of the gate is altered (e.g., by the adsorption of a gas molecule), the conduction of the channel will be altered. These changes can be detected as electrical signals and processed. Changes in the channel conduction are induced by adsorbed gases via several different mechanisms. The gas can chemically interact with the gate material and change its carrier concentration, the gas can induce dipole moments in the gate and alter the potential gradients at the gate-oxide interface, or the gas can form a chemical cell between the gate and the oxide. The MOS sensor is nonspecific and must be operated at an elevated temperature. Many studies have been performed on the $\mathrm{H}_{2}$-sensitive MOS gas sensor (i.e., MOS-capacitor or MOSFET), which has an $\mathrm{H}_{2}$ sensitivity of less than 0.1 ppm (Lundstrom 1981; Lundstrom and Soderberg 1981/1982).

\subsection{Applications}

Sensors employing electronic conducting polymers as sensing devices have been used to measure VOCs (Tourillon and Garnier 1982; Diaz and Kanazawa 1983). These substrates exhibit fast reversible changes in conductivity when exposed to gases or vapors at room temperature (Miasik et al. 1986; Bartlett and Ling-Chung 1989a). Organic and inorganic semiconductors have also been used to measure hydrocarbons; however, to increase the range of gases to which electrochemical sensors are sensitive, converting the VOCs to electroactive reaction products before detection is sometimes necessary. The conversion has been accomplished with high-temperature filaments (Stetter et al. 1984; Heiland and Kohl 1985; Otagawa and Stetter 1987) and reagents reacting at room temperature (Bott and Jones 1985) and has been tested by using primarily amperometric gas sensors. The following discussion is a brief review of investigations that have

contributed to advancements in the detection of VOCs by semiconductor and amperometric devices.

Boyle et al. (1989) examined the use of polyaniline films for the determination of levels of several gases. The properties of the conducting polymer film depended upon the doping level, the ion size of the doping agent, the solvent of synthesis, the protonation level, and the water content. The polymer is electrochemically deposited on gold electrode probes to a thickness of $50 \mathrm{~mm}$. The 
largest response was obtained for polar molecules, primarily methanol and ethanol. Weaker responses were obtained for acetone and acetonitrile, with no response for benzene. The lower limit of detection for methanol was about $1 \mathrm{ppm}$.

Bartlett and Ling-Chung (1989b) fabricated gas sensors from four different conducting polymers: polypyrrole, poly- $N$-methylpyrrole, poly-5-carboxyindole, and polyaniline. The sensors were fabricated by electrochemical deposition of the monomers across a 12-mm gap between two gold microband electrodes. Of the four polymers tested, poly-5-carboxyindole gave the most stable, reproducible response. Responses to methanol, ethanol, acetone, ether, and toluene were rapid (40-60 s) and reversible at $25^{\circ} \mathrm{C}$.

Parcher et al. (1989) used a conducting polymer film to fabricate an electrochemical gas chromatographic detector. A film of polyethylene oxide (PEO) and lithium triflate $\left(\mathrm{PEO}_{16}-\mathrm{LiCF}_{3} \mathrm{SO}_{3}\right)$ was coated on a microelectrode-based electrochemical cell. The detector operates on the principle that currents passed at the electrode-polymer interface depend on the reaction of electroactive solutes in the polymer phase. The response of the detector depends on the diffusion of the gaseous solute in the film and on the plasticizing effect that the solute partitioning has on the diffusion rate of an electroactive probe (ferrocene-carboxylic acid) in the polymer (Barbour et al. 1991). Gaseous solutes sorb into and plasticize the PEO polymer phase, resulting in larger diffusion coefficients and larger microelectrode currents. When a sufficient potential is applied to oxidize the ferrocene-carboxylic acid probe, currents flowing at the microelectrode are governed by the concentration of ferrocene and its diffusion rate in the polymer, making the process completely analogous to electrochemical voltametry. The response is dependent on changes in the diffusion rate of the electroactive probe. The forms of electrochemical potential control are the nature of the electroactive probe, the probe's concentration, the thickness of the polymer film, the concentration of the gaseous sample, and the partitioning properties of the gaseous solutes and polymer. The system was tested with methanol, ethanol, propanol, butanol, $n$-pentane, toluene, methylene chloride, acetonitrile, and pyridine.

Phthalocyanine semiconductors have a high sensitivity for a narrow range of strongly electrophilic gases such as nitrogen dioxide $\left(\mathrm{NO}_{2}\right)$ and $\mathrm{Cl}_{2}$ (Diaz and Kanazawa 1983). These semiconductors are sensitive to gaseous analyte concentrations as low as several parts per billion but are insensitive to commonly occurring gases such as water vapor, $\mathrm{CO}_{2}, \mathrm{CO}$, and many hydrocarbons. Unwin and Walsh (1989a) used a lead phthalocyanine (PbPc) film for a conductimetric sensor to detect chlorinated hydrocarbons. Chlorinated hydrocarbons were pyrolyzed over a heated Pt coil and exposed to tilms of PbPc supported on alumina substrates. The products of electroactive pyrolysis were $\mathrm{Cl}_{2}, \mathrm{HCl}$, and carbonyl chloride $\left(\mathrm{COCl}_{2}\right)$. $\mathrm{The}_{2} \mathrm{Cl}_{2}$ concentration produced via pyrolysis of the chlorinated organics and the response of $\mathrm{PbPc}$ were relatively insensitive to temperature when the $\mathrm{Pt}$ coil was operated at $700^{\circ} \mathrm{C}$ or above. At $180^{\circ} \mathrm{C}$, the interaction of the analyte with the $\mathrm{PbPc}$ film is completely reversible and capable of measuring concentration. Below $100^{\circ} \mathrm{C}$, the interaction is irreversible, and the sensor is most applicable to exposure monitoring. The response was reversible and decreased from 30 to $8 \mathrm{~min}$ over the range of $180-275^{\circ} \mathrm{C}$. The response of the sensor to chlorinated hydrocarbons increases in the order of $1,1,1$-trichloroethane $<$ trichloroethylene $<$ tetrachloroethylene according to the amount of $\mathrm{Cl}_{2}$ produced on decomposition. Interferents included nitrogen- and fluorine (F)-containing gases. By 
cycling the coil temperature, the response of the sensor to these gases can be minimized. The stability of the device is dependent on the conversion efficiency of the Pt coil and the reproducibility of the interaction between $\mathrm{Cl}$ and the polymer surface. Both of these processes can be affected by interferents generated during pyrolysis, which can poison the Pt catalyst or affect the polymer surface. The sensor cannot distinguish between $\mathrm{Cl}, \mathrm{F}$, and $\mathrm{NO}_{2}$.

Transducer Research, Inc. (TRI 1992a), has developed a VOC sensor that is based on a mechanism involving a change in room-temperature conductivity of thin films of $\mathrm{C}$ particles (Buttner and Stetter 1993). The sensor operates between temperatures of $-40^{\circ} \mathrm{C}$ and $+45^{\circ} \mathrm{C}$. The device exhibits a rapid response of 10-20 s that is reversible, with a recovery time of 10-20 s. The lower detection limit is about $100 \mathrm{ppm}$. The sensor responds nonselectively to chlorinated organics, aromatic compounds (e.g., BTX), and other volatile compounds. The precision of the response is about $25 \%$ within a range of $100-2,500 \mathrm{ppm}$. The power requirement is low, and a single lithium battery will operate the circuitry for over six months. The exposed lifetime is estimated to be several weeks.

Transducer Research, Inc. (TRI 1992b), has also developed a solid-state, crystalline salt ( $\mathrm{RCl}$ ) sensor for organic vapors containing $\mathrm{Cl}$. The $\mathrm{RCl}$ sensor responds to compounds such as $\mathrm{CCl}_{4}$, tetrachloroethylene, trichloroethylene, 1,1,1-trichloroethane, chloroform, dichloromethane, methyl chloride, and chlorobenzene in air directly and responds in water by using a silicone permeator (Buttner and Stettr.r 1993); however, the sensor cannot speciate the chlorinated organics because the mechanism of detection is a change in the high-temperature conductivity of the crystalline salt upon exposure to the pyrolyzed $\left(500-750^{\circ} \mathrm{C}\right)$ organic vapor. The relative sensitivity of the $\mathrm{RCl}$ sensor for electronegative species follows the order: $\mathrm{Cl}>$ bromine $\gg \mathrm{F}$, iodine $>>$ ail others. The sensor is sensitive to $\mathrm{HCl}$ but insensitive to $\mathrm{Cl}_{2}$ and $\mathrm{HF}$. The response is rapid $(30-60 \mathrm{~s})$ and reversible, with a recovery time of $60 \mathrm{~s}$ that is dependent on concentration. The lower detection limit is less than $1 \mathrm{ppm}$ and approaches $0.2 \mathrm{ppm}$; however, detection limits of $500 \mathrm{ppb}$ for trichloroethylene in field applications have been observed and approach $100 \mathrm{ppb}$. The operating range of the sensor in atmospheres containing chlorinated organics is $0.2-100 \mathrm{ppm}$, with an optimum between 0.2 and $25 \mathrm{ppm}$. The precision is $10 \%$. The sensor exhibits a nearly constant response for over 1,000 part per million-hours (ppm-h); and the lifetime, when exposed, is $1,000-2,000 \mathrm{ppm}-\mathrm{h}$. The unit weighs $2 \mathrm{~kg}$ and is $22 \mathrm{~cm} \times 13 \mathrm{~cm} \times 6 \mathrm{~cm}$, with an external $3-\mathrm{kg}$ battery/power control unit that operates for six to eight hours on a single charge (TRI 1992b).

Hornik (1990) combined a Pt-coil catalyst with a palladium (Pd)-MOS sensor to detect gases such as trichloroethylene, acetone, isobutane, $n$-hexane, chloroform, and ethyl ether. The MOS gas sensors are typically heated to about $250^{\circ} \mathrm{C}$ and, as a result, are only responsive to $\mathrm{H}_{2}$ and several hydrocarbons (e.g., acetylene) and alcohols such as ethanol. By combining the MOS sensor with a Pt catalyst that can be operated at temperatures of more than $1,100^{\circ} \mathrm{C}$, Hornik (1990) was able to make the MOS sensor sensitive to a more extensive group of hydrocarbons and to increase its sensitivity by keeping the sensor at $100-190^{\circ} \mathrm{C}$. The selectivity of the device originates from operating the catalyst at different threshold temperatures for the gases. Formation of $\mathrm{HCl}$ was found to interfere with the detection of chloroform and trichloroethylene. The sensitivity of the device for $n$-hexane was about $20 \mathrm{ppm}$. 
Amperometric gas sensors have also found wide application for detecting VOCs (Cao et al. 1992). Stetter et al. (1984) demonstrated that electrochemically inactive compounds such as cyclohexane, chloroform, tetrachloroethylene, and benzene can be detected and identified by these devices if the compounds are exposed to heated $\mathrm{Pt}$ or gold filaments before being introduced to a sensor. These investigators used three-electrode type sensors with platinum-black reference and counter electrodes and a sensing electrode made of platinum black, powdered gold, or vapordeposited $\mathrm{Pt}$ or gold on porous tetrafluoroethylene membranes. The liquid electrolyte was a sulfuric acid solution of 25-30 weight percent. Conversion of the substances to electroactive species required that the $\mathrm{Pt}$ filament be heated to $800^{\circ} \mathrm{C}$ or $1,050^{\circ} \mathrm{C} \pm 50^{\circ} \mathrm{C}$ and the gold filament to $950^{\circ} \mathrm{C} \pm 50^{\circ} \mathrm{C}$. The composition and temperature of the filament were observed to have a major effect on the response. Responses were proportional to concentration in the 0-50-ppm range and were usually in the $0-200-p p m$ range. The lower detection limits for cyclohexane, chloroform, tetrachloroethylene, and benzene were $2.3 \mathrm{ppm}, 0.8 \mathrm{ppm}, 1 \mathrm{ppm}$, and $3 \mathrm{ppm}$, respectively.

Using the theoretical basis presented by Zaromb and Stetter (1984) for the selection and effective use of arrays of chemical sensors to measure and identify mixtures of gases, Stetter et al. (1986) fabricated a microprocessor-controlled device, the chemical parameter spectrometer, containing an array of amperometric gas sensors that were adjusted to respond differently to electrochemically reactive substances. Two heated noble-metal filaments of Pt and rhodium (Rh) were used to convert the gases to electroactive products. The system contained four unique electrochemical sensors operated in four different modes (Stetter et al. 1986). Techniques of pattern recognition were used to identify the analytes. The sensitivity of the device to a mixture of benzene, cyclohexane, $\mathrm{CCl}_{4}$, chloroform, toluene, and tetrachloroethylene was about 20-300 ppm.

Unwin and Walsh (1989b) developed a sensor that was based on the pyrolysisamperometry technique, in which organic vapors are pyrolyzed on heated catalytic elements and are detected as their electroactive products $\left(\mathrm{CO} ; \mathrm{Cl}_{2}\right)$ by amperometric electrochemical cells. The heated filaments, or pellistors, were operaied at $700^{\circ} \mathrm{C}$. Six noble metals and 10 metal oxides were investigated, from which aluminum oxide, zinc oxide, $\mathrm{Rh}$, gold, $\mathrm{Pd}$, and $\mathrm{Pt}$ at $645^{\circ} \mathrm{C}$ (CO cell) and $\mathrm{Rh}$ at $665^{\circ} \mathrm{C}\left(\mathrm{Cl}_{2}\right.$ cell $)$ were chosen to detect nonsubstituted and chlorinated hydrocarbons, respectively. The performance of the device was tested with a mixture of acetone, $m$-xylene, toluene, trichloroethylene, cyclohexane, and benzene. The response times for the unsubstituted and chlorinated hydrocarbon sensors were 1 and $3 \mathrm{~min}$, respectively. The limit of detection was about $10 \mathrm{ppm}$. The lifetime of the resistance heating element was extended and temperature control was improved by using temperatures lower than $700^{\circ} \mathrm{C}$.

Komiya and Kimura (1990) developed an amperometric gas seusor for freons and other chlorinated hydrocarbons that consisted of an electrically heated $\mathrm{Pt}$ coil for pyrolysis at $600^{\circ} \mathrm{C}$ and gas membrane galvanic cells that operated at room temperature for detection of $\mathrm{HCl}, \mathrm{HF}$, and $\mathrm{Cl}_{2}$. The $\mathrm{HCl}$ and $\mathrm{Cl}_{2}$ sensors were specific, while the $\mathrm{HF}$ sensor also responded to acidic gases such as $\mathrm{HCl}, \mathrm{Cl}_{2}$, sulfur dioxide, and $\mathrm{NO}_{2}$. Hydrogen sulfide interfered with the operation of the $\mathrm{HCl}$ sensor. The degree of sensitivity of the $\mathrm{HCl}$ sensor to freons was proportional to the number of $\mathrm{Cl}$ atoms. For other chlorinated hydrocarbons, the response of the $\mathrm{HCl}$ sensor increases in the following order: tetrachlorethylene $<$ trichloroethylene $<1,1,2$-trichloroethane $<1,1,1$-trichloroethane. The response was fairly linear for concentrations up to $100 \mathrm{ppm}$, except 
for 1,1,2-trichloroethane, which was saturated at $100 \mathrm{ppm}$. Sensitivity was generally at the partsper-million level.

The identification of individual compounds in gas mixtures by the pyrolysis-amperometry technique has been accomplished without the use of sensor arrays by employing various modulating techniques with single-filament/sensor combinations. The advantages of this system include faster response, greater dynamic range, and the ability to carry both quantitative and qualitative information about several species on a waveform-type output. The temperature of the catalytic filament may be modulated periodically by using triangular-wave (Otagawa and Stetter 1987) or square-wave (Maclay et al. 1989) power inputs, or the filament can be maintained at a constant temperature and the gas concentration modulated (Stetter et al. 1990). The rate of the chemical reaction at the catalytic filament depends on the type of analyte and its concentration and also on the activity and temperature of the catalyst. The concentration of the reaction products is changed by varying the temperature of the catalyst or the residence time of the analyte in the reactor. The method is successful if the chemical reactions that the species are undergoing have different activation energies. The magnitude of the signal at peaks and valleys is directly proportional to concentration, even though a steady state is not attained when the device is operated in this mode. Transient, rather than steady-state, signals were processed to identify and quantify the gases. Stetter et al. (1990) improved the design by employing a catalytic microreactor in which frequency and amplitude-modulated concentrations can be produced. Vaihinger et al. (1991) produced a step-functional change of the gas concentration in a catalytic inicroreactor instead of using periodic modulations. Stationary gas streams are switched between th: reference and sample gas by magnetic valves, producing a step-functional change of the gas concentration at the sensor. The response function can be evaluated by using exponential functions. The time-constant parameters of the functions are selective for a specific gas and are independent of concentration.

\subsection{Summary}

Electrochemical sensors are fast, sensitive, inexpensive, and able to be miniaturized. Commercial vendors are listed in Table 6.1. Times for response and recovery are most often less than $1 \mathrm{~min}$, and the interaction of the analyte with the surface is most often completely reversible. In general, the operating range of electrochemical sensors is about $500 \mathrm{ppb}$ to $1,000 \mathrm{ppm}$, with sensitivities as low as 100 ppb being reported. Reproducibilities of $10 \%$ have been observed. Electrochemical sensors are also small in size; for example, the TRI VOC sensor has a diameter of $1 \mathrm{~cm}$ and is $2 \mathrm{~mm}$ thick, with a detection circuitry that is about $3 \mathrm{~cm} \times 5 \mathrm{~cm}$; however, the associated power supply for remote operation of some sensors employing pyrolyzers is large but not cumbersome. Electrochemical sensors are relatively inexpensive; for example, the TRI RCl sensor costs $\$ 250$.

Electrochemical detection of VOCs does, however, suffer some analytical difficulties. For many sensors, the VOCs must be pyrolyzed before detection to produce electroactive species. Matrix effects can be severe. Also, to identify specific compounds, arrays of sensors have to be 
TABLE 6.1 Commercial Vendors of Electrochemical Sensors

\begin{tabular}{|c|c|}
\hline Developer or Supplier & Address/Telephone No. \\
\hline City Technology Ltd. & $\begin{array}{l}\text { City Technology Centre } \\
\text { Walton Road } \\
\text { Portsmouth, England } \\
\text { PO } 61 \text { SZ } \\
\text { Phone: } 0703 \quad 325511 \\
\text { Fax: } 070538661\end{array}$ \\
\hline $\begin{array}{l}\text { Drager, National } \\
\text { Draeger, Inc. }\end{array}$ & $\begin{array}{l}\text { 101 Technology Dr. } \\
\text { P.O. Box } 120 \\
\text { Pittsburgh, PA } 15230 \\
\text { Phone: (412) } 787-8383 / 8389 \\
\text { Fax: (412) } 787-22.07\end{array}$ \\
\hline Gaztech International Corp. & $\begin{array}{l}\text { 6489-A Calle Rd. } \\
\text { Goleta, CA } 93117 \\
\text { Phone: }(805) \quad 964-1699 \\
\text { Fax: } \quad(805) \quad 964-2129\end{array}$ \\
\hline Teledyne Analytical Instruments & $\begin{array}{l}16830 \text { Chestnut St. } \\
\text { City of Industry, CA } 91749 \\
\text { Phone: }(818) 961-9221 \\
\text { Fax: } \quad(818) 961-2538\end{array}$ \\
\hline Transducer Research, Inc. & 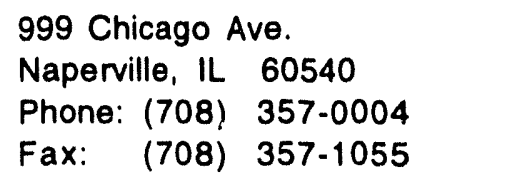 \\
\hline
\end{tabular}

used; or for single-filament/sensor combinations, the concentration of the ircoming gas stream or the temperature of the pyrolyzing filament must be modulated. All of these predetection operations add to the complexity of the technique.

\subsection{References for Chapter 6}

Barbour, C.J., et al., 1991, "Evaluation of a Theory for the Sensitivity and Selectivity of a Polymer Diffusion-Plasticization Based Solid-State Electrochemical Gas Chromatography Detector," Analytical Chemistry 63:604-610.

Bartlett, P.N., and S.K. Ling-Chung, 1989a, "Conducting Polymer Gas Sensors: Part II. Response of Polypyrrole to Methanol Vapour," Sensors and Actuators 19:141-150. 

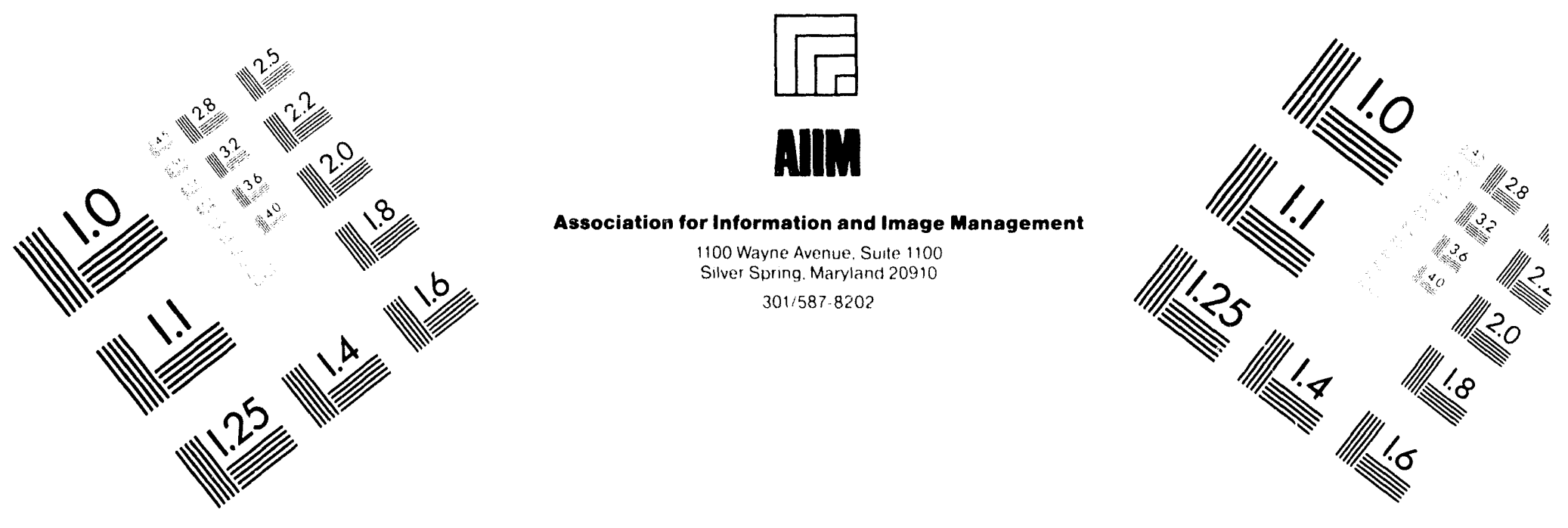

\section{Centimeter}

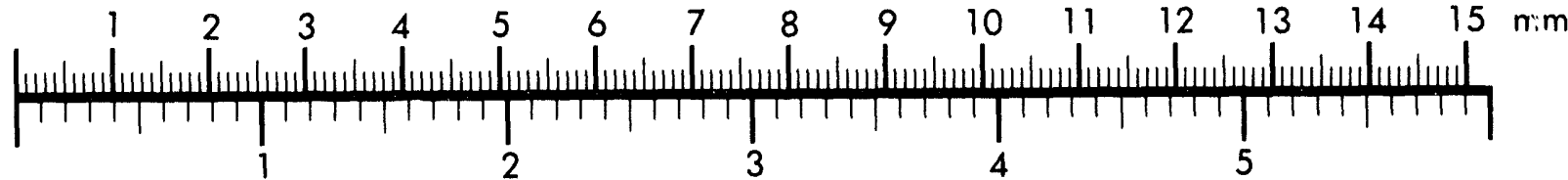
Inches
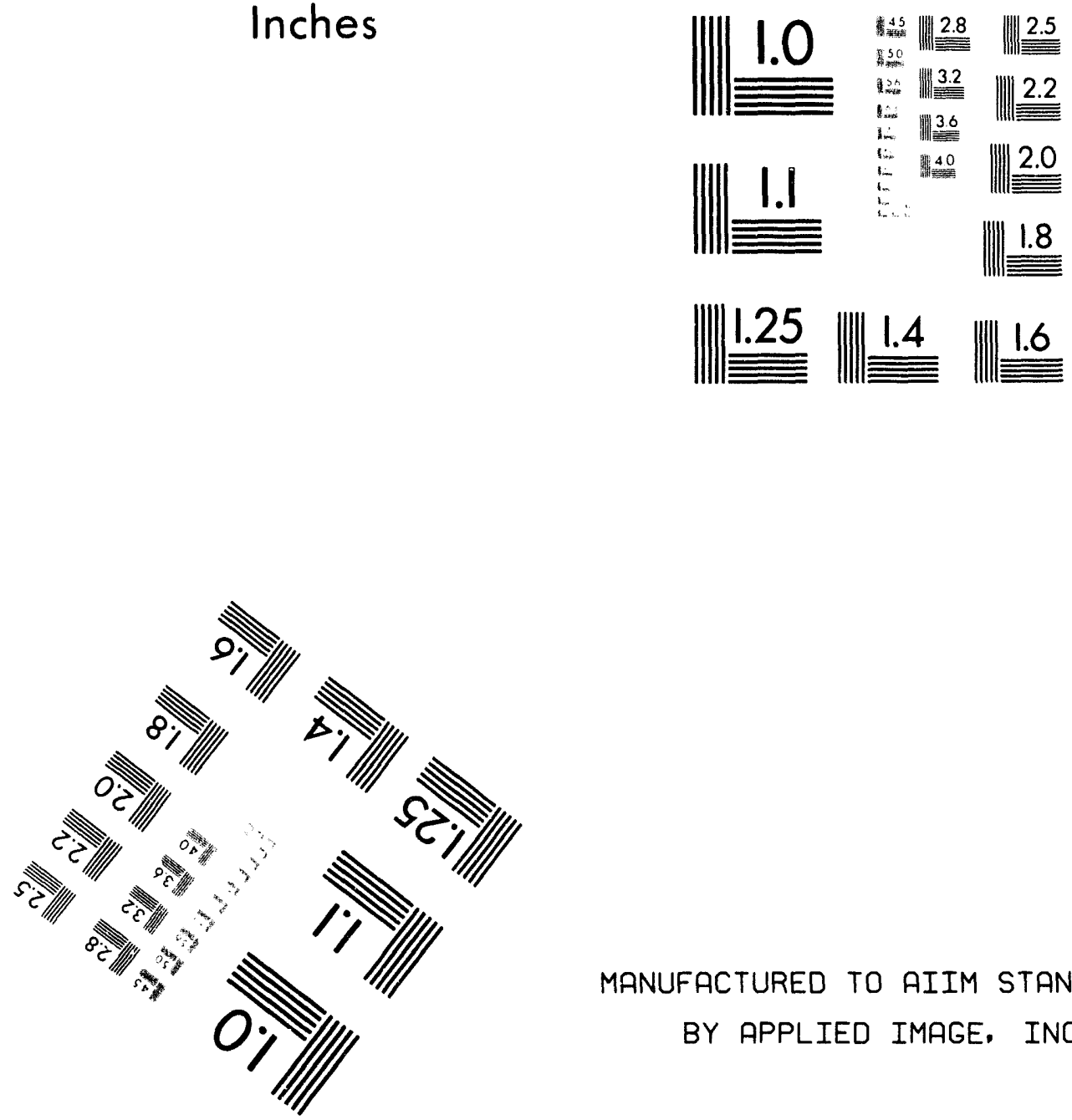

MANUFACTURED TO AIIM STANDARDS

BY APPLIED IMAGE, INC.

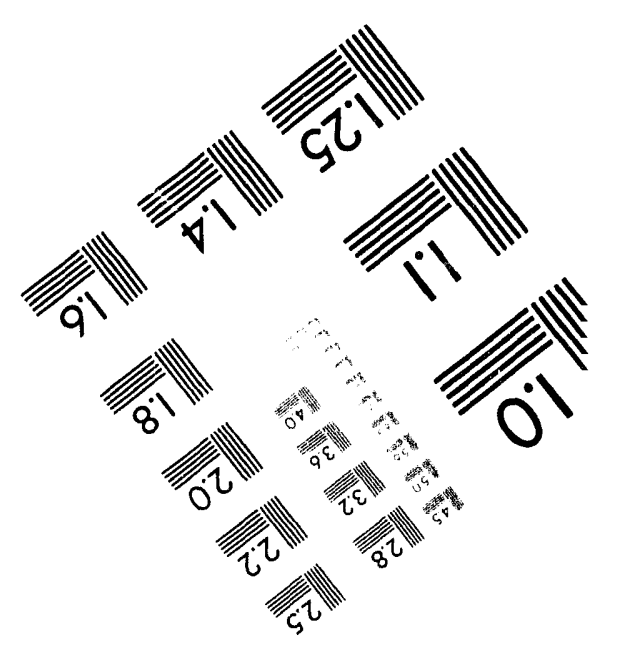



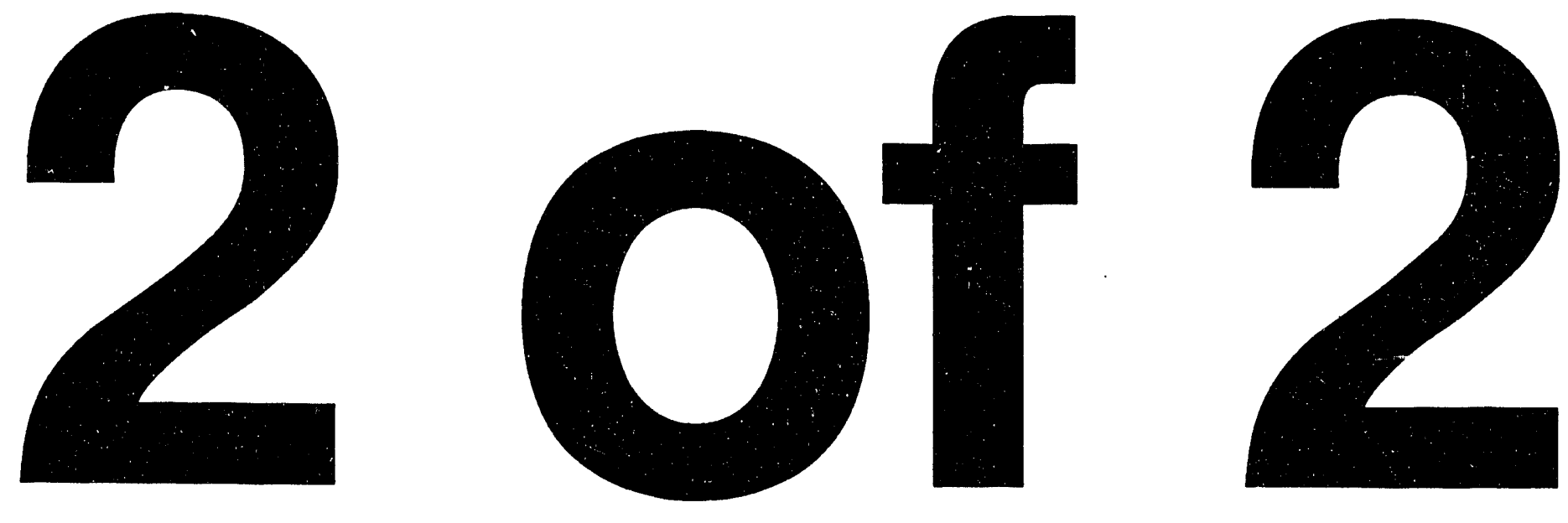
Bartlett, P.N., and S.K. Ling-Chung, 1989b, "Conducting Polymer Gas Sensors: Part III: Results for Four Different Polymers and Five Different Vapours," Sensors and Actuators 20:287-292.

Bott, B., and T.A. Jones, 1985, "The Use of Multisensor Systems in Monitoring Hazardous Atmospheres," in Proceedings of the Third International Conference on Solid-State Sensors and Actuators (Transducers '85), Philadelphia, Pa., June 11-14, pp. 128-131.

Boyle, A., et al., 1989, "Application of Electronic Conducting Polymers as Sensors: Polyaniline in the Solid State for Detection of Solvent Vapours and Polypyrrole for Detection of Biological Ions in Solutions," Synthetic Metals 28:C769-C774.

Buttner, W.J., and J.R. Stetter, 1993, Chemical Sensors for the Site Characterization and Analysis Penetrometer System (SCAPS): Sensors for the U.S. Army Environmental Center Site Characterization and Analysis Penetrometer System (SCAPS), Denver, Colo., May 11-13.

Cao, Z., et al., 1992, "The Properties and Applications of Amperometric Gas Sensors," Electroanalysis 4:253-266.

Diaz, A.F., and K.K. Kanazawa, 1983, Extended Linear Chain Compounds, vol. 3, J.S. Miller (editor), Plenum Press, New York, N.Y., p. 417.

Heiland, G., and D. Kohl, 1985, "Problems and Possibilities of Oxidic and Organic Semiconductor Gas Sensors," Sensors and Actuators 8:227-233.

Hornik, W., 1990, "A Novel Structure for Detecting Organic Vapours and Hydrocarbons Based on a Pd-MOS Sensor," Sensors and Actuators B1:35-39.

Janata, J., 1989, Principles of Chemical Sensors, Plenum Press, New York, N.Y.

Komiya, H., and S. Kimura, 1990, "Freon and Halogenated Hydrocarbon Detection with Electrochemical Sensors," Sensors and Actuators B 1:68-72.

Lundstrom, I., 1981, "Hydrogen-Sensitive MOS Structures: Part 1. Principles and Applications," Sensors and Actuators 1:403-426.

L.undstrom, I., and D. Soderberg, 1981/1982, "Hydrogen-Sensitive MOS Structures: Part 2. Characterization," Sensors and Actuators 2:105-138.

Maclay, G.J., et al., 1989, "Use of Time-Dependent Chemical Sensor Signals for Selective Identification," Sensors and Actuators 20:277-285. 
Miasik, J.J., et al., 1986, "Conducting Polymer Gas Sensors," Journal of the Chemical SocietyFaraday Transactions 82:1117-1126.

Otagawa, T., and J.R. Stetter, 1987, "A Chemical Concentration Modulations Sensor for Selective Detection of Airborne Chemicals," Sensors and Actuators 11:251-264.

Parcher, J.F., et al., 1989, "Solid-State Voltametry and Polymer Electrolyte Plasticization as a Basis for an Electrochemical Gas Chromatographic Detector," Analytical Chemistry 61:584-589.

Stetter, J.R., et al., 1984, "Monitoring of Electrochemically Inactive Compounds by Amperometric Gas Sensors," Sensors and Actuators 6:269-288.

Stetter, J.R., et al., 1986, "Detection of Hazardous Gases and Vapors: Pattern Recognition Analysis of Data from an Electrochemical Sensor Array," Analytical Chemistry 58:860-886.

Stetter, J.R., et al., 1990, "Sensor Array and Catalytic Filament for Chemical Analysis of Vapors and Mixtures," Sensors and Actuators B1:43-47.

Tourillon, G., and F. Garnier, 1982, "New Electrochemically Generated Organic Conducting Polymers," Journal of Electroanalytical Chemistry 135:173-178.

Transducer Research, Inc., 1992a, "A Selective Solid-State Detector for Chlorinated Hydrocarbons and Hydrogen Chloride in Air and Water," TRI product literature, Naperville, Ill.

Transducer Research, Inc., 1992b, "Case Study of the Chlorinated Organic Vapor (RCl) Monitor's Application in Hanford, Washington," TRI product literature, Naperville, Ill.

TRI: See Transducer Research, Inc.

Unwin, J., and P.T. Walsh, 1989a, "An Exposure 1.fonitor for Chlorinated Hydrocarbons Based on Conductometry Using Lead Phthalocyanine," Sensors and Actuators 18:45-57.

Unwin, J., and P.T. Walsh, 1989b, "Monitoring Organic Vapours Using PyrolysisAmperometry," Sensors and Actuators 17:575-581.

Vaihinger, S., et al., 1991, "Detection of Halogenated and Other Hydrocarbons in Air: Response Functions of Catalyst/Electrochemical Sensor Systems," Sensors and Actuators B4:337-343.

Wong, J.Y., 1992, "Performance Comparison among Various Types of Commercially Available Gas Sensors," in Gaztechnology Digest, vol. 1, Gaztech International Corp., Goleta, Calif. 
Zaromb, S., and J.R. Stetter, 1984, "Theoretical Basis for Identification and Measurement of Air Contaminants Using an Array of Sensors Having Partly Overlapping Selectivities," Sensors and Actuators $r: 225-243$. 


\section{Piezoelectric Sensors}

Piezoelectric devices have been developed to measure a wide range of organic compounds (Alder and McCallum 1983; Guilbault and Jordan 1988; Fox and Alder 1989; McCallum 1989). This review of the technology examines the piezoelectric detection of VOCs. The development of the various types of piezoelectric sensors is summarized, and a brief discussion of their application is presented.

\subsection{Basic Principles}

Piezoelectricity is produced by applying pressure to a crystal of dielectric material that does not possess a center of symmetry (Cady 1946). The applied pressure deforms the crystal lattice, causing a separation of the centers of gravity of oppositely charged species and producing a dipole moment in each molecule. An electrical potential forms between the deformed surfaces. Application of a voltage to the crystal produces physical distortions, and the crystal will vibrate mechanically for short periods until physical equilibrium is attained. Changing the mass of the crystal changes its resonant frequency; the greater the mass, the lower the frequency.

The development of microbalances from piezoelectric crystals was based upon the observation that perturbations in the resonant frequency of the crystals caused by very small changes in their inertia could be measured very accurately. The Sauerbrey equation (Bastiaans 1988) describes the relationship between the mass of thin metal films deposited on quartz crystals and the corresponding change in resonant frequency of the crystal:

$$
\Delta m=-2.3 \times 10^{-6} \Delta F \cdot A \cdot F_{0}{ }^{-2} \text {, }
$$

where

$$
\begin{aligned}
\Delta m & =\text { the mass change on the surface of the crystal }(\mathrm{g}), \\
\Delta F & =\text { the frequency change associated with the mass change (hertz }[\mathrm{Hz}]), \\
F_{0} & =\text { the initial resonant frequency of the piezoelectric crystal (megahertz [MHz]), and } \\
A & \left.=\text { the area of gas-sensitive surface (square centimeters }\left[\mathrm{cm}^{2}\right]\right)
\end{aligned}
$$

The theoretical sensitivity of a quartz crystal microbalance can be derived from Equation 7.1; for example, the sensitivities for a $9-\mathrm{MHz}$ and a $15-\mathrm{MHz}$ crystal would be about $400 \mathrm{~Hz} / \mathrm{mg}$ and $2,600 \mathrm{~Hz} / \mathrm{mg}$, respectively, resulting in a theoretical limit of detection of about $1 \times 10^{-12} \mathrm{~g}$ (Guilbault and Jordan 1988). 
Several types of crystals have been used to fabricate piezoelectric devices: quartz, lithium niobate, zinc oxide, tellurium oxide, and lithium tantalate (Fox and Alder 1989). Alpha quartz is the most commonly used because of its insolubility in water and the stability of its physicochemical properties up to temperatures of $579^{\circ} \mathrm{C}$. The resonant frequency of the quartz depends upon its physical dimensions and the thickness of the electrode that is deposited on its surface. Nine-megahertz AT- or BT-cut quartz (the designation refers to the orientation of the plate with respect to the crystal structure) is typically used in the form of disks, squares, or rectangles having surface areas of 10-16 square millimeters $\left(\mathrm{mm}^{2}\right)$ and thicknesses of $0.15 \mathrm{~mm}$ (Guilbault and Jordan 1988). Gold, silver, aluminum, or nickel electrodes are fabricated microlithographically from a thin metal film that is $v$. 1-evaporated onto the polished piezoelectric substrate in circles of $3-8 \mathrm{~mm}$ in diameter and thicknesses of 1,000-2,000 angstroms. The resonant frequency is determined with a frequency counter that is attached to the output of an oscillator circuit.

Several types of piezoelectric sensors are available: the bulk acoustic-wave (BAW) sensor. the SAW sensor, the flexural plate-wave (FPW) or Lamb-wave sensor, and the shear horizontal acoustic-plate mode (SH APM) sensor. In a BAW device, the resonant frequency of the whole crystal is monitored, while SAW devices monitor waves occurring within one or two acoustic wavelengths of the surface of the solid. The waves can also have an associated electric field if the material is piezoelectric. The waves are generated with an interdigital transducer electrode (IDT). A radio frequency (rf) voltage is applied to the electrodes, and a synchronously varying Rayleigh surface wave is generated in the substrate. The wavelength is determined by the spacing of the electrodes. The lower and upper frequency limits for a practical SAW device are about $10 \mathrm{MHz}$ and 3 gigahertz $(\mathrm{GHz})$, respectively.

The surface of the substrate must be very smooth to prevent energy loss from wave scattering at imperfections (Wohltjen 1984). Optically polished surfaces are adequate. The sensitivity and size of SAW delay oscillator sensors are directly related to their resonant frequency. A sensor operating at $3 \mathrm{GHz}$ exhibits frequency shifts 10,000 times greater than a $30-\mathrm{MHz}$ device for the same mass loading; however, the signal-to noise ratio for the $3-\mathrm{GHz}$ device would also be higher, leading to a shift that is less than 10,000 times greater. The area of the device is also dependent on the frequency. The reduction in the area of the device results in a corresponding reduction in the minimum detectable change in mass. In theory, a $3-\mathrm{GHz}$ sensor with $0.0001 \mathrm{~cm}^{2}$ of area will be able to detect $1 \times 10^{-12} \mathrm{~g}$ of material (Wohltjen 1984).

The SAW and BAW devices are both mass-sensitive and use a shift in resonant frequency as the indicating signal; however, several major differences are found between the two types of sensors. A SAW device operates at frequencies two orders of magnitude higher than a BAW device and therefore is more sensitive. The planar geometry of the SAW device allows it to be rigidly mounted and therefore more rugged than BAW devices. Also, SAW devices are microsensors and occupy volumes as small as $1 \times 10^{-9} \mathrm{~L}$; consequently, multiple SAW sensors can be mounted close together on the same substrate, allowing temperature drift compensation with a reference device. Equation 7.1 appears to indicate that a BAW sensor is the more sensitive device because a greater signal is obtained for a given frequency and mass loading; however, fabricating a BAW sensor with a resonant frequency greater than $15 \mathrm{MHz}$ is difficult because the small crystal thickness that is necessary makes the sensor very fragile. The SAW devices that 
operate in the range of $300 \mathrm{MHz}$ to $3 \mathrm{GHz}$ are easy to fabricate; and because the operating frequency is higher than that of a BAW device, their sensitivity is higher; for example, a $300-\mathrm{MHz}$ SAW device would produce a frequency shift 200 times greater than a $15-\mathrm{MHz}$ BAW sensor under identical mass-per-unit-area loadings (Wohltjen 1984). Another significant difference between the BAW and SAW devices is that the active surface of BAW crystals is the electrode surface; whereas for SAW crystals, the active surface is the quartz. The SAW sensors have found the widest application because of their small size $(<0.1$ cubic centimeters), ruggedness, low cost, electronic output, sensitivity, and adaptability to a wide variety of vapor-phase analytical problems.

Flexural plate-wave or Lamb-wave sensors have also been used for microgravimetry (Wenzel and White 1990). Flexural plate waves can be generated in and travel in thin composite plates of zinc oxide and aluminum and silicon nitride. Compared with BAW and SAW devices, the FPW device is more sensitive to added mass while operating at significantly lower frequencies, usually a few megahertz. Also, the FPW sensor can be operated in liquids because the electronics can be isolated from the surrounding media. The gravimetric sensitivity of acoustic-wave oscillators is inversely proportional to the mass per unit area of a characteristic region of the device. Therefore, to increase sensitivity, the mass of the region must be decreased with respect to the perturbing mass. The FPW device gets its high sensitivity and low operating frequency from its thinness.

The SH APM sensor has been developed for use in liquids (Martin et al. 1989; Andle et al. 1992). The BAWs are selectively excited and received in an acoustic-plate mode (APM) sensor by IDTs that have been photolithographically deposited onto the surface of a piezoelectric crystal plate. In SAW devices, the acoustic vibrations have displacement components perpendicular to the crystal surface that generate waves in the adjacent fluid. The concomitant loss of acoustic energy into the fluid will attenuate the waves and severely hamper use in fluids. The excited acoustic waves in APMs have distinctly different directions of propagation and displacement. The displacements may be predominantly in the propagation direction (longitudinal APMs) or perpendicular to the direction of propagation (shear APMs). The SH APMs, the ones that have displacements predominantly parallel to the crystal surface, are of the most interest. The SH APMs can be excited selectively by a choice of IDT periodicity, plate thickness, and excitation frequency to minimize energy loss to the fluid. The surface of the device can be coated with ligands that can bind species from solution. So far, these devices have not been tested to determine VOCs in aqueous solution.

\subsection{Applications}

Piezoelectric crystals are sensitive to mass and lack specificity to chemical substances; however, chemical vapor monitors can be fabricated from the crystals if a nonvolatile coating with which chemical substances can selectively interact is applied to the surface of the crystal (Wohltjen and Dessy 1979a,b; Wohltjen 1984). The interaction can be via physisorption or chemisorption. Chemisorption can be selective, but the binding process is irreversible. The SAW devices with coatings that chemically sorb analytes are best applied in dosimetric applications. Physisorption is reversible; however, because the energy of adsorption is low, the selectivity for analytes 
possessing similar physicochemical properties is poor. Many of the coatings for SAW devices are derived from stationary phases that are routinely used in GC. The interaction between common volatile subsurface contaminants and these phases is primarily caused by physical, not chemical, sorption. The polarizability of the common VOCs does vary somewhat with the degree of halogen substitution or the presence of conjugated double bonds; however, these substances are separated during GC primarily by differences in boiling point and because the piezoelectric crystals are operated at a single temperature. The specificity and resolution that are present in GC are not realized when these coatings are used on SAW devices. Consequently, the specificity of the coating materials to many VOCs is not very good.

Coatings can be applied by several different methods. In the simplest procedure for application, the coating material is dissolved in a suitable volatile solvent, applied to the surface as a drop from a syringe or pipette, and allowed to evaporate. Occasionally, spinning the crystal to expedite the evaporation is helpful. Other methods of coating include brush coating, where a solution of the material is painted onto the crystal's face; spray coating, in which an aerosol of the coating solution is prepared; electrochemical deposition; and plasma polymerization. The coating must be even and its mass kept to a minimum so that the crystal is not prevented from vibrating and producing stable resonance. Investigators have etched the surface of piezoelectric crystals to improve the quality and selectivity of covalently bound material coatings (Thompson et al. 1991). The degree of etching does not significantly change the surface morphology relative to the acoustic wavelength. The etching process improves selectivity by reducing nonspecific interactions through improved homogeneity of the surface with respect to the specific surface functional groups of interest in the analyte-receptor interactions.

Developers and suppliers of piezoelectric-based gas sensors are listed in Table 7.1. A brief discussion of the coatings that have been used on SAW devices to detect hydrocarbons and oi the detection limits and linear ranges of the devices is presented. Powdered activated charcoal, polyethylene glycol (PEG-400, PEG-750), quadrol, and tetrabase have been used to detect nitrobenzene with a 15-MHz quartz crystal (Sanchez-Pedreno et al. 1986). A linear response from 2-10 ppm (volume) (ppmv) was found. Charcoal was the most reproducible and had the best sensitivity, but the response was primarily nonlinear, with a narrow linear range of 0.7-7.6 ppmv. A limitation of charcoal is the nonspecificity of its interactions with organic compounds. Sensitivity increased in the following sequence: tetrabase < quadrol < PEG-400 < PEG-750. Several VOCs have been detected with Carbowax 20M, Pluoronic L-64, and squalene (Edmonds and West 1980). The sensitivities of SAW devices coated with these materials are reported in Table 7.2. Toluene has also been detected with a SAW device coated with Pluoronic F-68 (Ho et al. 1983). The sensor exhibited a linear range of 1-200 ppm. Interferences included benzene, $p$-xylene, ethylbenzene, and mesitylene. Toluene vapor has also been measured by using a SAW device coated with Carbowax 550 (Ho et al. 1980). The instrument had a linear range of 30-300 ppm, and interferences from benzene and alkylbenzenes were noted. Carbowax 1000 has been used to determine mononitrotoluene at $3 \mathrm{ppb}$ to $7.5 \mathrm{ppm}$, with a detection limit of $3 \mathrm{ppb}$ (Tomita et al. 1979). Interferences included chloroform, which, at high concentrations, led to dissolution of the coating. 
TABLE 7.1 Developers and Suppliers of Piezoelectric-Based Sensors

Developer or Supplier and Location

Application

Microsensor Systems

Bowling Green, Ky.

Femtometrics

Costa Mesa, Calif.

Amerasia Technology Inc.

Westlake Village, Calif.

Universal Sensors

Metairie, La.

Xsensor

Delft, the Netherlands

Vaisala

Finland

Ciba-Geigy

Basel, Switzerland

Sandia National Laboratories

Albuquerque, N.M.

Ames Laboratory

Ames, lowa
SAW detectors with gas chromatographs for industrial hygiene and environmental control

SAW sensors for measurement of ozone and detection of airborne particulates

Prototype SAW sensors for detection of explosives such as TNT and RDXa

BAW sensors with and without coatings for R\&D use and for several sensing applications

SAW and FPW sensors and their support electronics in integrated circuit form

SAW devices as dew-point sensors

SAW sensors for internal process control applications

SAW detectors used with gas chromatograph to measure VOCs

BAW and SAW sensors for gaseous species (e.g., combustion gases, formaldehyde)

a RDX, Cyclonite; and TNT, 2,4,6-trinitrotoluene.

Source: Adapted from Bastiaans et al. (1993). 
TABLE 7.2 Representative Sensitivities for SAW Devices Coated with Various Substrates

\begin{tabular}{llc}
\hline \multicolumn{1}{c}{ Analyte } & Substrate & $\begin{array}{c}\text { Sensitivity } \\
\left(\mathrm{mg} \mathrm{m}^{-3} \mathrm{~Hz}^{-1}\right)\end{array}$ \\
\hline Chloroform & Carbowax 20M & 115 \\
Ethylbenzene & Pluoronic L-64 & 34 \\
o-Xylene & Pluoronic L-64 & 31 \\
Acetone & Carbowax 20M & 280 \\
Hexane & Pluoronic L-64 & 825 \\
Cyclohexane & Squalene & 410 \\
\hline
\end{tabular}

Source: Adapted from Edmonds and West (1980).

Large organic molecules that exhibit host-guest complexation properties can also be used as coatings for SAW devices (Overton et al. 1988). The large organic molecule (host) combines with a smaller molecule (gut st) as a neutral complex in a process known as inclusion. The host must possess a cavity of specific size and shape and the ability to establish an attractive force with the guest that is reversible. Overton et al. (1988) used a coating of [6.6.6.]cyclophane hexalactam trimer to detect methylene chloride and chloroform. Chemically modified cyclodextrins have been used to determine aromatic VOCs (Lai et al. 1988). These substrates exhibited a specificity for benzene over alkanes, nitrobenzene, and toluene, which gave the largest interference. Modified cyclodextrins with fluorocarbonylbenzene and benzyl functionalities have also been used to detect toluene, 2-nitrotoluene, 3-nitrotoluene, nitrobenzene, chlorobenzene, and bromobenzene (Elmosalamy et al. 1991). A coating of hexaepoxyoctacosahydro[12]cyclacene has been used for nitrobenzene, with no interference from aromatics except 2- and 3-nitrotoluene (Elmosalamy et al. 1989). Liquid crystals have also been used to detect VOCs (Mierzwinski and Witkiewicz 1987). The selectivity of liquid crystals is caused by their structure. These molecular receptors respond to the shape of the analyte molecule. Some representative sensitivities are presented in Table 7.2.

Electrochemically deposited polypyrrole has also been used as a substrate (Slater and Watt 1992; Vigmond et al. 1992). In its oxidized state, polypyrrole has perchlorate anion on its surface. In its neutral state, the electrons of polypyrrole can interact with those of the analyte; and polypyrrole has been found suitable for toluene and dichloromethane. Plasma-polymerized copper phthalocyanine has been used for planar molecules with conjugated double bonds, such as nitrobenzene, at a sensitivity of $780 \mathrm{ppb}$ (Kurosawa et al. 1990). 
Arrays of SAW devices have been used to improve the qualitative and quantitative analysis of hydrocarbon mixtures (Carey and Kowalski 1986). Investigators have used various coatings having hydrogen bond donors or acceptors (such as carbonyl, ether, nitrile, nitrogen, carboxyl, hydroxyl, and amoxidime functionalities) in a sensor array to detect organophosphorous compounds (Ballantine et al. 1986; Rose-Pehrsson et al. 1988). The hydrocarbons were identified and quantified by a combination of principal component and cluster analysis. Nonhydrogen bonding coatings, such as polyisobutylene and polyisoprene, have been used to nonspecifically detect isooctane, dichloroethane, and toluene, largely because of dipole-dipole interactions. For hydrogen bonding substances, derivatives having hydrogen bond acidity have been derived from 4,4-isopropylidenediphenol (bisphenol A) to detect hydrogen bond bases (Abraham et al. 1991).

Batterman and Zellers (1993) used a sensor array system to determine aliphatic, aromatic, and halogenated hydrocarbons. These investigators tested a wide range of coatings on the SAW device and found that polydiphenoxyphosphazene, polyisobutylene, diethylene glycol adipate, and polychloropene provided the best results with respect to vapor classification. These investigators were able to identify and quantify specific VOCs (such as chloroform, hexane, benzene, trichloroethylene, isooctane, and $m$-xylene) at concentrations in the microgram-per-liter to milligram-per-liter range, singly or in mixtures. Compensation for temperature and for relative humidity was necessary for operation. These investigators developed a rew method of pattern recognition, called extended disjoint principal components regression analysis, to analyze the data from the sensor array.

\subsection{Summary}

One of the most severe limitations of SAW devices for VOC analysis is their lack of specificity. Investigators have demonstrated that these devices can identify and quantify individual classes of compounds such as aromatics or olefins because of their differences in polarizability; however, the halogenated hydrocarbons are difficult to separate because of the similarities of their dipole-dipole interactions. Some of the more promising coatings include substrates that are sensitive to the shape of the analyte. The use of sensor arrays has also improved the qualitative and quantitative capabilities of SAW devices; however, arrays are most suitable for separating and quantifying classes of compounds, rather than for obtaining information on a single compound in a complex mixture.

\subsection{References for Chapter 7}

Abraham, M.H., et al., 1991, "Hydrogen Bonding: Part 18. Gas-Liquid Chromatographic Measurements for the Design and Selection of Some Hydrogen Bond Acidic Phases Suitable for Use as Coatings on Piezoelectric Sorption Detectors," Journal of the Chemical Society-Perkin Transactions 2:1417-1423. 
Alder, J.F., and J.J. McCallum, 1983, "Piezoelectric Crystals for Mass and Chemical Measurements," Analyst 108:1169-1189.

Andle, J.C., et al., 1992, "An Acoustic Plate Mode Biosensor," Sensors and Actuators B8:191-198.

Ballantine, D.S., Jr., et al., 1986, "Correlation of Surface Acoustic Wave Device Coating Responses with Solubility Properties and Chemical Structure Using Pattern Recognition," Analytical Chemistry 58:3058-3066.

Bastiaans, G.J., 1988, "Piezoelectric Transducers," in Chemical Sensors, T.E. Edmonds (editor), Blackie, Glasgow, United Kingdom, pp. 295-319.

Bastiaans, G.J., et al., 1993, Chemical Sensors Technology Development Planning Workshop, U. S. Department of Energy, Office of Environmental Restoration and Waste Management, Office of Research and Development; Characterization, Monitoring, and Sensor Technology Integrated Program, Washington, D.C.

Batterman, S.A., and E.T. Zellers, 1993, Assessment of Subsurface VOCs Using a Chemical Microsensor Array, final report, U.S. Department of Energy, Office of Environmental Restoration and Waste Management, Office of Research and Development, Technology Development, Washington, D.C.

Cady, W.G., 1946, Piezoelectricity, McGraw-Hill Book Co., New York, N.Y.

Carey, W.P., and B.R. Kowalski, 1986, "Chemical Piezoelectric Sensor and Sensor Array Characterization," Analytical Chemistry 58:3077-3084.

Edmonds, T.E., and T.S. West, 1980, "A Quartz Piezoelectric Device for Monitoring Organic Gaseous Pollutants," Analytica Chimica Acta 117:147-157.

Elmosalamy, M.A.F., et al., 1989, "Studies of Two Epoxyoctacosahydrol[12]cyclacene Derivatives as Sensor Coatings on Quartz Piezoelectric Crystals for Detecting Aromatic Vapours," Analytical Proceedings (London) 26:12-15.

Elmosalamy, M.A.F., et al., 1991, "Evaluation of Sensors Coated on Piezoelectric Quartz Crystals for the Determination of Aromatic Compounds," Analytical Proceedings (London) 28:326-328.

Fox, C.G., and J.F. Alder, 1989, "Surface Acoustic Wave Sensors for Atmospheric Gas Monitoring: A Review," Analyst 114:997-1004.

Guilbault, G.C., and J.M. Jordan, 1988, "Analytical Uses of Piezoelectric Crystals: A Review," CRC Critical Review of Analytical Chemistry 19:1-28. 
Ho, M.H., et al., 1980, "Continuous Detection of Toluene in Ambient Air with a Coated Piezoelectric Crystal," Analytical Chemistry 52:1489-1492.

Ho, M.H., et al., 1983, "Portable Piezoelectric Crystal Detector for Field Monitoring of Environmental Pollutants," Analytical Chemistry 55:1830-1832.

Kurosawa, S., et al., 1990, "Gas Sorption to Plasma-Polymerized Copper Phthalocyanine Film Formed on a Piezoelectric Crystal," Analytical Chemistry 62:353-359.

Lai, C.S.I., et al., 1988, "Piezoelectric Quartz Crystal Detection of Benzene Vapour Using Chemically Modified Cyclodextrins," Journal of the Chemical Society-Perkin Transactions 2:319-324.

Martin, S.J., et al., 1989, "Characterization of SH Acoustic Plate Mode Liquid Sensors," Sensors and Actuators 20:253-268.

McCallum, J.J., 1989, "Piezoelectric Devices for Mass and Chemical Measurements: An Update," Analyst 114:1173-1189.

Mierzwinski, A., and Z. Witkiewicz, 1987, "Piezoelectric Detectors Coated with Liquid-Crystal Materials," Talanta 34:865-871.

Overton, E.B., et al., 1988, "Detection of Solvent Vapors Using Piezoelectric Sensors," in First International Symposium: Field Screening Methods for Hazardous Waste Site Investigations, EPA/600/D-89/189, L.R. Williams (editor), U.S. Environmental Protection Agency, Environmental Monitoring Systems Laboratory, Las Vegas, Nev., pp. 57-60.

Rose-Pehrsson, S.L., et al., 1988, "Detection of Hazardous Vapors Including Mixtures Using Pattern Recognition Analysis of Responses from Surface Acoustic Wave Devices," Analytical Chemistry 60:2801-2811.

Sanchez-Pedreno, J.A.O., et al., 1986, "The Investigation of Coating Materials for the Detection of Nitrobenzene with Coated Quartz Piezoelectric Crystals," Analytica Chimica Acta 182:285-291.

Slater, J.M., and E.J. Watt, 1992, "Piezoelectric and Conductivity Measurements of Poly(pyrrole) Gas Interactions," Analytical Proceedings (London) 29:53-56.

Thompson, M., et al., 1991, "Response Selectivity of Etched Surface Acoustic Wave Sensors," Analytica Chimica Acta 248:143-153.

Tomita, Y., et al., 1979, "Detection of Explosives with a Coated Piezoelectric Quartz Crystal," Analytical Chemistry 51:1475-1478. 
Vigmond, S.J., et al., 1992, "Characterization of the Polypyrrole Film-Piezoelectric Sensor Combination," Talanta 39:449-456.

Wenzel, S.W., and R.M. White, 1990, "Flexural Plate-Wave Gravimetric Chemical Sensor," Sensors and Actuators 22:700-703.

Wohltjen, H., 1984, "Mechanism of Operation and Design Considerations for Surface Acoustic Wave Device Vapour Sensors," Sensors and Actuators 5:307-325.

Wohltjen, H., and R. Dessy, 1979a, "Surface Acoustic Wave Probes for Chemical Analysis: 1. Introduction and Instrument Description," Analytical Chemistry 51:1458-1464.

Wohltjen, H., and R. Dessy, 1979b, "Surface Acoustic Wave Probes for Chemical Analysis: 2. Gas Chromatography Detector," Analytical Chemistry 51:1465-1470. 

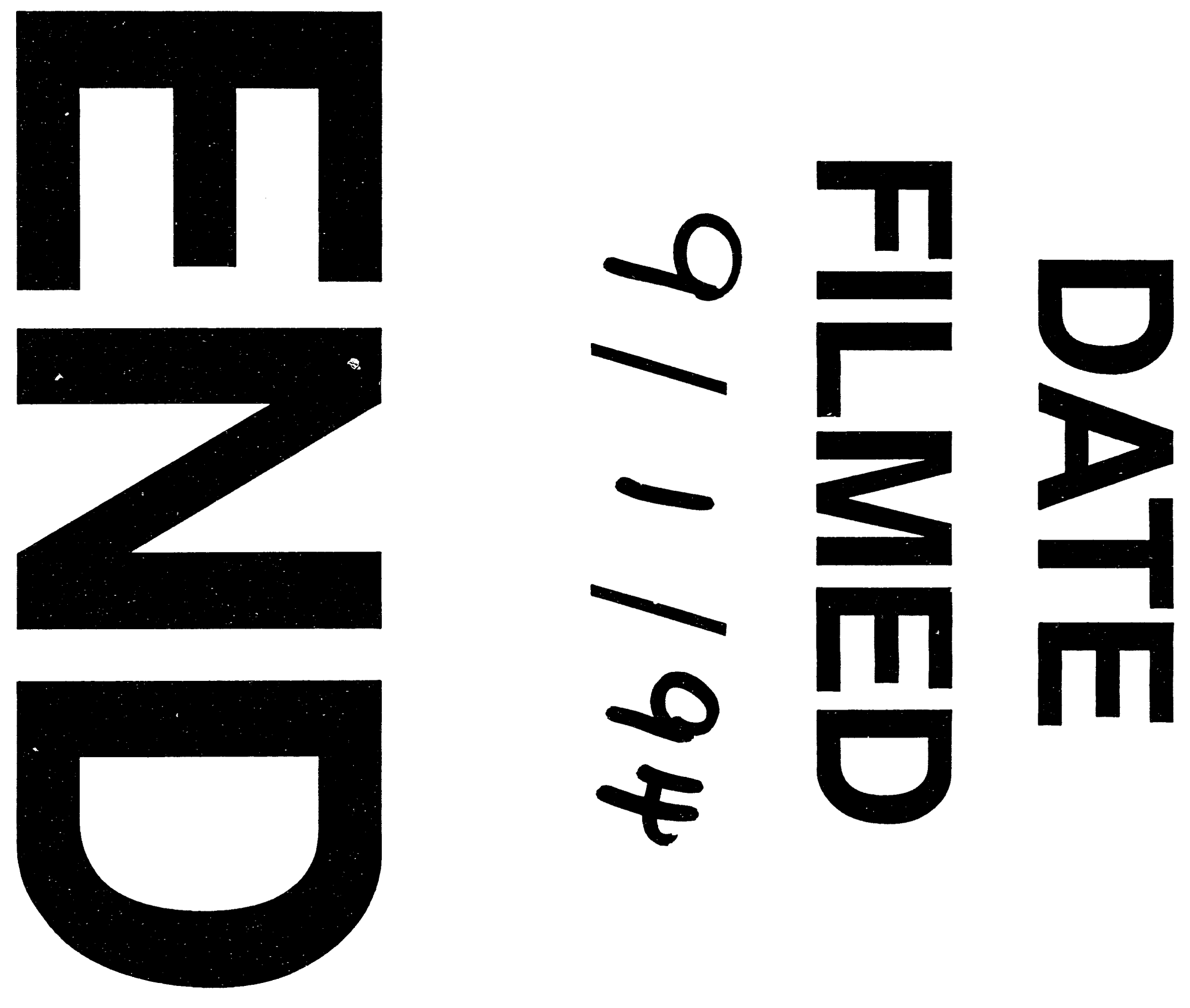
